\title{
HEARING THE ADOLESCENTS’ VOICE
}

A study evaluating the use of conjoint analysis for use with adolescents to determine preferences for inpatient hospital facilities

by

Catherine Gibson

A thesis submitted to Victoria University of Wellington

in partial fulfilment of the

requirements for the degree of

Master of Arts (Applied)

in Nursing

Victoria University of Wellington

2005 
Parties shall assure to the child who is capable of forming his or her own views the right to express those views freely in all matters affecting the child, the views of the child being given due weight in accordance with the age and maturity of the child 


\begin{abstract}
Some adolescents spend considerable time in hospital in environments that are designed either with adults or with younger children in mind. This research used the economic technique of conjoint analysis and an informal discussion to canvas opinions regarding ideal combination of inpatient facilities and, because of the changing youth culture, the use of cell phones in hospital. The content of the conjoint analysis was, with the exception of the inclusion of the question regarding the use of cell phones, derived from the literature. Because conjoint analysis does not appear to have been used with adolescents one of the questions to be answered was whether this was a method of research that could be used with adolescents. The research was undertaken with 29 young people, most of who were from CanTeen (the adolescent cancer support group) in Wellington.
\end{abstract}

The conjoint analysis, and discussion with the adolescents supported the general findings from the literature that adolescents do not want to be nursed in either overtly paediatric or, in their words, 'dull adult wards', as they enjoy bright lively surrounds. Ideally they would like to be nursed with their peer group and so have the opportunity to interact with young people of their age. The research demonstrated that adolescents are able to understand the concept of conjoint analysis and also supported findings from overseas that these healthcare consumers value having their opinions canvassed and are well able to give constructive and well thought out opinions. A report on the findings of this research will be presented to Capital and Coast District Health Board with the expectation that it will be considered when the final decisions are made regarding the upgrading of Wellington Hospital's present facilities as it is anticipated that these facilities will contain dedicated adolescent beds within the paediatric unit. 


\section{Acknowledgments}

My sincere thanks to everyone who has helped and encouraged me, in particular Dr. Kathy Nelson, my supervisor for her insight, guidance, advice and encouragement. I would also like to acknowledge and thank all the staff at the staff at the Graduate School of Nursing and Midwifery, Victoria University of Wellington for their words of wisdom in the classroom which gave me the enthusiasm to continue when spirits were low.

This thesis would not have been possible without the support of my employer, Capital and Coast District Health Board and in particular Julia Payne, Clinical Director, Child Health. Thank you.

The help and encouragement of my husband, David has been immeasurable. His support when the numbers appeared strange was invaluable, as were his assurances that I could achieve what I had started when I knew nothing at all about the methodology! Thank you also to William, for lending me your computer and not complaining when my books and papers took over your bedroom.

Thank you to my co-worker Jo, also undertaking the thesis research journey, for your camaraderie and unfailing good humour, to have someone who was experiencing the same highs and lows was invaluable. Also Donna, who must have wondered at times how we would ever finish.

And finally the lovely young people who helped me with my data collection, in particular the members of CanTeen, Wellington. Thank you. 


\section{Table of Contents}

ABSTRACT ..........................................................................................................................II

ACKNOWLEDGMENTS ...................................................................................

TABLE OF CONTENTS ........................................................................................ V

LIST OF FIGURES ............................................................................................................. VII

LIST OF TABLES .................................................................................................................. VII

1. INTRODUCTION.......................................................................................................... 1

2. THE ADOLESCENT .............................................................................................. 4

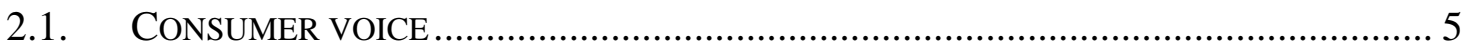

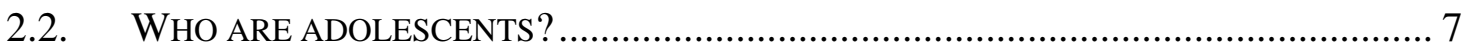

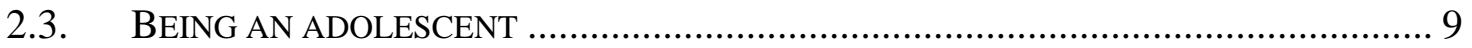

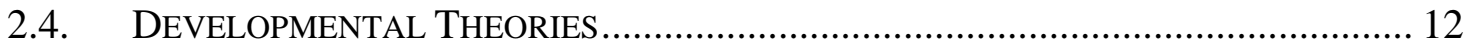

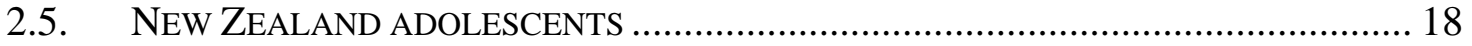

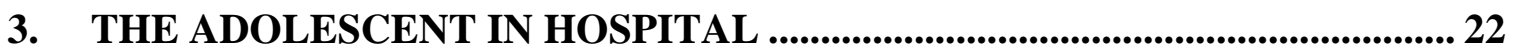

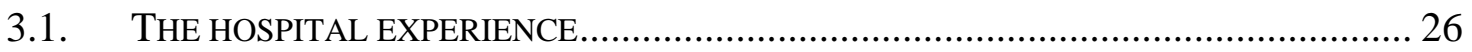

3.1.1. : The needs of the adolescent in hospital .................................................... 28

3.1.2. : The adolescent with a chronic illness........................................................ 35

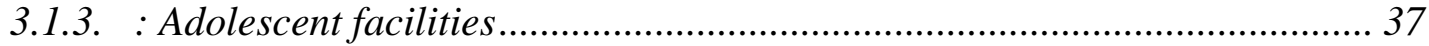

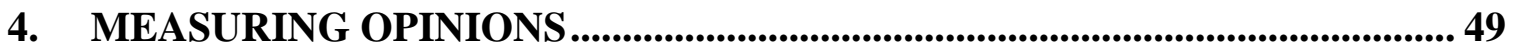

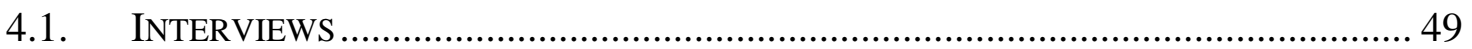

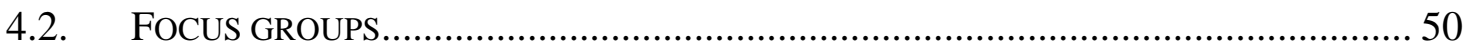

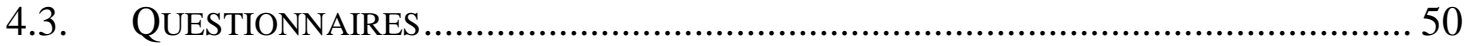

4.4. CONJOINT ANALYSIS ................................................................................ 51

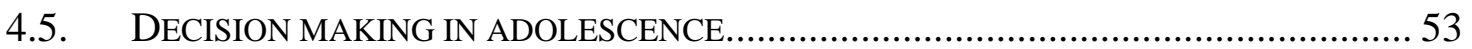

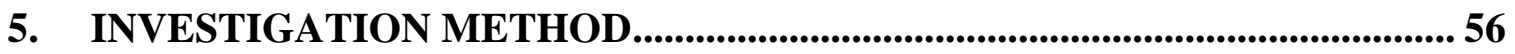

5.1. CONJOINT ANALYSIS BASIC ASSUMPTIONS ……............................................... 56

5.1.1. Method Description .................................................................................. 57

5.1.2. Defining the attributes ............................................................................... 58

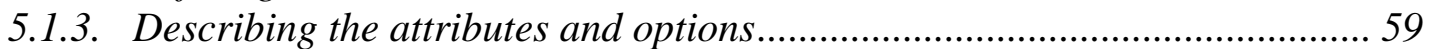

5.1.4. Hypothetical scenarios and card production................................................. 61

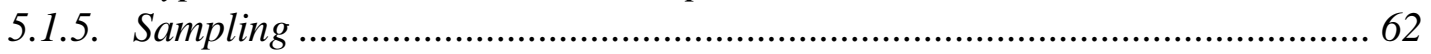

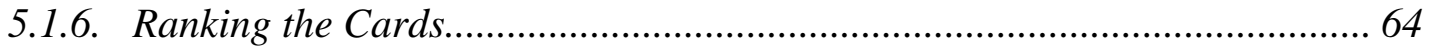

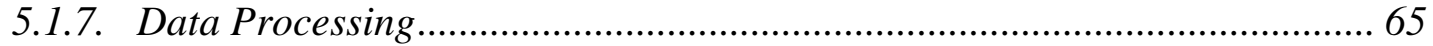

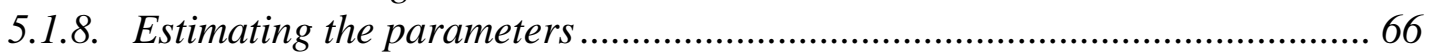

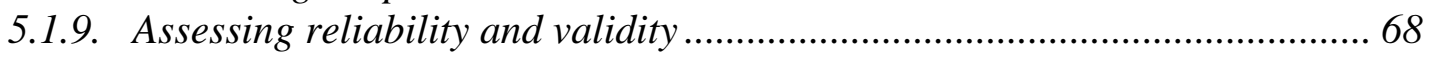




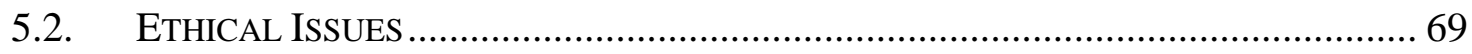

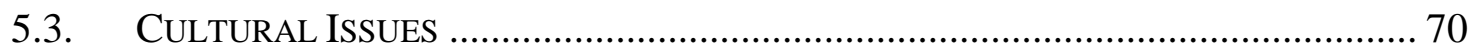

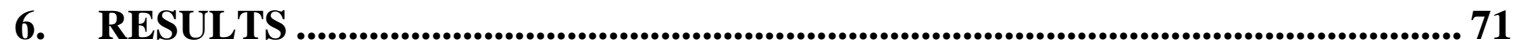

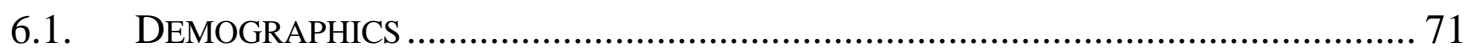

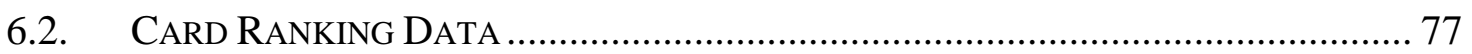

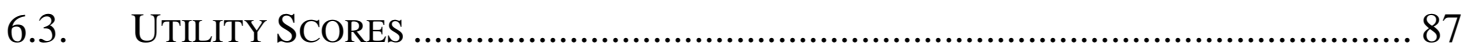

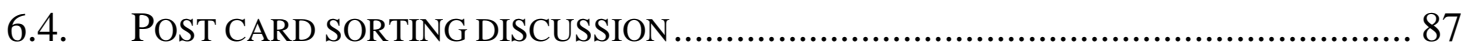

7. DISCUSSION OF RESULTS ................................................................................. 90

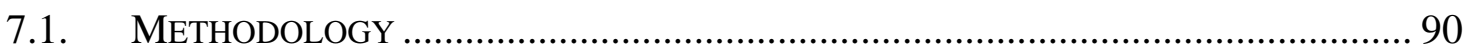

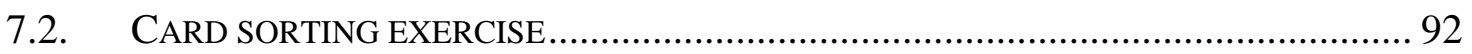

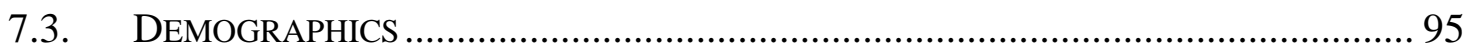

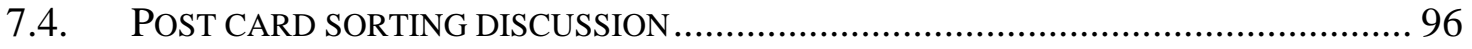

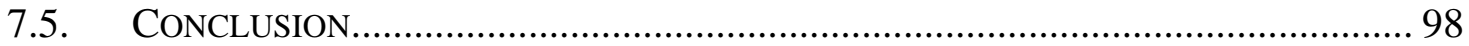

Appendix 1: Starship Teenage room information Starship Teenage room information101 Appendix 2： Subset of conjoint cards .......................................................................... 102

Appendix 3: $\quad$ Examples of cards used........................................................................ 103

Appendix 4: Demographic information sheet........................................................... 104

Appendix 5: Letter from CanTeen............................................................................ 105

Appendix 6: Regional Ethics Committee approval ....................................................... 106

Appendix 7: C\&CDHB Maori Health Unit ................................................................. 107

Appendix 8: Statistical examples........................................................................ 108

Appendix 9: Conjoint summary ........................................................................ 110

Appendix 10: Conjoint summary graph..................................................................... 112

Appendix 11: Decision making and cost ................................................................ 113

Appendix 12: CanTeen Newsletter entry ...........................................114

Appendix 13. Table of Contents of cards …............................. 115

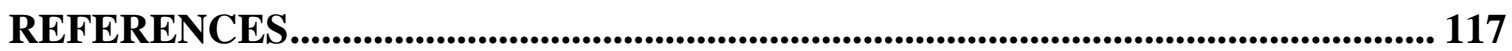




\section{List of figures}

Figure 1: Gillick Competence........................................................................................ 33

Figure 2: Gender mix of adolescents in study and exposure to inpatient setting ............. 72

Figure 3: Developmental age of adolescent when inpatient stay occurred........................ 73

Figure 4: Location of inpatient stay ............................................................................ 74

Figure 5: Number of inpatient admissions (longer than three days)................................. 75

Figure 6: Ethnic mix of study participants...................................................................... 76

Figure 7: Ethnic mix of students in New Zealand ....................................................... 76

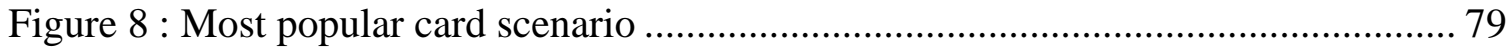

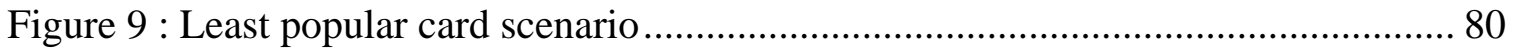

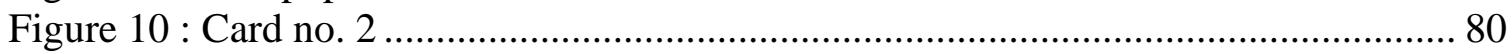

Figure 11: Example of data page produced for each respondent...................................... 82

Figure 12: Summary of percentage importance of facilities for all participants .............. 84

\section{List of tables}

Table 1: An analysis of New Zealand legislation and its relationship to adolescence ..... 20

Table 2: Literature regarding inpatient hospital facilities................................................ 40

Table 3 : Individual participant card ranking............................................................... 78

Table 4 : Percentage ranking for each card.................................................................. 79

Table 5 : Preference in card ranking $\quad 81$

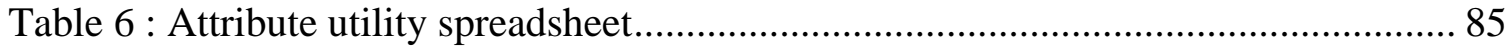

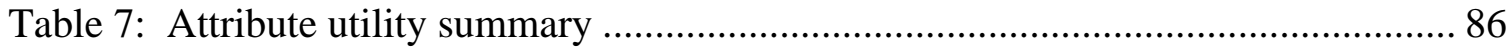




\section{Introduction}

I see no hope for the future of our people if they are dependent on the frivolous youth of today, for certain all youth are reckless beyond words. When I was a boy, we were taught to be discreet and respectful of elders, but the present youth are exceedingly unwise and impatient of restraint.

Hesoid, 800BC

My practice passion for 25 years has been in the field of child health and in particular the adolescent age group. A new regional hospital is to be built in Wellington and it is anticipated that when the Children's Hospital is eventually upgraded, one of the wards may contain a dedicated adolescent area. As I member of the senior nursing team I have been involved in discussions regarding the proposed new facilities. Throughout the whole of the planning process I have become acutely aware of the lack of consumer voice in the discussions regarding the proposed hospital inpatient facilities. We plan with the best of intentions, with the welfare of the consumers of our service uppermost in our minds. But when do we ask our consumers, the children, young people and their families, what they want? What is important to them?

This research reports on the findings of a small study to ascertain if the relatively new survey technique of conjoint analysis can be used to determine the preferences of adolescents for environmental aspects of the inpatient services that could be provided for them in the acute health care setting (Wellington Hospital). Conjoint analysis is a methodology dependent on the decision-making skills of its participants so it was important to ascertain if this age group had the skills to undertake this type of research. The study was conducted to answer two questions. The first was whether this methodology is suitable for use with adolescents, as it does not appear to have been used 
before with an adolescent population. The second was whether it is a suitable way of determining preferences for inpatient facilities.

This research recruited a group of adolescents from CanTeen, Wellington who had either personal knowledge of the hospital experience or knowledge because they are the sibling of an inpatient, or ex inpatient, with cancer. The adolescents undertook the conjoint analysis card sorting exercise, filled in demographic information sheets, discussed their understanding of the methodology and then if they wanted to entered into an informal discussion regarding inpatient facilities.

Following this introductory chapter the thesis is structured in the following way. Chapter 2 describes the context of the research and its evolution. This includes a description of the background to the research including national and regional statistics regarding adolescents in New Zealand. A definition of adolescence is offered and developmental aspects of this age group are examined, along with the theoretical background of the tasks of adolescence. This section also reviews the social wellbeing and health of adolescents in New Zealand today.

The adolescent in hospital is discussed in Chapter 3. Overseas literature regarding adolescents in hospital is examined. The needs of adolescents in hospital, with regard to their psychosocial development, are discussed and how these needs are accommodated, or not accommodated, in hospital. A number of overseas studies are reviewed where adolescents were asked their opinions regarding inpatient stays. There is also a brief discussion of the needs of adolescents with chronic disabilities who are hospitalised.

Chapter 4 discusses measuring opinions, as this is an important aspect of conjoint analysis. Different ways of measuring opinions, through questionnaires, surveys, focus groups and conjoint analysis are briefly outlined. The reasons for choosing to use conjoint analysis are explained along with a description of this methodology. Decisionmaking is an important part of conjoint analysis so this is explained in relation to adolescence. 
The investigation method in Chapter 5 describes how a conjoint analysis is undertaken. This chapter describes the different stages of the analysis and includes a description of CanTeen, the support group for adolescents with cancer, who kindly helped me to complete the collection of data. Ethical and cultural issues are presented, along with how the data is processed.

The penultimate chapter, Chapter 6 contains the data collected. This includes demographic data collected from the participants at the time of the card sorting exercise and data tables describing the card ranking data. There is a description of the results, along with a description of the utility scores used in a conjoint analysis. This chapter also contains details of the post card sorting discussion with the young people of CanTeen. A discussion of the results and conclusions I have drawn from the conjoint analysis are presented in the final chapter along with the ideas and opinions from the adolescents in CanTeen. 


\section{The Adolescent}

I would that there were no age between sixteen and three and twenty... for there is nothing in between but getting wenches with child, wrongdoing the ancientry, stealing and fighting.

Shakespeare, c1610

Adolescent health has been the focus of my Masters study over the past five years. From personal observations and recently from a more in depth study of the literature, it is my opinion that this age group is not as well served as it could be, by the health system, either overseas or here in New Zealand. The paediatric health system in New Zealand is geared towards the younger child. One only has to walk into most paediatric units to find Pooh Bear or Thomas the Tank Engine adorning the walls. Whilst this is definitely the right environment for the younger child, adolescent patients are not so enamoured. At 13 or 14 years of age a poster of Britney Spears or a Mazda RX7 20B Triple Rotor Twin Turbo, according to my adolescent son, would be much more acceptable wall decorations (Gibson, W., personal communication, August $4^{\text {th }}$, 2004).

Adolescents, up to 16 years of age, who require an inpatient admission to Wellington Hospital, are predominantly nursed in an acute paediatric ward. This paediatric ward (Ward 18) accommodates all children with oncology problems regardless of age and includes all children (from 6 to 16 years of age) with other health needs (excluding adolescents with a mental health diagnosis). Wellington Hospital has never provided dedicated space for adolescents in an inpatient setting but Capital and Coast Health District Health Board has recently opened a 13-bed adolescents unit catering for young people with diagnosed mental health problems. The Regional Rangatahi Adolescent Unit situated on the Kenepuru campus in Porirua has been open for two years and serves the 
lower half of the North Island from Gisborne through to Wellington. At present a new regional hospital is being constructed on the Wellington Hospital site. As part of this redevelopment the Children's Hospital will be refurbished when the main hospital buildings have been completed. Currently there are plans for the creation of a dedicated adolescent area within one of the Paediatric wards, for adolescents requiring an inpatient admission.

The need for dedicated hospital facilities for adolescent patients has been stressed repeatedly for at least 45 years (Gillies \& Parry Jones, 1992; Platt, 1959). In the late 1950s the Ministry of Health in the United Kingdom (UK) commissioned a report to review hospital services for children and adolescents. This landmark report, known as the Platt Report, remains a benchmark for health services for children and adolescents worldwide. The Platt Report (1959) stated adolescent requirements were different from younger children and that they required separate facilities when they were inpatients. Twenty years later the Court Report (Committee on Child Health Services, 1976) reiterated that it had become increasingly evident that adolescents had needs and problems sufficiently distinguishable from those of children and adults to warrant consideration as a distinct group for healthcare provision. In 1997, the UK House of Commons Select Committee on Health stated that services for adolescents should be given a greater focus and priority. Although these, and many other, recommendations have been widely accepted globally, there remains a deficit in many contemporary adolescent services (Hutton, 2000).

\subsection{Consumer voice}

Traditionally the extent of patients' involvement in the planning and development of any new or upgraded health-care facilities has been minimal and they have been developed under the direction of health professionals and governing bodies (Flatman, 2002; Hutton, 2000). Because of this little appears to have been asked of adolescents, when new facilities are developed, as to what they want or need from a health-care facility. 
Literature from overseas is advocating a greater involvement of patients and the community in the planning and developing of services (Battrick \& Glasper, 2004; Royal College of Paediatrics and Child Health, 2003). In recent years taking account of the views of consumers has permeated all public services and the importance of the views of the user in developing health care services has been acknowledged (Aynsley-Green et al., 2000; Macfarlane \& McPherson, 1995). However, this involvement appears mainly to mean the voices of the adults, the physicians and nurses, rather than the voices of the consumers themselves, and as Aynsley-Green et al. comment, that although this consultation is welcome, there is an inadequate voice for children and adolescents in the action teams. This lack of consumer voice is still evident. In the UK Standard for Hospital Services (Department of Health, 2003), only one registered children's nurse and one health visitor were appointed to represent the interests of all children and young people in Britain and no young people were consulted at all.

There is overseas research into the environmental needs of hospitalised children and some of this deals with the needs of adolescents, but none stems from New Zealand (Burr, 1993; Farrelly, 1994; Fisher, 1994; Harding-Price, 2003; Kari, Donovan, Li \& Taylor, 1999). These studies and descriptive pieces are discussed in Chapter 2. There appears to be a dearth of literature exploring the consumers' (patients') point of view with regard to actual hospital planning and/or ward design. Architects and members of the nursing and medical profession are reputedly consulted before building, but not the patients themselves (Pattison \& Robertson, 1996). These views are reflected by Hutton (2000) who comments that 'the adolescent voice is scarce within the literature with regard to ward design' (p.14). However it is recognised that their views need to be sought. Therefore before a new unit is established in Wellington this research aims to ascertain what sort of facilities a group of Wellington adolescents would like to see built/developed. The needs of adolescents requiring psychiatric care were not investigated. 


\subsection{Who are adolescents?}

The first question I needed to answer was to find out of whom exactly the adolescent population comprised, what made this age group different, and why this age group needed to be considered as a special group. The word adolescence is used interchangeably with teenager and young person in the literature. Literature from the 1970s and 1980s tends to refer to teenagers rather than adolescents, with more recent publications referring to adolescents or young people. I use the terms adolescent and young person/people interchangeably.

This portion of the human life span called adolescents refers to, in Western society, the period of time between being a child and becoming an adult, and lasts approximately 10 years (Gray, 1988). However, in many societies (for example, rural India and many African countries) this long transition from childhood to adulthood does not exist and adulthood often comes much younger, with the assumption of adult roles and responsibilities often happening at puberty. The Collins Dictionary of the English Language (Collins, 1979) defines adolescence as the period of human development that occurs between the beginning of puberty and adulthood. It derives from the Latin verb adolescere - to grow up, and describes a teenager as 'a person between the ages of 13 and 19 inclusive'. Whaley and Wong (1996) use the term 'adolescent' synonymously with 'teenage years' and Lore (1993) describes it as 'a time of striving to achieve emotional and social maturity and is characterised by the capacity for change' (p. 1223). The British Paediatric Association (1996) views adolescence as the phase of intellectual, social, emotional and physical change through which an individual progresses in passing from childhood to maturity and suggests that it cannot be rigidly defined in chronological terms.

The chronological definition of adolescence varies from nine to 21 years of age (Clarke \& Cook, 1986; Edgar, 1998; Whaley \& Wong, 1996; World Health Organisation, 1977). This loose chronological definition can be further expanded however, by a method derived from sociology, which is called the social status acquisition approach 
(Kuykendall, 1989; Lore, 1993). This divides the passage from childhood to adulthood into arbitrary age groups that are created by society and loosely grouped into a 'child' or 'adult' context. This approach acknowledges that at various chronological ages, individuals gain additional social privileges and status, which can be used to define the stage of life they have reached. In East Africa, Masai males are circumcised at 10 years of age, after which they are expected to join the adult males in the hunt. Somalian girls are circumcised at 12, after which they are considered to be of a marriageable age and there are many other initiation rites that are chronicled from developing countries that mark the transition from child to adulthood (Santrock, 2004). In New Zealand society we also have examples of this chronological definition. Sixteen year olds are allowed to leave school (adult), attempt to get a job (adult), marry with parental consent and can legally have sex (unless they are homosexual). At 15 the adolescent is able to drive a car (adult) and a year older can go into the armed forces and fight for their country (adult), albeit not on the front line. However, where alcohol is concerned, at the end of the working day the adolescent is not able to order a beer and must stay on lemonade until they are 18. However, these same young people have been paying a full adult fare on the bus from the age 14 and on an aeroplane from the age of 12 (Gray, 1988). In some countries such as the United States of America this social acquisition picture can get even more muddled as different states impose different laws on the same subject. An example of this is that in the state of Washington DC the drinking age is 18, across the border in Virginia it becomes 21, and further south in the North Carolina falls to 16.

As can be appreciated from the above, identifying the exact age of an adolescent can be problematic. This is reflected in the statistics that are collected by different government departments in New Zealand. I have found it difficult to collect accurate statistics as different government department use different age formats, and also age bands have changed over time. According to a publication produced by the Ministry of Education, New Zealand in Profile (2001) adolescents make up over 7\% of the New Zealand population. This document states that there are 249,866 secondary school children out of a population base of 3,794,625. Statistics New Zealand's figures from the 1996 National Census Summary are somewhat higher giving the number of 10 to 14 year olds as 
264,186, and 15 to 19 year olds as 262,977, making up $14.57 \%$ of a total population. To compare this with the population 18 years ago, the 1986 census figures quoted by Gray (1988) stand at 423,456 teenagers or $14.11 \%$ (age not stated) out of a population of under 3 million. The latest census figures from 2001 reported there were 675,087 people aged 12 to 24 years living in New Zealand, making up just fewer than $18 \%$ of the total population. Overseas the figures for adolescents in developed countries are reputedly around 15\% (Royal College of Paediatrics and Child Health, 2003) with the number of young people, aged between 10 and 20, in the UK making up 13 - 15\% of the population and $14.6 \%$ in the USA.

\subsection{Being an adolescent}

The confusion with describing an adolescent is reflected in being an adolescent, which is not an easy or comfortable task. There are a myriad of emotional, social and psychological changes at this age, together with pubertal changes in growth and strength (Berk, 2003; Smith, 2004). This stage of development is summed up by Kuykendall (1989) who comments 'There is probably no other age which causes as much chaos and muddle within any family unit' (p.26). These years are a period of developmental crisis where the young people often question the fundamental values of their parents. Adolescents adjust to many changes at one time, great physical growth (the most rapid since the first year of life) and hormonal changes that alter, not only physical structures, but thoughts, desires and emotions.

Many authors focus on the changes and transitions of this age (Bennett, 1998; Berk, 2003; Muscari, 1998). They describe this time as the period between childhood and adulthood, beginning with the changes associated with puberty and culminating in the assumption of adult roles and responsibilities. This period encompasses the complex interactions between physical, mental, emotional and social development which all takes place at a rapid pace. One of the most poignant accounts of what it feels like to enter adolescence appears in the diary of Anne Frank (1975) a Jewish girl who lived in hiding 
with her family in Holland during the German occupation on World War 11. Unable to leave her hiding place and go outside for fear of being captured, Anne turned her diary into the friend she longed for. The entries quoted here were written shortly before Anne and her family were discovered and sent to their deaths in a concentration camp.

Wednesday, $5^{\text {th }}$ January, 1944

Yesterday, I read an article about blushing by Sis Heyster. This article might have been addressed to me personally. Although I don't blush very easily the other things in it certainly all fit me. She writes roughly something like this - that a girl in the years of puberty becomes quite within and begins to think about the wonders that are happening to her body.

I experienced that, too, and that is why I get the feeling lately of being embarrassed about Margot, Mummy and Daddy. Funnily enough, Margot, who is much more shy that I am, isn't at all embarrassed.

I think what is happening to me is so wonderful, and not only what can be seen on my body, but all that is taking place inside. I never discuss myself or any of these things with anybody; that is why I have to talk to myself about them.

Each time I have a period - and that has only been three times - I have the feeling that in spite of all the pain, unpleasantness, and nastiness, I have a sweet secret, and that is shy, although it is nothing but a nuisance to me in a way, I always long for the time that I feel that secret within me again. (pp. 116-117) 
The following day Anne had this to say

My longing to talk to someone became so intense that somehow or other I take it into my head to choose Peter [a teenager hiding in the same house as the Franks].

Sometimes if I've been upstairs into Peter's room during the day, it always struck me as very snug, but because Peter is so retiring and would never turn anyone out who became a nuisance, I never dared stay long because I was afraid he might think me a bore. I tried to think of an excuse to stay in his room and get him talking without it being too noticeable, and my chance came yesterday. Peter has a mania for crossword puzzles at the moment and hardly does anything else. I helped him with them, and as we sat opposite each other at his little table, he on the chair and me on the divan.

It gave me a queer feeling each time I looked into his deep blue eyes and he sat there with that mysterious laugh playing round his lips. I was able to read his inward thoughts. I could see on his face that look of helplessness and uncertainty as to how to behave, and at the same time, a trace of his sense of manhood. I noticed his shy manner and it made me feel very gently; I couldn't refrain from meeting those dark eyes again and again, and with my whole heart I almost beseeched him: oh tell, tell me, what is going on inside you, oh can't you look beyond this ridiculous chatter?

But the evening passed and I noted nothing happened except that I told him about blushing - naturally not what I have written, but just that he would become more sure of himself as he grew older (pp. 118-119.) 
These diary entries, written less than 24 hours apart when Anne was $14 \frac{1}{2}$ years old, vividly reveal the intimate connection between the physical changes of puberty and the social characterises of adolescence.

The Greek philosopher Aristotle described adolescents in the fourth century as 'passionate, irascible, and apt to be carried away by their impulses.... they regard themselves as omniscient and are positive in their assertions, this is, in fact the reason for their carrying everything too far' (quoted in Kiell, 1964, p. 18-19). Many centuries later, William Shakespeare's story of Romeo and Juliet presented a strikingly similar version of adolescence, where uncontrolled emotions and desires dim reason and lead to tragedy.

The first great theorist of adolescence Jean-Jacque Rousseau saw adolescence in much the same light. In Emile (1762) his treatise on human nature and education, Rousseau comments:

As the roaring of the waves precedes the tempest so the murmur of rising passions announces this tumultuous change, a suppressed excitement warns us of the approaching danger. A change of temper, outbreaks of anger, a perpetual stirring of the mind, make the child almost ungovernable. He becomes deaf to the voice he mused to obey, he is a lion in a fever, he distrusts his keeper and refuses to be controlled.

(Cole \& Cole, 2001, p. 172)

Child development is a complex process!

\subsection{Developmental Theories}

Many theorists have attempted to organize their observations of child development and behaviour into a description of principles or a set of stages. Each theory focuses on a 
particular facet of development. Most developmental theorists separate children into age groups by common characteristics and these theories are the result of changing cultural values, philosophical thinking about children and scientific progress (Berk, 2003). In the mid twentieth century a variety of theories emerged which continue to be used today, including Freud, Erickson, Piaget and Havinghurst. These theorists describe 'tasks' that need to be achieved within age groups. These are now briefly outlined in the context of their views on adolescence.

The psychoanalytic techniques used by Sigmund Freud (1856 - 1939) led him to believe that early childhood experiences form the unconscious motivation for actions in later life. He developed a theory that sexual energy is centred in specific parts of the body at certain ages (Freud, 1961). Unresolved conflict and unmet needs at a certain stage lead to a fixation of the body at certain ages. He describes the task of adolescence as being the reestablishment of the balance of psychological forces, which have been upset during middle childhood (Santrock, 2004). Middle childhood produces erratic behaviour and psychological conflict due to the awakening of primitive forces, adolescence is the time of maturing, when these forces are brought under control. Freud in his psychoanalytic theory describes adolescence as the genital stage because it is during this period that sexual intercourse becomes a major motive of behaviour.

Erickson offers developmental theories establishing psychosocial stages during eight periods of human life, in which attitudes and skills are acquired to make the individual an active and contributing member of society (Erickson, 1968; Turner \& Helms, 1987). For each stage Erickson identifies a crisis, that is, a particular challenge that exists for healthy personality development to occur. The word crisis in this context refers to normal maturational social needs rather than a single critical event. Each developmental crisis has two possible outcomes. When needs are met, the consequence is healthy and the individual moves on to future stages with particular strengths. When needs are not met, an unhealthy outcome occurs that will influence future social relationships (Berk, 2003). 
The psychosocial stage Erickson describes for adolescence is the stage of 'identity versus identity confusion' (Erickson, 1968). He describes this as the time when the young person needs to find the answer to the question "Who am I and where is my place in society?” He believed that the young persons' developmental task was to identify selfchosen values and vocational goals leading to a lasting personal identity. If this was not achieved he believed that the young person would be unable to establish a meaningful definition of self and experience confusion in one or more adult roles (Turner \& Helms, 1987).

Piaget (1896 - 1980) offers a cognitive-developmental theory (Atherton, 2003; Piaget, 1969). He believed that we all actively construct knowledge as we manipulate and explore the world. Age and maturational ability largely influence this. (Piaget's theory offers a basis as to why adolescents should be able to undertake conjoint analysis, which was used for collecting data in this research). According to Piaget the capacity for abstract thinking begins around the age of 11, or early adolescence. He termed this the formal operational stage with the development of formal operational thought. This formal operational stage is Piaget's fourth and final stage of cognitive development. He believed that this stage emerges at $11-15$ years of age and follows the concrete operational stage of late childhood.

Formal operational thought can be described as the process of being able to conjure up hypothetical possibilities or abstract propositions and the attempt to reason logically about them. One way to appreciate the abstract quality of this is by the following statement:

I began thinking about why I was thinking what I was. Then I began thinking about why I was thinking about why I was thinking about what I was.

(Santrock, 2004, p. 342)

At the same time that adolescents think more abstractly and idealistically, they also think more logically. Hypothetical-deductive reasoning is Piaget's term for the adolescents' 
ability, in the stage of formal operational thought, to develop hypotheses, or best guesses, about ways to solve problems. They then systematically deduce, or conclude the best path to follow. By this he meant that the adolescent can think logically about abstract propositions and test hypotheses systematically. Piaget also said that adolescents become concerned with the hypothetical, the future, and ideological problems. This describes how the adolescent no longer requires objects of thought and can come up with new, more general logical rules through internal reflection (Atherton, 2003). This theory, best described as the information-processing approach, emphasises that individuals manipulate information, monitor it, and strategise about it. Individuals develop an increasing capacity for processing information, which allows them to acquire increasingly complex knowledge and skills (Santrock, 2004). This hypothetico-deductive reasoning means that when the young person is faced with a problem they can now begin to theorise on all the possible factors that might affect an outcome and from it produce specific hypotheses about what might happen. They are then able to test these hypotheses in an orderly fashion to see which ones work in the real world. Adolescents are at an age when they can reason and make choices, and appreciate having their views acknowledged (Aynsley-Green et al., 2000; Berk, 2003).

Havinghurst (1971) describes tasks of adolescence. Havinghurst describes the adolescent tasks of forming a clear identity, achieving a masculine or feminine social role and developing cognitive skills and the ability to think abstractly. He comments that the young person will need to accept a new body image and develop a personal value and ethical system which goes hand in hand with developing his or her own ideology. To achieve this task they will need to gain autonomy, which means gaining emancipation from parents or other carers. The young person also needs to achieve financial and social independence and prepare for an economic career. They need to develop new and maturer relationships with members of both sexes and prepare for marriage and family life. The final task described by Havinghurst is the need for the adolescent to develop the ability to control their behaviour according to socially acceptable norms while taking responsibility for their own behaviour. Russell-Johnston (2000) points out that although Havinghurst's tasks of adolescence were developed with educationalists in mind 30 years ago, they 
remain relevant today and have been widely adapted and adopted by health practitioners. For this reason I have used them as a framework for identifying ways of meeting the developmental needs of young people in hospital. These will be described in the Chapter 3.

Kuykendall (1989) offers a description of three adolescent stages based on what is happening to them socially, intellectually, emotionally, physically, sexually and psychologically. Using this approach he divides adolescence into early, middle and late stages, according to the myriad of behaviours and the issues that a young person is going through at a particular time. Each of these stages has distinct developmental milestones that the adolescent needs to achieve.

In Kuykendall's (1989) definition early adolescence is used to describe the 10 to 14 year age range. This is the stage that heralds the biological changes of puberty that transform the size and shape of the young people's bodies and evoke new, strange feelings. These biological changes are also accompanied by changes in social life. After many years of relatively little interest in the other sex, most boys and girls begin to find each other attractive, and their mutual attraction brings about changes in their interactions with peers and close friends. Simultaneously, their relationship with their parents or care givers change, as their reliance on their parents' support is replaced by an increasing responsibility to caring for others.

This early adolescent stage can be very simply described as the 'Am I Normal?' phase (Carr-Gregg \& Shale, 2002). The developmental issues of this age group are mainly due to puberty and focus on the new bodily sensations of this age and a preoccupation with normality. Puberty describes the time when one becomes able to conceive children (Bennett, 1998). The average duration of puberty is three years and follows a predictable sequence, although the time of onset, rate of change and age of completion are extremely variable. During this time height and weight increase and peak during the adolescent growth spurt at around 14 years of age, $25 \%$ of the final height and $50 \%$ of final weight is achieved during this time (Bennett, 1998). Young people become very sensitive to their 
changing body images, wondering if they are normal and 'is every one else doing it to'? Adolescents can become extremely self-conscious with their bodies and are usually very modest. The experience of puberty is to have a changing body which feels out of control and the typical aggressiveness, sexual arousal and unpredictability of the early adolescent is due largely to hormonal changes (Bennett, 1998).

Same sex peer groups grow in importance as the young person strives to find out where they fit, and a desire to be an accepted member of a group that they want to be identified with, increases. Emancipation from home ties begins and high levels of physical activity, daydreaming and mood swings and stretching boundaries are common. One of the most bewildering times for parents of this age group is the young person's increasing desire to be different, with regards to clothing and hair style but at the same time their increasing need to be the same as their peers.

Mid adolescence or the 'Who am I' phase is how Carr-Gregg and Shale (2002) describes the 14 to 17 year old group. Here the major development issues relate to conflicts developing over a growing need for independence, further distancing from parental or caregiver bonds and the increasing need for peer friendship. Peer groups set behaviour standards as parents begin to exert less authority, and the adolescents' search for their individual identity increases. Risk taking behaviour increases and enjoyment of new intellectual powers often brings them into conflict with parents or caregivers.

Late adolescence, the 17 to 20 year old group are concerned about 'where is my place in the world' (Carr-Gregg \& Shale, 2002, p.39). This stage places strong emphasis on functional role definition in terms of work, lifestyle and relationship plans. This is when the young person begins to mature and to take on lifetime adult roles. They are more comfortable with their gender role, which has now been established. Relationships that involve mutual caring and responsibilities develop. The wider boundaries allowed by further education or the workplace are explored. 


\subsection{New Zealand adolescents}

New Zealand's adolescents are a diverse group and display many different social and cultural characteristics. There are differences in age, sex, ethnicity, nationality, geographic location and mobility, and the youth population is changing in size and composition (Ministry of Youth Development, 2003). The following section gives an overview of the health and social wellbeing of this age group in New Zealand.

The Office of Ethnic Affairs reports that the youth population of New Zealand (those aged 12-25 years) is ethnically more diverse than the rest of the New Zealand population. In 1996 two-thirds (67 \%) of youth belonged to the European ethnic group while onefifth (20 \%) were New Zealand Mäori. This compares with $75 \%$ of all New Zealanders who reported that they were European and $16 \%$ who said that they were Mäori. The Asian and Pacific Islands groups each made up 6\% percent of the youth population compared with 4\% and 5\% respectively of the total New Zealand population. (Office of Ethnic Affairs, 2001).

In 2003 the Ministry of Youth Development compiled a report which profiled the health and wellbeing of New Zealand youth. This document, the early findings of a national secondary school youth health survey conducted in 2000, detailed how the overall proportion of young people as part of New Zealand's population is declining. The reasons for the decline are lower birth rates and fewer women of childbearing age. However, the proportion of Maori, Pacific and Asian young people is increasing, reflecting their relatively high birth rates and numbers of women of childbearing age.

Good health in this age group is closely linked to positive relationships with others, supportive family environments, good emotional and mental well being, cultural identity and physical health. Environments free of risk factors such as poverty, violence and abuse are all important for healthy development (Adolescent Health Research Group, 
2003a; United States Department of Health, 1994). Despite a documented rise in the suicide rate of young people in New Zealand in the 1990s, it is reported that there have, in recent years, been decreases in the rates of suicide and motor vehicle accidents causing death or injury among these young people. However, adolescents have higher rates of unplanned pregnancy and more deaths from motor vehicle accidents and injuries than other age groups. In fact, injuries are the leading cause of death and hospitalisation for the 12 to 24 age group, with motor vehicle deaths being the leading cause of death in late adolescence and early adulthood (Ministry of Youth Development, 2003).

Adolescence is seen as a critical transition period when life-long health patterns are established (Muscari, 1999). It is a time of questioning and conflict, when young people try to work through their own views on fundamental issues, measuring these ideas against the society in which they live. Adolescence is a time when young people make many important decisions about a variety of behaviours that will affect them for the rest of their lives. Two examples of this could be in relation to smoking and sexual health. Most smokers start smoking in their teen and it is believed that if young people can be discouraged from smoking it is highly likely they will never start (Macdonald, 2004). A youth health status report by the New Zealand Ministry of Health (2002) states that 10 to $30 \%$ of young New Zealanders have had sexual intercourse by the time they reach 15 years of age, and about half have had intercourse by the time they are 17 years old. Compared to other age groups, young people are over represented in the rates of sexually transmitted infections. These infections include genital herpes, gonorrhoea, chlamydia and genital warts. Currently this age group is being targeted with a national television advertising campaign to use condoms. Cartoon characters and rap music proclaim: 'No rubba, no hubba bubba!’

It is reported that mental illness becomes more common as young people move through adolescence. The most common mental health issues include anxiety, depression, conduct disorders and alcohol and substance abuse. The study produced by the University of Auckland's Adolescent Health Research Group (2003b) found that alcohol is the main drug of choice by young people aged 13 to 18 years old and that the use of alcohol, 
tobacco and other drug use are closely linked to factors such as family circumstances and socio-economic status. These in turn may affect the risk of a range of problems including early or unprotected sex and increases in depression and suicide. The recent study (New Zealand Ministry of Health, 2002) of secondary students found that $10.2 \%$ of male students between the ages of 13 and 18 years of age reported using cannabis at least weekly. This peaks in the 15 year old age group. As outlined earlier identifying the exact age of an adolescent is problematic. This is also reflected in the statutes and laws that govern us. In New Zealand the age of majority and therefore full legal capacity is attained at 20 years of age (Age of Majority Act, 1970). Up until this age, a range of statutes, which are set out in Table 1, governs the rights and obligations of young people.

Table 1: An analysis of New Zealand legislation and its relationship to adolescence

\begin{tabular}{|c|c|}
\hline Legislation & Description \\
\hline Electoral Act (1956) & $\begin{array}{l}\text { For the purposes of the right to vote, an 'adult' is a } \\
\text { person of, or over, the age of } 18 \text { years }\end{array}$ \\
\hline \multirow[t]{2}{*}{ Crimes Act (1961) } & $\begin{array}{l}\text { A child between the ages of } 10 \text { and } 14 \text { can be prosecuted } \\
\text { for murder, manslaughter or a minor traffic offence if } \\
\text { they know that the act or omission was wrong or that it } \\
\text { was contrary to the law. }\end{array}$ \\
\hline & $\begin{array}{l}\text { It is an offence for a male to have a sexual relationship } \\
\text { with a female less than } 16 \text { years of age, or a male less } \\
\text { than } 18 \text {. A female of or over the age of } 21 \text { commits an } \\
\text { offence if she engages in sexual relations with a girl } \\
\text { under the age of } 16 \text {. }\end{array}$ \\
\hline Guardianship Act (1968) & $\begin{array}{l}\text { A person who has reached the age of } 16 \text { can give consent } \\
\text { to medical or dental treatment or surgical intervention } \\
\text { without requiring parental consent. Consent at a younger } \\
\text { age is contingent upon a sufficient understanding for that } \\
\text { consent to be fully informed. }\end{array}$ \\
\hline $\begin{array}{l}\text { Children, Young Persons } \\
\text { and their Families Act } \\
\text { (1989) }\end{array}$ & $\begin{array}{l}\text { For the purposes of care and protection and of youth } \\
\text { justice, a young person is defined as a person over } 14 \text { and } \\
\text { less than } 17 \text { years of age. } \\
\text { A young person of } 14 \text { years or over can be left in charge } \\
\text { of younger children without adult supervision. }\end{array}$ \\
\hline Education Act (1989) & $\begin{array}{l}\text { Schooling is compulsory to the age of } 16 \text {, but it is } \\
\text { possible to leave school earlier with the permission of the } \\
\text { school principal (and on application from the parent). }\end{array}$ \\
\hline Privacy Act (1993) & There is no age restriction affording both children and \\
\hline
\end{tabular}




\begin{tabular}{|l|l|}
\hline & $\begin{array}{l}\text { adults protection from unlawful or arbitrary interference } \\
\text { with privacy }\end{array}$ \\
\hline Human Rights Act (1993) & $\begin{array}{l}\text { Age is described as one of the prohibited grounds of } \\
\text { discrimination. "Age” is defined as having a lower limit } \\
\text { of } 16 \text { years. }\end{array}$ \\
\hline
\end{tabular}

Ministry of Health Information Service, 2004.

When looking at the diverse definitions of an adolescent, it is perhaps not surprising that this age group can cause many challenges. These challenges can also be confounded when considering the cultural diversity in New Zealand. New Zealand society contains many groups including, among others, Maori, Samoan, Tongan, Eastern European, Western European, New Zealand European, Ethiopian, Cambodian, South African and Chinese. When considering the different cultural mores superimposed onto a 'New Zealand' lifestyle, and then factoring in expectations from different social, socioeconomic and personal backgrounds, it gives us some idea of why adolescence can be a challenging age.

This chapter has described adolescence as a process rather than a stage, as there are many adjustments to make (Friedman, 1989). It has highlighted the difficulty in stating exactly at what age adolescence begins or ends and that a variety of age ranges have been suggested, from 9 to 21 years of age. It has also demonstrated that the length of time that the process takes varies between individuals and cultures. When looking at the physical and psychosocial and aspects of development of adolescents, it can be seen that young people are indeed a special group as they are neither child nor adult. This unique age is characterised by a myriad of interrelating changes in the body, the mind and relationships with others (Taylor \& Muller, 1995). When the adolescents' usual support from family, peers and others is interrupted by hospitalisation a situational crisis is added to the normal developmental crisis that the adolescent is experiencing. Smith (2004) states that 'hospitalisation is thought to be an interruptive process that, if not managed in the correct manner, may adversely affect the developmental period of adolescence and impact on psychological well being' (p. 26). The adolescent in hospital is explored in the following chapter. 


\section{The adolescent in hospital}

The impact of the physiological, social, intellectual and emotional changes which adolescents experience is likely to be intensified by hospital admissions through acute or chronic illness. Adolescents have distinctive and different needs from both child and adult patients.

British Paediatric Association, 1996

The previous chapter has explored the general development issues and tasks that adolescents face, this one will focus on the adolescent in hospital. Fifty three thousand, four hundred and twelve young people between the age of ten and 19 were discharged from publicly funded hospitals in 2001/2002 (New Zealand Health Information Service, 2003). Drawing from my experience in child health I believe, that as paediatric nurses, we are not well taught in the area of adolescent development/health/medicine. Because of this we are often not as aware as we could be of the many physiological, psychological and psychosocial issues that these young people face. Lack of specialist adolescent nursing education is also apparent from overseas literature and has been reported by a number of authors (Bering \& Gephardt, 1997; Burr, 1993; Geehan, 2003; Gillies \& Parry Jones, 1992). A report produced by the UK's Royal College of Paediatrics and Child Health (2003) commented that most hospitals recognised the importance of adolescent services and the particular skills needed by staff, but most failed to achieve them. There is post registration education available in the adolescent health field, but this is not a prerequisite for employment when nursing adolescents. This chapter reviews literature relating to the adolescent in hospital, how they view the ward environment and how hospitalisation can impact on their psychosocial development. Some of the literature reviewed is a dated but I believe it remains relevant today. This literature, along with my own experience as a nurse, was the main basis for developing the information necessary for the construction of the conjoint analysis cards which will be described in Chapter 4 . 
In the literature, adolescence appears to be regarded generally as a time of life that is associated with good physical and mental health (Patton, Sanci, \& Sawyer, 2002; Smith, 2004; Taylor \& Muller, 1995). However, good health is not universal during this period and some adolescents will come into contact with the health services because of either acute or chronic health problems. These both commence during adolescence or will have arisen during childhood and continue to be problematic during adolescence. It has been suggested that the number of adolescents requiring healthcare is likely to increase since more children with chronic and life-threatening illnesses are now surviving into their teens and beyond (Lansdown, 1996; Patton et al., 2002). In their report in 2003, on the health needs of adolescents, the Royal College of Paediatrics and Child Health comment that:

Attendances at health care facilities by young people aged 12 to 19 years are about half those of the traditional 'child' population aged 0 to 14 years, but their use of hospital beds is slowly increasing as more young people with chronic diseases are surviving childhood (p. 17).

In the year 2004, 780 young people between the age of 12 and 16 years (inclusive) were admitted to the Child Health Service (Ward 18 and Paediatric Day Ward) at Wellington Hospital. This included 139 day stays and 641 as inpatients (Sebescue, G., personal communication, September $\left.17^{\text {th }}, 2004\right)$. The number of young people admitted to other wards in the hospital has not been able to be established in a meaningful way as the numbers available included every young person seen in the emergency department and as an outpatient, as well as those who had an inpatient.

The Platt Report was published in the UK in 1959. This document recognised the need to regard adolescents as a distinct group in health care and the need for separate facilities. One of the recommendations of this report was that inpatient facilities should take into account not only the physical differences of this age group but also their unique psychosocial needs. Following the publication of this report adolescent inpatient units were first established in Britain and North America in the early 1960s. These units were 
set up as a way to provide optimal, developmentally appropriate care for hospitalized adolescents. In more recent times guidelines have been produced in the UK detailing the optimal hospital environment for children. These included reports published by the Department of Health (1991 \& 2003) which still state, as the Platt report did, that good practice required the provision of appropriate psychosocial intervention in a suitable hospital environment.

A position paper by the United States' Society for Adolescent Medicine (1992) comments that in the 1970 s several organisations including the Society for Adolescent Medicine, the American Academy of Paediatrics, and the American Association for the Care of Children's Health developed guidelines for the establishment of adolescent units. Fisher (1994) conducted an informal survey with New York based programme directors from these organisations (in New York) and found a continued interest in adolescent units as a viable option in adolescent health care in North America, even though the provision of appropriate adolescent care was not yet available at all units. At the time he commented there was tension between the need for adolescent units and the desire of some specialists to create or maintain disease or organ-specific inpatient units. This tension was also reported by Suresh, Doull \& Thomas (2000) who commented that because of this there was a decrease in the number of medical/surgical adolescent beds available, despite the fact that hospitals noted specific benefits associated with having an adolescent unit.

A number of authors (Farrelly, 1994; Gillies \& Parry Jones, 1992; Henderson, Goldacre, \& Yates, 1993) have looked at the health service setting for hospitalised adolescents in the United Kingdom. They all reported that very few adolescent units and associated services have been set up in the UK in the past 30 years, with the exception of those within the psychiatric service. A more recent survey of the use of hospital beds by adolescents in the UK undertaken by the noted Adolescent physician, Russell Viner (2001) echoes this. He describes that little attention has been paid by the health service in the UK to the use of health services by adolescents, and that only $9.8 \%$ of Health 
Authorities had specifications for the management of the physical health of adolescents in their area hospitals.

The report published by the Department of Health in Britain states as Standard 5.4 for Hospital Services:

The care of young people should be reviewed in the particular circumstances of each hospital, to make sure that their separate needs, including for safeguarding, are recognised and met. Separate adolescent units may be the best solution but this will not always be the case, and many hospitals will address their needs quite adequately by grouping them together in separate bays in the paediatric ward.

(Department of Health, 2003, p. 36)

Viner and Keane (1998) have produced comprehensive evidence-based guidelines pertaining to the adolescent patient and report that specific service specifications for adolescent care in hospital are an essential part of best practice for the care of young people. In New Zealand a specialist adolescent ward was commissioned in Auckland when the Auckland Starship Children's Hospital was built in the mid 1990s. Unfortunately this ward is no longer open and from what I have been able to establish there are no specialised adolescent units in hospitals, for general admissions, in New Zealand. Rather this age group is nursed on general paediatric or on adult wards. Starship Hospital does however have a Teenage play specialist, probably the only one in NZ (Appendix 1). The mental health picture is equally poor as there are only three specialist inpatient adolescent units in New Zealand for those young people in need of acute mental health care. Therefore many adolescents requiring admission for mental health problems, who cannot be accommodated in these units, are generally cared for in general adult psychiatric wards and others are managed by their family (Ministry of Health, 1998). 


\subsection{The hospital experience}

Despite the fact that there are no specialist units available, when these young people do come into our health service we try to give them the best and most appropriate care that we can offer. When we consider however the complexities of adolescent development, it can be appreciated that nursing these young people is often not an easy task. Authors such as Gordon (1981), Mackenzie (1988) and Smith (2004) emphasise that the normal stresses of adolescence can be further exacerbated by being in hospital. Others go on to comment that in hospital these often mixed-up youngsters are further confused when their physiological needs are well attended to, but their emotional and social needs often completely disregarded (Taylor \& Muller, 1995). Evidence examined within the study completed by Smith on quality care for adolescents highlighted the fact that staff attitudes and knowledge have a direct effect on the hospital experience of adolescents. This reflects the findings of Denholm (1990) who surveyed the positive and negative memories of hospitalisation for this age group four years after admission, and who found that the most abiding negative memory was one of being out of place. One of the main stressors appears to be that at a time when they are trying to grow into adults they are often placed in a paediatric ward full of younger children and sometimes even babies (Geehan, 2003).

There appears to have been little research that involves asking adolescents where and how they want to be nursed. A survey at a small school in England was conducted by Blunden (1993) to find out where adolescents wanted to be nursed. Eighty five well children, aged between 11 and 13 completed the survey. The majority of the children opted for care within an adolescent unit. However some of the young teenagers aged 13, expressed the preference that if an adolescent unit were not available they would rather be nursed in adult wards. Other authors found that when teenagers were asked their views concerning health care they frequently stressed the importance of the environment being suitable for adolescents (Resnick, Blum \& Hedin, 1990; Whelan, 2003). This did not necessarily mean a dedicated unit, but all mentioned dedicated space, albeit a bay or portion of the ward area which was away from the younger children. These surveys were 
conducted on healthy adolescents who probably had little or no experience of hospitalisation.

In a small study conducted by Burr (1993) seventeen adolescents aged 14 to 16 years of age who were receiving care in adult wards were interviewed about their hospital experience. All expressed negative comments about being nursed on an adult ward. Their comments mostly referred to the elderly population in the ward, the lack of cleanliness and being in a mixed gender ward. They also reported feeling lonely, bored and frightened of both other patients (comments about old people moaning) and of their own treatment (nurses not being aware of the young person's needs in respect to explanations about procedures). However, adolescents also comment that they also prefer not to be with, or to be treated, as babies and young children (Lansdown, 1996). Comments from a descriptive piece about adolescents being cared for on children's wards described they were also not satisfied with the environment. In this case problems were the lack of privacy and the fact that that bed time was at 7.30 p.m. (Gillies, 1992).

In 1992 the Nursing Times printed a short article written by an adolescent named Daniel Steven. Daniel was 14 and had been admitted to a children's ward for surgery. He made this observation:

This is where I had my appendix out when I was $10 \ldots$ The same Snoopy mobile hangs from the ceiling....The TV in the middle of the room is too loud. Fellow patients play with Lego and Alex in the bed next to me pees on the floor.

(Steven, 1992, p. 17)

Similarly, an unnamed 17 year old writes

The idea of early lights out, Postman Pat videos and screaming kids did not appeal to me.

(Lansdown, 1996, p. 191)

Denholm (1990) interviewed adolescents about their memories of hospital four years after discharge. He found that recollections of admission tended to focus upon the environment and loneliness, boredom, depression and fear. They also remembered the 
lack of privacy, and their need to have time on their own, as well as the inevitable two year olds! Daniel Steven (1992) also commented that because of lack of amenities for his age group boredom took on a new meaning and he began to feel thankful for the loud TV. The environmental needs of the adolescent in hospital in relation to their developmental stages are outlined in the next section.

\subsubsection{The needs of the adolescent in hospital}

The concept of an appropriate environment has been documented repeatedly throughout the literature, suggesting that the unique needs of the adolescent patient cannot always be met either in the adult or child-orientated environment (Viner \& Keane, 1998). Rather, in an ideal world all adolescents would be nursed in adolescent units with staff trained in adolescent care. However in reality, overseas as well as in New Zealand, this is not the case and given New Zealand's population size, is probably never likely to be. Paediatric units are geared towards the young child and the overseas literature contains many examples of how adolescents feel when they are nursed with younger children where often their developmental and psychosocial needs are not adequately addressed. The previous Chapter described various developmental tasks of adolescence. Havinghurst's (1971) tasks are now each discussed within the context of a hospital environment with some suggestions that are offered by various authors as to how these tasks can be achieved in the hospital. By examining these tasks the unique needs of the adolescent are outlined and the difficulty of meeting these needs without adequate training and facilities is highlighted.

\section{Hospitalisation and the task of accepting a new body image}

Accepting a new body image which often appears to result in an increasing desire for privacy, is one of the key developmental tasks of adolescence (Mackenzie, 1988). The British Paediatric Association (1996) association has recognised that adolescent patients have a special need for privacy which is not always recognised. This view is supported by other authors who found that the adolescents whom they interviewed put privacy at 
the top of their list of needs (Brook, 1986; Gillies \& Parry Jones, 1992; Sharma \& Finlay, 2003). These authors suggest that this need increases when physical development begins, on average, at about the age of 12 and comment that privacy is needed for physical examinations and treatments as well as for maintaining hygiene. A lack of privacy can provoke embarrassment for the adolescent, who may not have fully adjusted to bodily changes. This opinion is supported by Denholm (1990) who suggests adolescents are developing a pride in their own sexuality which can easily be destroyed during hospitalisation.

Bathing facilities are often mentioned when young people are surveyed (Burr, 1993; Gillies \& Parry Jones, 1992; Sharma \& Finlay, 2003; Shelley, 1993). Children’s wards tend to have small toilets, limited facilities for the disposal of menstrual products and low wash hand basins, which are a boon for five year olds but not for 15 year olds. Gillies \& Parry Jones note that sometimes policies also need to be reviewed with teenage patients in mind. For example, children in hospital are usually supervised when bathing, this is necessary for a five year old whereas a 13 year old just wants to lock the door. However, Smith (2004) suggests that within appropriate adolescent units, there is sufficient evidence to suggest that the issue of privacy is less important as the adolescent does not fear the sudden appearance of a seven or a 70 year old.

\section{Hospitalisation and tasks relating to independence: Gaining emancipation from parents; developing personal values; controlling own behaviour}

Berk (2003) and Santrock (2004) believe that maturing as an adolescent involves developing a sense of independence, which means making decisions and having increased responsibilities in everyday life. They go on to point out that when properly addressed, with staff that are well versed in the developmental needs of adolescence, the young person can be allowed increasingly to make decisions relating to their own care. However, often this can be overlooked when they are an inpatient in a paediatric or adult focused unit. Hospitalisation can also run the risk of infantilising teenagers as decisions 
are made for them, turning increasingly independent adolescents at home into being adolescents dependent on others in hospital.

Kmietowicz (2003) suggests that hospitalised adolescents need a sustained supportive environment that allows them to maintain their growing independence and other authors describe that if they are involved in discussions and decisions about their care this will encourage it (Meyers, Thompson, \& Weiland, 1996). This opinion was also offered over 25 years ago by the World Health Organisation (1977), which stated that involving young people in their own health care is more likely to lead to a successful outcome. Other, more recent authors argue that although patients recover more quickly if given opportunities to gain control over some aspect of their lives within hospital, adolescents are often not consulted about their care (Hallstrom \& Elander, 2004; Kari et al., 1999).

Independence with regard to the environment is described as evolving during adolescence (Burr, 1993; Santrock, 2004). This can be curtailed in the hospital environment when, for example, the adolescent who is allowed at home to travel outside the home environment independently finds that hospital policy may specify that any inpatient in the paediatric ward is not allowed to leave the ward unaccompanied, for any reason (Burr, 1993; Godfrey, 1998). This makes sense for a six year old but an adolescent who comes and goes independently at home may find this restriction hard to accept, especially if reasons for this are not explained. Similarly, for safety reasons, children are commonly reported as being not allowed into ward kitchens (Russell-Johnstone, 2000; Sharma \& Finlay, 2003) but this seems like yet another unnecessary restriction for a teenager who is used to self catering at home, especially bearing in mind the appetites of some youngsters. Fisher (1994) remarks that increasing independence with activities such as bed time can be thwarted when a lack of continuity among staff allows young people to stay up late one night, only to be sent to bed early the next. 


\section{Hospitalisation and developing relationships with members of both sexes from social interaction}

The social needs of this age group differ from those of a younger or older age (Lansdown, 1996; Shelley 1993). Many teenagers are easily bored and comment that this could be relieved by more age appropriate activities (Gillies, 1992). It is reported that activities provided are often geared for the toddlers or the younger school child with Play-stations and television being the only diversions available for the older children (Norwich Union Healthcare, 2003). Young people said they were bored and lonely and all remarked that their needs were different to other age groups. According to Boyd and Hunsberger (1998) the availability of activities and the atmosphere and appearance of the ward environment has a major effect on adolescents coping with hospitalisation. It has been suggested that adolescents require age appropriate recreational opportunities such as a specific room set-aside for socialising (Reddihough \& Court, 1979). This study recommended that a specific lounge should be set aside where adolescents could socialise with their peers. This conclusion has been supported by more recent research, Kari et al. (1999) when 77\% of teenagers surveyed thought that a specific "teenagers room” could be an improvement on the facilities provided.

A recent paper produced in the United Kingdom (Norwich Union Healthcare, 2003) looking at the views of nurses and adolescents on the provision of healthcare in hospitals pointed out that adolescents today have grown up in the electronic age with internet and email. Therefore it is not surprising that when asked what facilities they would most like to see in an adolescent unit, they said 'computers'. Other authors describe the importance of peer company (Farrelly, 1994; Russell-Johnston, 2000; Sharma \& Finlay, 2003), and comment that those with chronic conditions are more likely to be bored than those who are admitted once with an acute condition and so need greater attention (Clarke \& Cook, 1986). Other authors comment that contact with peers often has more importance to the adolescent than time spent with the family and that areas where teenagers can host their peers, away from the younger children, are needed (Kari et al. 1999; Reddihough \& Court, 1979). 


\section{Hospitalisation and taking responsibility for own behaviour in relation to education}

Schoolwork can be extremely important for this age group, with many young people taking exams during their adolescent years. It is important for these young people to keep up with their studies as missing school work can cause anxiety (Sharma \& Finlay, 2003). Providing facilities for study, away from the noise of the ward, would appear to be imperative. Sharma and Findlay found that the adolescents surveyed considered they did have the opportunity to do school work while hospitalised. Denholm (1990) looked at positive and negative experiences reported by hospitalised adolescents and described how some adolescents reported a benefit to their personal learning from being alone and inactive while in hospital. Those who had received help were particularly appreciative of

it. Furthermore, a teaching programme for those older adolescents in hospital for any length of time is thought to promote employment opportunity, independence and social interaction (Viner \& Keane, 1998). However, within Viner and Keane's study, data analysis failed to identify educational facilities as a reported psychosocial factor pertaining to the physical environment. Although it may be assumed from opinion that the provision of educational facilities within the ward environment is of paramount importance, Viner and Keane suggest that there is insufficient evidence available to say that this is an important psychosocial factor identified by the adolescent patient. However, recommendations supporting the provision of a specific Adolescent Unit suggest that the provision of educational facilities within the hospital environment is mandatory for the adolescent patient in order to meet their psychosocial needs (Gillies \& Parry Jones, 1992; National Association for the Welfare of Children in Hospital, 1990; Shelley, 1993).

\section{Hospitalisation and the task of increasing autonomy involving decision making, competence and supporting emancipation from parents}

Involvement in decision making is described as being of paramount importance in the nursing of these young people. This supports their increasing autonomy and assists in the development task of distancing themselves from their parents care (Hallstrom \& Elander, 2004). The ability to make decisions about care can be related to intellectual 
competence (Santrock, 2004). Beauchamp and Childress (2001) describe competence in decision making as a continuum ranging from total inability as a child to full competence as an adult. Children over 16 are presumed to be competent to give consent to medical treatment and those under this age may demonstrate their competence by meeting standards set by the courts. This is termed Gillick competence.

Gillick V West Norfolk and Wisbeck Area Health Authority and the
DHSS (1985)
In 1980, the Department of Health and Social Security in England
issued a notice outlining the circumstances in which a girl under 16
years of age could access contraceptive advice and treatment without the
knowledge or consent of a parent. Victoria Gillick, a mother of five
girls under the age of 16 years, objected to this erosion of her parental
rights and applied for a declaration that the advice in the circular was
unlawful. In the legal battle that followed, Victoria Gillick lost in the
first instance, won unanimously in the Court of Appeal; and eventually
lost to a 3-2 majority in the House of Lords. Health care professionals
in England, with responsibility for prescribing contraception to girls
under 16 now refer to the guidelines that resulted from this case -
otherwise known as determining 'Gillick Competence'.
(Fallon, 2003)

\section{Figure 1: Gillick Competence}

The literature describes that inclusion in decision making and discussion however, is not always achieved by medical and nursing staff when caring for adolescents (Godfrey, 1998; Harding-Price, 2003). Sometimes nurses think that the young person is included in all decision-making and discussions, but at other times they see their involvement as secondary to parents. Teenagers need to be involved and to understand the implications 
of what is happening to them and they need to be given enough responsibility to take control (Miller, 2001; Runeson, Enskar, Gunnel \& Goran, 2001). They also need to know what options are available to them so that they can make choices and seek information when they require it. Knowledge is power for teenagers, and helps to restore independence, which is so vital to their coping strategies (Evans, 1998; Meyers et al., 1996). By allowing adolescents to make their own decisions nursing and medical staff can give some control to the adolescents in their care, which they badly need so that they can see that their feelings and values were respected. It is also reported that a sense of responsibility can be encouraged and fostered by allowing the young people to be active participants in their own care (Meyers et al., 1996; Schultz \& Liptak, 1998; Taylor \& Muller, 1995).

Medication is another issue that has been described as sometimes contentious for this age group (Kyngas, 2003). Some teenagers take regular medication at home on a continual basis or self medicate if required. However, following admission this independence is often curtailed. Hospital regulations and guidelines concerning medications have to be followed, and medications are usually always dispensed and checked by registered nurses. Compromise in some regular medicine administration for adolescent patients who are considered responsible could mean more continuity for these young people. However, there is some evidence that fewer adolescents are completely independent at home than is recognised (Gillies \& Parry Jones, 1992). These authors go on to comments that only $15 \%$ of teenagers who required special care at home were allowed to cope by themselves, in the remaining $85 \%$ of the cases the caregiver, mostly mothers, gave more care than was thought necessary for the teenagers wellbeing, and did not allow them the independence they could have achieved.

It is also recognised that to achieve the developmental task of increasing autonomy open lines of communication must always exist and adolescents should be treated in an environment of open trust and honesty. The literature supports this ethos and communication appears not to be generally a major concern of adolescents in hospital (Kari et al., 1999; Sharma \& Finlay, 2003; Stevens, 1998). However, it is stated that it is 
very important for nurses to be able to communicate with parents about the adolescent's need for maintaining their developing autonomy whilst in hospital (Hentinen, 1996; Taylor \& Muller, 1995). This means that although teenagers need to maintain the support and understanding of their parents, at the same time they need to avoid regression to childlike behaviour and dependence on others. This is never more important than for the adolescent with a chronic or life limiting illness which is outlined in the following section.

\subsubsection{The adolescent with a chronic illness}

Adolescents with a life threatening or life limiting disease have additional needs when they are hospitalised. One of the challenges of nursing this age group is in the promotion of healthcare delivery that reflects a transition from childhood to adulthood and the achievement of autonomy when this transition is compounded by the psychosocial challenge presented by a serious illness. In this situation it is imperative that the development tasks of adolescence should be reflected in the framework of a nursing care model which adequately reflects adolescent development (McKinney, 1977). Other authors believe that it is often difficult for parents to treat their teenager as normal, and allow them the freedom that is necessary given the problems associated with illnesses which offer an uncertain future. Yet, they must do this if the child's psychological development and adjustment be normal (Maguire, 1996; Patton et al., 2002). Providing support to a young person and their family with any life threatening illness is a challenge as it requires the nurse to acknowledge the struggle between dependence and independence that is part of adolescent development. The adolescent should be able to achieve a sense of self and self worth, accept their physical gender role, achieve a sense of independence from parents and carers and acquire social skills and socially responsible behaviour despite their illness (Viner \& Keane, 1998). This key role in the care of teenagers, especially those who may be forced into increased dependence as their condition deteriorates, is acknowledged by Gregorowski (1998) who emphasises the importance of: '... enabling adolescent and family to recognise how the disease has 
affected usual relationships and finding ways to reclaim as much independence as the young person requires' (p. 17).

Another important consideration is that young people with a chronic illness have often begun their treatment as a child and now they are teenagers and the communication between them and the ward nurses does not always catch up (Taylor \& Muller, 1995). It is hoped that most nurses encourage adolescents to be as independent as possible. However, when staff have been used to dealing with the adolescent as a much younger child they will sometimes continue to do treat the adolescent in that way. The young person may have their increasing independence inadvertently taken away from them if staff continue to carry out the care themselves rather than taking time to teach the young adolescent how to do it. Young people need to be able to give input into the care they receive and the choices they make. In this way the planning, implementing and evaluation of future care can centre upon their developmental needs. These changing needs should be evaluated every time the adolescent is admitted, which will acknowledge their increasing maturity. When true family centred care is practiced, giving the adolescent the flexibility to make choices can be addressed (Gregorowski, 1998; McKinney, 1977). This approach gives the young person the knowledge that their views and wishes are being taken into account and that the nursing staff acknowledge they are increasingly able to make new decisions regarding their own care (Maguire, 1996; Patton et al., 2002).

Adolescence is also reported as a time when compliance with treatment can become an issue for young people with chronic diseases (Fotheringham \& Sawyer, 1995; Kyngas, 2000). This can be demonstrated by the young person with diabetes deciding that they do not want to record their blood sugar levels any longer or the adolescent with asthma refusing to take their medications. According to Hentinen (1996) risk taking, experimentation and breaking away from family constraints are three characteristics of adolescent development. Therefore, these young people need to be cared for by nursing and medical staff who are aware of the developmental changes that the adolescent is 
experiencing both physiologically and psychologically and socially so the appropriate care can be planned.

This section has outlined the desirability of an appropriate inpatient environment for adolescents which will address their unique psychological, physiological and psychosocial needs and not treat them as children. This has been documented repeatedly throughout the literature, suggesting that the special needs of the adolescent patient cannot be met adequately either in the adult or child-orientated environment (Viner \& Keane, 1998). The inpatient environment is however made up of a whole range of different facilities. It is the facilities that could impact on the quality of the inpatient experience that I wanted to examine in the conjoint study. Before the conjoint analysis could be conducted, the facilities that could be found in an inpatient setting needed to be established. The following section identifies a range of facilities that were identified from the literature.

\subsubsection{Adolescent facilities}

While first planning this study the convening of several focus groups, a recommended first stage of conjoint analysis was mooted. These groups would comprise of adolescents from a number of different social settings such as a church group or a youth group to elicit their views about inpatient facilities However, it was decided that the time frame and budget available for the research would not allow this to be undertaken in a meaningful manner so the literature was reviewed and the attributes that had been reported as being important to adolescents overseas were ascertained. There is not an exhaustive amount of information available which examined inpatient hospital facilities in relation to adolescents. The information collected has been collated and appears in Table 2, with a description of the findings in relation to the environment. Most of this information is derived from descriptive information and not from formal research. The authors documented in the table comment on the facilities that are important to the adolescent population in an inpatient setting. The table lists facilities in alphabetical order, rather than the importance authors give them. There is no information available, 
that I could find, to ascertain whether similar attributes are important to New Zealand adolescents. This was one of the desired for outcomes from this research. 
Table 2: Literature regarding inpatient hospital facilities

\begin{tabular}{|c|c|c|c|c|}
\hline Author & Source of data & $\begin{array}{l}\text { Number of } \\
\text { participants }\end{array}$ & Content & Facilities mentioned \\
\hline $\begin{array}{l}\text { Burr } \\
(1993)\end{array}$ & Interviews & $\begin{array}{l}25 \text { adolescents } \\
12 \text { parents } \\
20 \text { nurses in } \\
\text { UK hospitals }\end{array}$ & $\begin{array}{l}\text { Provision of healthcare for } \\
\text { adolescents. Asked if their } \\
\text { expectations of hospital were } \\
\text { different from reality; whether } \\
\text { they liked or disliked what was } \\
\text { provided and what they would } \\
\text { like in an ideal setting }\end{array}$ & $\begin{array}{ll}\text { - } & \text { Bathrooms/toilets } \\
\text { - } & \text { Bedtime } \\
\text { - } & \text { Location } \\
\text { - } & \text { Peer contact } \\
\text { - } & \text { Privacy }\end{array}$ \\
\hline $\begin{array}{l}\text { Farrelly } \\
\text { (1994) }\end{array}$ & $\begin{array}{l}\text { Literature } \\
\text { review }\end{array}$ & & $\begin{array}{l}\text { Describes literature on the } \\
\text { special care needs of } \\
\text { adolescents in hospital }\end{array}$ & $\begin{array}{ll}\text { - } & \text { Developmental needs } \\
\text { - } & \text { Privacy } \\
\text { - } & \text { Schooling }\end{array}$ \\
\hline $\begin{array}{l}\text { Fisher } \\
(1994)\end{array}$ & Descriptive & & $\begin{array}{l}\text { Describes advantages and } \\
\text { disadvantages of adolescent } \\
\text { inpatient units }\end{array}$ & $\begin{array}{ll}\text { - } & \text { Bedtime } \\
\text { - } & \text { Developmental needs } \\
\text { - } & \text { Location } \\
\text { - } & \text { Peer contact } \\
\text { - } & \text { Recreational need } \\
\text { - } & \text { Schooling } \\
\end{array}$ \\
\hline $\begin{array}{l}\text { Gillies } \\
(1992)\end{array}$ & Descriptive & & $\begin{array}{l}\text { Describes the issues involved in } \\
\text { the care of adolescents in } \\
\text { hospital }\end{array}$ & $\begin{array}{ll}\text { - } & \text { Independence } \\
\text { - } & \text { Location } \\
\text { - } & \text { Peer contact } \\
\text { - } & \text { Privacy } \\
\text { - } & \text { Recreational need } \\
\text { - } & \text { Schooling }\end{array}$ \\
\hline
\end{tabular}




\begin{tabular}{|c|c|c|c|c|}
\hline Author & $\begin{array}{l}\text { Source of } \\
\text { data }\end{array}$ & $\begin{array}{l}\text { Number of } \\
\text { participants }\end{array}$ & Content & Facilities mentioned \\
\hline $\begin{array}{l}\text { Gillies \& } \\
\text { Parry Jones } \\
(1992)\end{array}$ & Descriptive & & $\begin{array}{l}\text { Looking at the suitability of the } \\
\text { paediatric setting for } \\
\text { hospitalised adolescents and the } \\
\text { case for adolescent units }\end{array}$ & $\begin{array}{ll}\text { - } & \text { Location } \\
\text { - } & \text { Peer contact } \\
\text { - } & \text { Privacy } \\
\text { - } & \text { Recreational need } \\
\text { - } & \text { Schooling } \\
\end{array}$ \\
\hline $\begin{array}{l}\text { Glasper \& } \\
\text { Cooper } \\
(1999)\end{array}$ & Descriptive & & $\begin{array}{l}\text { Describing the need for } \\
\text { specialist inpatient adolescent } \\
\text { units }\end{array}$ & $\begin{array}{ll}\text { - } & \text { Location } \\
\text { - } & \text { Peer contact } \\
\text { - } & \text { Privacy } \\
\text { - } & \text { Recreational need } \\
\end{array}$ \\
\hline $\begin{array}{l}\text { Godfrey } \\
\text { (1998) }\end{array}$ & Descriptive & & $\begin{array}{l}\text { Describing how it is to be a } \\
\text { teenager in hospital }\end{array}$ & $\begin{array}{ll}\text { - } & \text { Décor } \\
\text { - } & \text { Location } \\
\text { - } & \text { Peer contact } \\
\text { - } & \text { Recreational need } \\
\end{array}$ \\
\hline $\begin{array}{l}\text { Harding Price } \\
\text { (2003) }\end{array}$ & Descriptive & & $\begin{array}{l}\text { A parents view of } \\
\text { improvements which could be } \\
\text { made in inpatient facilities for } \\
\text { adolescents }\end{array}$ & $\begin{array}{ll}\text { - } & \text { Location } \\
\text { - } & \text { Peer contact } \\
\text { - } & \text { Privacy } \\
\text { - } & \text { Recreational needs }\end{array}$ \\
\hline $\begin{array}{l}\text { Kari, Donovan, } \\
\text { Li \& Taylor } \\
\text { (1999) }\end{array}$ & Questionnaire & $\begin{array}{l}347 \text { adolescents } \\
\text { In North } \\
\text { London } \\
\text { secondary } \\
\text { schools }\end{array}$ & $\begin{array}{l}\text { What adolescents want in } \\
\text { hospital }\end{array}$ & $\begin{array}{ll}\text { - } & \text { Location } \\
\text { - } & \text { Peer contact } \\
\text { - } & \text { Privacy } \\
\text { - } & \text { Schooling }\end{array}$ \\
\hline
\end{tabular}




\begin{tabular}{|c|c|c|c|c|}
\hline Author & $\begin{array}{l}\text { Source of } \\
\text { data }\end{array}$ & $\begin{array}{l}\text { Number of } \\
\text { participants }\end{array}$ & Content & Facilities mentioned \\
\hline $\begin{array}{l}\text { Lansdown } \\
\text { (1996) }\end{array}$ & $\begin{array}{l}\text { Guide for } \\
\text { family and } \\
\text { carers }\end{array}$ & & Need of hospitalised adolescents & $\begin{array}{ll}\text { - } & \text { Location } \\
\text { - } & \text { Peer contact } \\
\text { - } & \text { Recreation need } \\
\text { - } & \text { Schooling }\end{array}$ \\
\hline $\begin{array}{l}\text { Norwich Union } \\
\text { (2003) }\end{array}$ & Interviews & $\begin{array}{l}200 \text { teenagers } \\
\text { between the } \\
\text { ages of } 13 \text { and } \\
18 \text { and } 212 \\
\text { nurses } \\
\text { throughout the } \\
\text { UK }\end{array}$ & $\begin{array}{l}\text { The views of adolescents and } \\
\text { nurses on the provision of } \\
\text { healthcare in hospitals }\end{array}$ & $\begin{array}{ll}\text { - } & \text { Decor } \\
\text { - } & \text { Location } \\
\text { - } & \text { Peer contact } \\
\text { - } & \text { Recreational need }\end{array}$ \\
\hline $\begin{array}{l}\text { Russell- } \\
\text { Johnston } \\
(2000)\end{array}$ & Survey & $\begin{array}{l}35 \text { nurses from } \\
33 \text { hospitals in } \\
\text { the UK }\end{array}$ & $\begin{array}{l}\text { The adequacy of facilities that } \\
\text { were available for adolescents } \\
\text { in their workplace }\end{array}$ & $\begin{array}{ll}\text { - } & \text { Bathroom facilities } \\
\text { - } & \text { Bedtime } \\
\text { - } & \text { Location } \\
\text { - } & \text { Recreational area } \\
\text { - } & \text { Use of kitchen }\end{array}$ \\
\hline $\begin{array}{l}\text { Sharma \& } \\
\text { Finlay } \\
\text { (2003) }\end{array}$ & Questionnaire & $\begin{array}{l}57 \text { adolescents } \\
\text { admitted to an } \\
\text { adolescent unit } \\
\text { in the UK, aged } \\
10 \text { to } 18 \text { years }\end{array}$ & $\begin{array}{l}\text { The view of adolescents as to } \\
\text { what constituted an ideal ward }\end{array}$ & $\begin{array}{ll}\text { - } & \text { Accommodation for parents } \\
\text { - } & \text { Bathrooms } \\
\text { - } & \text { Décor } \\
\text { - } & \text { Kitchen facilities } \\
\text { - } & \text { Location } \\
\text { - } & \text { Peer contact } \\
\text { - } & \text { Privacy } \\
\text { - } & \text { Recreation need } \\
\end{array}$ \\
\hline
\end{tabular}




\begin{tabular}{|c|c|c|c|c|}
\hline Author & $\begin{array}{l}\text { Source of } \\
\text { data }\end{array}$ & $\begin{array}{l}\text { Number of } \\
\text { participants }\end{array}$ & Content & Facilities mentioned \\
\hline $\begin{array}{l}\text { Shelley } \\
\text { (1993) }\end{array}$ & Descriptive & & $\begin{array}{l}\text { Examination of the environment } \\
\text { in which teenagers were being } \\
\text { nursed in the UK and were their } \\
\text { needs being adequately met }\end{array}$ & $\begin{array}{ll}\text { - } & \text { Bathrooms } \\
\text { - } & \text { Location } \\
\text { - } & \text { Peer contact } \\
\text { - } & \text { Privacy } \\
\text { - } & \text { Schooling }\end{array}$ \\
\hline $\begin{array}{l}\text { Whelan } \\
\text { (2003) }\end{array}$ & Descriptive & & $\begin{array}{l}\text { Looking at how the needs of } \\
\text { teenagers with cancer are met in } \\
\text { hospital and where they should } \\
\text { be treated. }\end{array}$ & $\begin{array}{ll}\text { - } & \text { Accommodation for parents } \\
\text { - } & \text { Location } \\
\text { - } & \text { Peer contact } \\
\text { - } & \text { Recreation need } \\
\text { - } & \text { Schooling }\end{array}$ \\
\hline
\end{tabular}




\section{Themes related to inpatient hospital facilities which have been identified as being important to adolescents in the literature reviewed}

Location of the inpatient experience: The problems faced by some adolescents when admitted to adult or children's wards are described in a variety of ways by all of the authors. Burr (1993) undertook research focused on the inpatient environment for adolescents aged 12 to 18 with a physical health disorder. She interviewed 25 inpatient adolescents aged comprising 10 in adult wards and 15 in the children's ward. Twelve parents, four with adolescents in an adult ward and eight with adolescents in the children's ward were also interviewed. In the same study 20 registered nurses who participated in the care of adolescents were interviewed, comprising 10 in adult wards and 10 in the children's ward. She comments on location of the stay in regards to the isolation described by adolescents when they are admitted to an adult ward. Due to this isolation they reported having feelings of anger, and then feeling 'awful' and 'guilty' about their feelings. This was particularly in relation to adolescents who commented that stopping the old people "moaning and dying" would help them to overcome their feelings of isolation. The parents who were interviewed also disliked the adult facilities commenting that they were surprised there were so many ill patients. Two of the adolescents commented that they thought they had been admitted to the 'old people's ward' by mistake. More than half of the teenagers interviewed in the Norwich Union research (2003) said they thought than adolescents do not fit into a traditional hospital structure as they fall between the children's ward and the general adult ward and they supported the introduction of specific adolescent units in hospitals. An overwhelming nine in ten of the teenagers interviewed thought such wards would be beneficial for them and their peers.

Several issues that were highlighted by adolescents when admitted to a children's ward were described by Harding-Price (2003). One of the main issues was the noise from young children and the general activity that was generated by young children playing. Problems with the physical environment were described by Gillies (1992) who comments that children's wards often provide beds that are too small and that facilities are more 
appropriate for the younger children. Harding-Price also comments on the need of adolescents, particularly those receiving chemotherapy, for a 'stable' environment, which means being nursed with others in the same age group who enjoy the same environment. She describes that when these adolescents are nursed in a child orientated environment this is not always conductive to their wellbeing for example the fact that expecting them to want lights out at 9 p.m. or putting up with crying babies is not what they need to get better. The environment is related to the provision of medical and nursing care by Godfrey (1998). She describes the necessity of nursing and medical staff having to adapt from caring for a baby one minute to a teenager the next as being problematic, and also the fact that adult physicians may have limited experience of a childhood disease such as cystic fibrosis. Sharma and Finlay (2003) found that the environment needed to be friendly, have lots of natural light and appropriate wall decorations. All of the adolescents interviewed by Burr (1993) said that they would prefer to be nursed with their own age group.

Privacy: This refers to 'personal space' both in the bed sense and in being able to have confidences respected (Kari et al., 1999). Other authors, Gillies (1992) and HardingPrice (2003) related privacy to the fact that when an adolescent is admitted to a ward with young children nearby their 'personal space' is not respected. This was particularly evident when the adolescent was receiving chemotherapy and needed their privacy either because of extreme mood swings or nausea caused by their treatment. Gillies and ParryJones (1992) also comments on the fact that nurses who look after smaller children sometimes do not always recognise that teenagers are easily embarrassed and their privacy is not always respected. Sharma and Finlay (2003) regarded personal space in regards to privacy and commented on the lack of privacy for private telephone calls.

Bathroom facilities: Relate to having a lock on the toilet door, a mirror to put on makeup, shaving point, hairdryer, and 'adult' sized toilets and basins. Gillies (1992) recognise that privacy for washing and bathing should be scrupulously maintained and that hospital policy may need to be reviewed with teenagers in mind. She gives an example of this as supervision when bathing which is necessary for a five year old but 
this is an extreme embarrassment to a 13 year old. The lack of shaving sockets, full length mirrors and locks on the bathroom door were highlighted by Russell-Johnston (2000). Gaps under the bathroom door and small toilets and doors that could not be locked were described by Sharma and Finlay (2003) as being unacceptable. The parents of adolescents admitted to adult wards interviewed by Burr (1993) reported they considered the washing and toilet facilities were inadequate there. However, in the same study, the parents of adolescents admitted to children's' wards also found the washing and toilet facilities poor.

Bedtime: Authors found that 'bedtime at 7.30' was a most common cause of surprise and distress for the adolescents who were nursed in a paediatric ward (Burr, 1993: Fisher, 1994). However, Harding-Price (2003) described that even the later time of having to go to bed with lights out at 9 p.m. as being particularly detrimental to the establishment of a stable environment for teenagers who were used to going to be much later at home. Russell-Johnston (2000) comments that deciding ones own bedtime and lights out was desirable in enabling independence.

Age appropriate recreation facilities and contact with peers: Are referred to by most of the authors in one way or another. These include room to accommodate friends from school, the availability of a pool table, TV/video/DVD player and the availability of videos appropriate. Gillies (1992) remark that when there are limited recreation facilities available adolescents can be told to make less noise and have no opportunity to be alone, so somewhere where the stereo can be turned up and adults and small children are excluded unless invited is needed. Russell-Johnston (2000) makes the observation that table games such as snooker or table football are particularly valuable in encouraging fathers to visit and interact with their teenage children. Sharma and Finlay (2003) saw socialising as a very important activity for this age group. It was also suggested that because teenagers have grown up in the electronic age with the internet and email, computers would be a necessity (Norwich Union Healthcare, 2003). 
Décor: Includes comments about adult wards being dreary referred to by Burr (1993) and the need for bright, clean walls by Sharma and Finlay (2003).

Peer contact: This is mentioned by most of the authors. Gillies (1992) commented that peer contact is essential, and this is often lacking as adolescents are nursed in various locations, but that this can be overcome if a central 'youth group' can be established. However, this requires that all wards that might nurse adolescents to be aware of its existence. Visiting hours refers mostly to the importance adolescents place on the availability of an environment that enables their peers to visit freely and to be accommodated in surroundings in which they feel comfortable (Glasper \& Cooper, 1999; Harding-Price, 2003; Kari et al., 1999).

Kitchen use: This includes the quality, choice and availability of food. It describes that the adolescents have their own kitchen facilities for making snacks, hot drinks and the ability to do this without nursing supervision. Sharma and Finlay (2003) were the only authors who commented about the quality and availability of food and Russell-Johnston (2000) on the availability of kitchen facilities that were open for adolescent use.

Schooling: With exams often on the horizon, what kinds of facilities are important? Is there a teacher to help them? Most of the authors refer to schooling, usually in the need to have somewhere private and quiet where the adolescent can study. Farrelly (1994) comments on the anticipation of missing school, falling behind and then the need to make up the missed school work resulting in significant anxiety and Harding-Price (2003) refers to the distress of hospitalisation disrupting examinations. Whelan (2003) comments that teachers should be an essential member of the multidisciplinary team as they have an important role in providing formal lessons, facilitating examinations and working in close liaison with local schools and home tutors to 'fill the gaps' caused by school absences. Whelan also goes on to comment, as he was looking at facilities for cancer patients up to the age of 20, that for those in higher education it is equally important, as is providing vocational guidance, particularly when employment plans must be adjusted to account for consequences of cancer, such as amputation. 
This chapter has described how the hospital environment can help or hinder the developmental tasks of adolescence. It also discussed how this age group does not appear to be as well served as it could be in the health system and that adolescents are often nursed inappropriately with much younger children or adults. Understanding the needs of the consumer has been acknowledged for many years and this is particularly true for children and young people as their needs are particularly varying and conflicting (Hart, 1992). Health authorities and primary care groups need to recognise that children and young people make up a significant proportion of health service users, and that developing child and young people centred services means listening to the children's views. The following chapter looks at different ways of eliciting opinions from the adolescent group and suggests a method for listening to our young people and so being able to incorporate their wishes into the design and planning of their environment in an inpatient setting. 


\section{Measuring opinions}

Our children/tamariki: seen, heard and getting what they need

New Zealand Ministry of Health, 1998

To undertake this research I needed to elicit opinions from adolescents. The following chapter suggests different ways in which opinions could have been canvassed from adolescents and why they were rejected. It explains conjoint analysis, the method chosen, in some detail and also describes the decision making process. Four ways of measuring the opinions of adolescents were considered.

\subsection{Interviews}

Interviewing adolescents who had been in hospital was mooted. I considered a structured interview with questions to elicit views from the adolescents about the facilities that were provided in Wellington and some idea of what they would consider to be necessary in a new facility. This approach would have given me qualitative data that could give me an insight and understanding of the issues important to the adolescent who has to spend time as an inpatient in hospital. However, I had in mind to collect quantitative data that I could use to try and influence the hospital management in their planning decisions. In my eventual data collection I did ask the adolescents three questions regarding the method of data collection. These were whether they understood what was asked of them, whether they found the method easy to use and if there were any other points that I could add to any future research. 


\subsection{Focus groups}

The running of focus groups was considered. Focus groups are in depth qualitative interviews with a small number of carefully selected people who are brought together specifically to discuss a selected topic. This group would generate data through the give and take of group discussion. Small groups might have given me the information I was wanting. I decided against this method because the literature informed me that the quality of the data is influenced by the skills of the moderator (Krueger \& Casey, 2000). I felt that I did not have the necessary skills to run a group and I did not have a budget to employ a skilled facilitator.

\subsection{Questionnaires}

The use of questionnaires was considered as these have been used by other researchers with adolescents (Fisher, 1994; Harding-Price, 2003; Kari et al., 1999; Norwich Union Healthcare, 2003), and provide quantitative data. Whilst looking at the possibility of using questionnaires the types of questions that could be asked were explored. It was ascertained that many questionnaires are designed to measure attitudes and that attitudes are based on information that has already been gained, feelings (liking and disliking) and intended behaviour. I thought that these were aspects that I would be interested in looking at, so I decided to find out a little more about attitude.

Aaker, Kumar \& Day, (1998) comment that 'attitudes are mental states used by individuals to structure the way they perceive their environment and guide the way they respond it' (p. 272). My exploration of how to measure attitude highlighted that there were different components to attitude. There are three related aspects that form an attitude: a cognitive or knowledge component which is described as all known information about a subject, a liking component which is the overall feeling towards a subject based on knowledge and an action component which is the expectation of future behaviour (Underhill, 1999). When looking at these different ways to view attitude, and how they could be measured when asking for opinions about the inpatient health facilities the concept of conjoint analysis was discovered. Conjoint 
analysis appeared to be able to provide the quantitative measure that I was looking for. When we are asked to make choices in a questionnaire the choices are usually made in isolation, and one choice does not depend on previous choices. However, in reality we can not usually have 'the best' of everything. So, if the adolescent has to make choices about which aspects of an inpatient service are most important to them, as Capital and Coast District Health Board (C\&CDHB) probably cannot provide an inpatient service with everything, conjoint analysis should provide a mechanism by which the adolescent could choose which aspects they would keep and which they would sacrifice. By ascertaining which environmental factors of an inpatient service are most valuable to the adolescent patients, we can probably offer a combination of the particular attributes that they find most attractive. In doing this we can help to increase the patient satisfaction with our service.

\subsection{Conjoint analysis}

Conjoint analysis was developed in the 1970s and is said to have its roots in mathematical psychology (Ryan \& Hughes, 1997). It is a survey technique which has, in the past, been primarily used for market research to develop effective product design. It is also sometimes referred to as Trend or Discrete Choice Analysis (Aaker et al., 1998). The technique is based on the premise that any product or service can be described by its characteristics or attributes, and that when we choose a product or service to use we weigh up which of the attributes provided are most important to us. Conjoint analysis requires that various attributes and options for that attribute, pertaining to a service or product, are described on a series of cards. Each card differs, drawing out different points. The cards are then given to the target group to rank in order of preference. The way that the cards are ranked is then examined. The data collected reveals to what extent the individual characteristics that make up the service or product are valued.

The main principle governing conjoint analysis is choice; this is summed up in the following scenario:

When we are given choices we make decisions on what best suits or needs at a given time. If we were asked to describe the 
perfect airline we would name the one that flies closest to the destination that we need to get to, on the day that we want to travel and which will get us to our destination at the time we want to arrive - having flown the shortest route. We want the cheapest fare, the most comfortable seats and the best food. However, in reality we may not be able to have everything. We have to decide whether time, or destination, or route, or cost is the most important to us and choose our airline accordingly.

This principle is the same whether we are buying an airline ticket, a jar of strawberry jam or staying in a hotel, we weigh up which attributes are important to us in the product or service, and make our choice accordingly. Conjoint analysis requires this to be done when examining hypothetical scenarios.

For this research conjoint analysis was used to elicit the views of adolescents, about the 'product design' of inpatient hospital facilities. This method of information gathering was chosen over other survey methods as conjoint analysis is said to be designed to closely resemble the decision process that people make, when they look at alternatives available in a product or service (Ross, Avery \& Foss, 2003). Conjoint analysis examines the trade-offs that are made to determine the combination of attributes that will be most satisfying to the consumer so the optimal features for a service can be determined. It determines the relative importance of each attribute, attribute option, and combinations of attributes options. If the most preferable service is not feasible for some reason then conjoint analysis can be used to identify the next most preferred alternative.

In recent years conjoint analysis has been used in several health care areas including eliciting patients and community preferences in the delivery of health service (Ryan \& Hughes, 1997); developing outcome measures and establishing patient's preferences in the doctor-patient relationship (Ryan \& Farrah, 2000); studying patient satisfaction (Markham, Diamond \& Herjmeansen, 1999); investigating women’s preferences for intrapartum care and assessing women's preferences for miscarriage management (Longworth, Ratcliffe, \& Boulton, 2001; Ryan \& Hughes, 1997); views on cataract 
surgery options (Ross et al., 2003) and consumer preferences in the development of health promotion programmes (Sproth, 1989).

These studies examined such options as location of services (Longworth et al., 2001; Ryan \& Farrah, 2000; Ryan \& Hughes, 1997) continuity of care, availability of medical intervention such as pain relief, possibilities of complications following miscarriage and cataract surgery management, options, views and cost (Ross et al., 2003; Ryan \& Hughes, 1997) and who makes the decisions in care and waiting times for appointments (Markham et al., 1999; Ryan \& Farrah, 2000). The willingness to pay for a hypothetical hip protector and so for a reduction of the risk of a fracture of the femur was examined by Tesler and Zweifel (2002). Their study looked at ease of handling, wearing comfort and out of pocket costs which were traded off against risk reduction.

\subsection{Decision making in adolescence}

In order to undertake a conjoint analysis, adolescents would be asked to perform tasks which would require them to think about hypothetical situations. Because of this the question of whether this age group would be capable of undertaking the task that would be asked of them was mooted. There have been a small number of quantitative studies previously relating to the physical environment provided for adolescents (Fisher, 1994; Oppong-Odiseng \& Heycock, 1997; Stevens, 1998). The data in these studies were obtained from questionnaires, interviews and surveys and from this Smith (2004) concludes that it may be assumed that adolescents are able to make judgements concerning what is important to them. Adolescents have also reached the formal operational stage in Paiget's stages cognitive development. This stage was described in Chapter 3 which explained how adolescents can think logically and hypothesise. From this I conjectured that adolescents would be well able to undertake the logical thought that is necessary in conjoint analysis, as following hypothetical reasoning the adolescents would need to make decisions about the choices of card.

Decision making is the process of identifying and choosing between alternatives, which is the basis of conjoint analysis. At the time of making a decision, the decision 
maker has, at the very least, two alternatives, which are the actions which might be taken. The ideal is that a good decision will be made which will lead to a good outcome. However, a bad decision may lead to a good outcome, and conversely a good decision may lead to a bad outcome. The quality of a decision is evaluated on the basis of the decision maker's alternatives, information, values, and logic at the time the decision is made.

Every decision is made within a decision environment which is defined as the collection of information, alternatives, values, and preferences available at the time of the decision (Underhill, 1999). Therefore it would appear that an ideal decision environment would include all possible information, all of it accurate, and every possible alternative. However, this is not the case. If more information than is required to make a good decision is provided, this can be detrimental to good decision making. A person may get information overload. In this state so much information is available that the decision-making ability actually declines because the information in its entirety can no longer be managed or assessed. Selective use of information may occur. This is when the decision maker will choose from among all the information available, only those facts which support a preconceived idea will be chosen. Another problem can be decision fatigue. This is when the decision-maker cannot be bothered, which will result in either a fast careless decision or no decision at all. This shows that the material given to the participants in a conjoint analysis must be of the right quality and quantity and delivered in the right manner for good decision making to be made.

Decisions are never made in isolation. Gathering information, exploring alternatives and making choices are made in a context of other decisions. Many decisions made earlier have led up to this decision and made it possible. Many decisions will follow from it. Every decision made affects the decision stream and the collections of alternatives available afterwards. This is one of the reasons that led me to use the participants that I chose for this research. The participants are described in the following chapter. 
This chapter has outlined why the decision to use conjoint analysis was made and has given a brief outline of the method. The next chapter describes in detail how the conjoint analysis was conducted. 


\section{Investigation method}

Adolescence - the time between puberty and adulthood - we have been slow to give adolescence the same concentrated care that has gone into the study of the baby and younger child. If as a society we are to understand our adolescents instead of being estranged from them, we have to catch up fast on our ignorance of what life means to adolescents today, and what the world looks like through their eyes.

Hemmings, 1960

Conjoint analysis is based on the premises that any product or service can be described by its characteristics or attributes, and that when we choose a product or service to use we weigh up which of the attributes provided are most important to us. Undertaking a conjoint analysis involves defining attributes of a product or service that are important to the consumer and describing scenarios containing a series of attributes in different combinations on a series of cards. The cards are then presented to the 'customer' or 'target group' who are asked to arrange the cards in order of preference for the whole scenario. The order of the cards, and what they describe are then analysed by the SPSS Conjoint programme and the importance of each of the attributes in relation to one another is determined.

\subsection{Conjoint analysis basic assumptions}

There are basic assumptions that are made in a conjoint analysis. The first assumption is that every service or product is made up of a 'bundle' of attributes. These attributes can be, for example, as easily described as colour or cost, or be more involved such as location. However, every service or produce contains a selection of attributes. Two of these attributes that go to make up the 'bundle' for an inpatient service may be the location of the inpatient stay, for example in an adult or a paediatric ward and some of the facilities that are available in the ward such as the availability of a recreation room or a kitchen. 
The second assumption is that each of the attributes will have different 'options'. To follow on from the first example, colour can be broken down into red, blue and green for example. The location of the inpatient experience could be broken down into adult ward, paediatric ward or adolescent ward. The final assumptions are that the 'utility' or desirability of the service is a simple function of the utilities or the 'desirability' of the attributes, and that the desirability predicts the attractiveness of the service or product and that the participants will tell the truth and are able to understand what is asked of them.

\subsubsection{Method Description}

There are five steps involved when undertaking a conjoint analysis:

1. Defining the attributes of the product/service: these are the characteristics of the service or product which are being examined and which the target group are going to be asked to assess.

2. Describing options of the characteristics: each of the characteristics will have different options. This could be that the characteristic is present or absent or that the characteristic is present but in a different form.

3. Completing scenarios containing one option of each of the attributes: combinations of the attributes are described on cards.

4. Presenting the participants with cards containing the scenarios: the target group are asked to rank the cards in order of preference.

\section{Analysing the data received.}

The above method is called the full-concept approach, and the SPSS Conjoint package was used to generate attribute cards and to analyse the data. 


\subsubsection{Defining the attributes}

The first task in the conjoint analysis was to identify the characteristics of an inpatient facility that were important to adolescents. For this research this was achieved, with one exception, by the literature search summarised in Table 2. This is not to suggest that there were not many more characteristics that could have been added to the list. However, a decision was taken to use the attributes that appeared repeatedly in the literature. The only attribute that did not appear in the literature was the cell phone. The use of cell phones was added to the scenario list because of the prevalence of cell phone use for phone calls and texting within our adolescent population. Aikman (2005) in an article in The Wellingtonian newspaper describes how keeping in touch with friends via cell phone has become wildly popular amongst adolescents in the last few years. The same article quotes the deputy principal of Wellington Girl's College who says that $85 \%$ of girls appear to bring a cell phone to school, and that cell phone use is most popular among younger adolescent girls who ‘can’t do without them' (p. 3).

As it was necessary to present the target group with cards that described scenarios that could be found in an inpatient setting and that could be easily understood, only five attributes were used. The literature informed me that if too many attributes are described, the task of differentiating between the scenarios becomes too difficult (Aaker et al., 1998; Ross et al., 2003). For each attribute two or three different options were created pertaining to recreation, location, kitchen facilities, cell phone use and bathroom facilities. These attributes and options are as follows, with a description of what the attribute describes and why they were chosen. The full description of the attributes was given to the adolescents before the card sorting exercise, so they would know exactly what each of the options meant. 


\subsubsection{Describing the attributes and options}

\section{Recreational facilities:}

Selected as an attribute because the literature suggested that it was important to the adolescents surveyed. There were many comments about boredom and the lack of adolescent specific activities. Two levels/options were developed:

Attribute 1, option 1 was a common/sitting room shared with all ages; this was explained as a recreation room that would not be dedicated to adolescents. If the adolescents were being nursed on an adult ward the sitting room would probably contain a TV, but would be used by inpatient adults and their families. If the young people were being nursed in a paediatric ward, the recreation/sitting room would be used by the children on the ward (possibly all ages) and their parents and friends.

Attribute 1, option 2 was a common/sitting room for adolescents only; this was described as a dedicated adolescent space. There was no mention of what it would contain but it was suggested that it might contain such items as a DVD player (or equivalent), a television set and perhaps an item such as a pool table. This room would only be used by adolescents and their friends. Adults would not be allowed, except by invitation and consensus from other young people visiting the room. It may be a room that is used by other adolescents in the hospital.

\section{Location:}

Selected as an attribute because the children and adolescents in the literature who were surveyed commented on the desirability of being nursed with their peers and not with younger or older people. Three options/levels were developed.

Attribute 2, option 1 was described as adolescent bay adjacent to paediatric ward; this describes an area that was dedicated to adolescents. Again, the young person may be nursed in a single room, a two bedded or four bedded cubicle, but this would be with other young people of a similar age.

Attribute 2, option 2 was described as a paediatric ward; this means that the adolescents are nursed in a paediatric ward. They might have a single room or be 
nursed in a two or four bedded cubicle with other adolescents, but this was not guaranteed.

Attribute 2, option 3 was described as an adult ward; this suggests that the adolescent was nursed in a ward that was predominantly adult focused. The young person may be nursed in a single room, but could equally be nursed in a two bedded cubicle or a four bedded cubicle with older adults as the other occupants.

\section{Kitchen facilities:}

Selected as an attribute because of statements in the literature about the desirability of being able to make snacks. Two options/levels were developed.

Attribute 3, option 1 allows for a kitchen area which can be used by adolescent to make hot drink/snack, this also describes an area where the young people can go unsupervised. There would be facilities to make a snack or a drink and somewhere to store their own food if required.

Attribute 3, option 2 suggests that there is no snack making facility; this means that although there might be a kitchen area the young person is not allowed into the area unsupervised.

\section{Cell phone usage:}

No references were found relating to cell phone usage in the literature reviewed. However, a recent newspaper article by Aikman (2005) quoted a local high school principal regarding adolescents and cell phones as 'it's part of what they need now'(p. 3). Two options /levels were developed.

Attribute 4, option 1 allows for cell phones to be used in designated areas. It is appreciated that cell phones cannot be allowed in the ward area as they can interfere with electronic devices, but there would be an area near to the ward, or a recreation room where the young people could phone or send text messages.

Attribute 4, option 2 means that no cell phones allowed in any area. 


\section{Bathroom facilities:}

There were many comments in the literature about bathrooms and toilets. Two options/levels were developed.

Attribute 5, option 1 describes facilities as being suitable for an adolescent population. There would be adequate privacy and the facilities would have such items as shaving points, adequate lighting and mirrors.

Attribute 5, option 2 describes facilities that may not be adolescent dedicated, there may not be locks on the doors, and this was used to describe the 'normal' ward facilities. In a paediatric ward this might mean that there are small toilets and hand basins. There might not be locks on the bathroom doors. There would be no facilities for shaving.

These scenarios were then combined to provide pictures of hypothetical inpatient settings, with one option for each of the five attributes. This method is called the fullconcept approach, and the SPSS Conjoint package was used to generate the attribute cards. The full concept approach in Conjoint uses a fractional factorial design, which means that it presented a suitable fraction of all possible alternatives. This is used because presenting all alternatives would make ranking the cards impossible thereby potentially invalidating the responses (Aaker et al., 1998) and this method is described in the following section.

\subsubsection{Hypothetical scenarios and card production}

The third step in the conjoint analysis is to combine the attributes to complete hypothetical scenarios. Even after careful selection of the attributes and their options, all combinations of the attribute options would generate too many scenarios for the target group to consider. With just the five attributes mentioned there are 48 combinations (3x2x2x2x2)! To present 48 cards for consideration and ranking would be too great a task to undertake in a meaningful way. It can be appreciated from these calculations that the number of scenarios increases with the number of characteristics and options, which is why only five attributes were used in this study. All of the factors and their different options are entered into SPSS ORTHOPLAN. 
The programme calculates all of the possible combinations and then produces a subset of cards to use from the factors and options specified. A subset containing eight scenarios was produced by SPSS from the five attributes and the two or three options (Appendix 2).

This subset then needed to be reproduced onto individual cards, which could be presented to the participants so that they could be placed into order of preference. Each scenario was reproduced on one card. Having one card per scenario helps the respondent to focus on just the one scenario being evaluated. The SPSS guide (SPSS Inc., 1990) recommends that stimuli should be standardised - this means that all of the cards should be the same size, the same colour and contain information that is portrayed in a similar manner. This is so that the participants will rank the cards in order of preference of the words contained on the card rather than the appearance. Two of the cards which were produced from the eight scenarios produced by orthoplan are found in Appendix 3 and a complete list of the cards in Appendix 13.

Demographic information was collected from all of the participants. I was hoping to ascertain from the demographic information if there were any differences in the way the cards were ranked, this might indicate a difference in factor preference between ages and/or gender, or if preferences changed with length of time as an inpatient. A copy of the demographic information sheet is attached in Appendix 4. The next step in conjoint analysis was for sampling to occur; this meant that the cards needed to be ranked in order of preference by the target group of adolescents.

\subsubsection{Sampling}

The scenarios needed to be presented to the target population, which in this instance were adolescents. One of the aims of this research was to ascertain if conjoint analysis was a method that could be understood and used by this age group. All of the previous research that I could locate had been used with adults. Ideally a study should have been undertaken with a representative sample of all adolescents. However, because of time and logistic constraints a group of adolescents who had previous knowledge of hospitals was used. For this study I elected to ask the young people of CanTeen if they would be agreeable to help me. 
The co-ordinator of CanTeen Wellington was approached to see if the young people engaged with this service would be agreeable for me to come to one of their meetings so that they could rank the cards and give me some demographic information about themselves. Agreement was reached subject to ethical approval (Appendix 5). Two young people from another region, who were members of CanTeen, and four young people in the Wellington region who had been in hospital but who were not members of CanTeen also offered to participate. These six young people are included because their inclusion is not seen as an issue impacting on the validity of the study.

Information regarding the number of participants required for a preliminary study varies. Ryan and Farrah (2000) commented that their pilot study contained 30 participants, whereas Ryan and Hughes (1997) stated that a pilot questionnaire was given to a convenience sample of women before the main study of 600 women but did not state the sample number. Tesler and Zweifel (2002) conducted a small pre-study test with 10 participants before their main study of 500. The other papers reviewed using conjoint analysis did not mention pilot, preliminary or pre-studies. No information could be found that indicated the minimum numbers of people who should be involved in a preliminary study.

The participants for the preliminary study were recruited using convenience sampling, from Members of CanTeen, New Zealand. Schneider, Elliott, LoBiondo-Wood and Haber (2003) describe this as using a population group that is accessible and thought to reflect the target population. All current members of CanTeen New Zealand were considered as appropriate to the research as inclusion criteria only required that potential participants be adolescent. CanTeen is a youth-orientated cancer patient support group founded in 1985 by a New Zealand cancer survivor studying in Sydney, Australia. Michael Carr-Gregg, its founder, developed cancer as a late adolescent. It was his experience of being treated at Wellington Hospital that inspired him to form CanTeen Australia while studying there. His passion was embraced and developed by a group of six young cancer patients and was supported by a number of health professionals. Collectively, they recognised that young people with cancer were being treated in an environment that was dominated by either young children or adults, and further, they realised that isolation from one's peers can have a serious 
impact on one's ability to cope with diagnosis. A visiting New Zealander met Michael Carr-Gregg and learnt about the teenage support group in Australia. They both decided to bring the concept back to New Zealand, and established CanTeen New Zealand (Thomas, 2004).

\subsubsection{Ranking the Cards}

The date set for the CanTeen meeting to collect the data turned out to be a particularly unpleasant Wellington evening, with a southerly storm in progress. The regular monthly committee meeting was held first and then I was invited into the meeting room and introduced by the CanTeen coordinator to the members present. There were more members present than I had been expecting, but I had brought sufficient sets of cards and demographic sheets. I introduced myself and gave a short description of the research. The young people were advised of their right not to complete the exercise if they did not want to. Nobody declined so each adolescent was given a demographic information sheet to complete.

An explanation was given as to what each of the scenarios meant and each young person was given a set of cards and instructed how to proceed. The young people sat round a large table and laid their own cards out in front of them. They were asked to rank the cards in order of preference. Each was given a full set of cards which they were asked to consider individually and then rank them in the most preferred scenario to the least preferred scenario. They were instructed to take just two of the two cards and consider them both and then rank them as most preferred or least preferred. They then were asked to take one more card and again compare it with each of the two cards and place it on the table in its order of rank. They were instructed to repeat this process until all of the eight cards were ranked in order. In this way only two cards were being considered at any one time. This method of decision making to rank the cards was not described in any of the literature reviewed but suggested by a colleague who had used conjoint analysis (personal communication, D. Gibson $6^{\text {th }}$ June, 2004). The youngest member of the group was at first unsure what to do, but when one of the older girls explained to him again what was required he quickly completed the task. The young people were then asked to mark the cards one through eight, with one 
being the most preferred scenario. This was done so that in the event of the cards being muddled, the order confused would not be lost. Each set of cards had previously been marked with an identification number on the reverse, which was repeated on the demographic form. The cards were then stapled to the demographic forms, collected and stored in a box file until they were needed for analysis.

Following the ranking exercise the young people were thanked for their participation and I asked if any of them would like to have a general discussion about inpatient services. It was stressed that there was no obligation to stay. Of the 29 participants, a total of 12 young people participated in discussions. The young people were asked if there were any aspects of an inpatient service that they thought important that were not mentioned on the cards, or if there were any aspects of an inpatient stay that they would like to discuss. Several themes emerged from the conversations relating to what is important for this age group. Formal notes were not taken at the time of the discussion but as soon as I had left the meeting I reflected on the time spent with the young people and made notes of the comments that had been made.

Sets of cards, demographic sheets and explanations were also sent to two adolescents involved in CanTeen but not present at the meeting. Three adolescents who were not members of CanTeen but who had spent time in hospital were also included. All of these young people offered to participate and were included because their inclusion was not seen as an issue impacting on the validity of the study, as they were all adolescents who had spent time in hospital. Three of these young people were instructed personally and two by post. Sets of cards and an explanation were posted out and one set of cards and demographic form returned. These results are included in the 29 participant's results and are not separately reported.

\subsubsection{Data Processing}

The data from the conjoint cards, which had been arranged in sequence by the participants, were entered into a spreadsheet. The data were entered twice and the two data sets compared. Any differences were checked and resolved, all data points that were identical were assumed to have been entered correctly. As a final check the data were checked independently by a colleague. After entering the spreadsheet data 
the SPSS Conjoint programme was run. Depending on the order in which the cards had been placed by each of the participants the programme generates values or 'utilities' for each of the options described, in relation to one another. These utilities are described as the 'partworths' of each of the attributes. Simply put, they are the 'desirability'. The partworths are computed by the SPSS Conjoint 8 programme and these partworth scores indicate the influence of each factor option on the respondent's preference for a particular combination. The programme produces a page of output data for each of the participants showing their particular partworth scores in relation to each of the attributes. This shows the importance of each attribute for that participant. A reproduction of the page, produced for participant 3, is shown in Figure 11. A summary page (Appendix 9) is also produced. This page, which is displayed in the same manner as for the individual participants, contains an amalgamation of all the data. Aaker et al. (1998) state that when the partworths of each of the attributes are summed for each of the scenarios being considered, the rank order of these total value scores should match the respondents' rank ordering of cards as closely as possible.

\subsubsection{Estimating the parameters}

The basic conjoint model may be represented by the following formulae. These are explained in full, with figures from the analysis, in Appendix 8.

Where

$$
\begin{aligned}
& \begin{array}{ll}
U(X) & =\text { overall utility of an alternative } \\
\alpha_{i j} & =\text { the partworth contribution or utility associated with the } j \text { th level } \\
& \left(j, j=1,2, \ldots k_{i}\right) \text { of the } i \text { th attribute }(i, 1=1,2, \ldots m) \\
k_{j} & =\text { number of options for each attribute } i \\
m & =\text { number of attribute } \\
x_{i j} & =1 \text { if the } j \text { the option of the } i \text { th attribute is present and } 0 \text { if otherwise }
\end{array}
\end{aligned}
$$

Equation 1: The desirability of the utility $(U)$ equals the sum of the partworth contributions $\left(\alpha_{i j} x_{i j}\right)$

$$
U(X)=\sum_{i=1}^{m} \sum_{j=1}^{k_{i}} \alpha_{i j} X_{i j}
$$


Equation 2: The importance of attribute $I_{i}$ is defined in terms of the range of the part worths $\alpha_{i j}$ across the options for that attribute:

$$
I_{i}=\left\{\max \left(\alpha_{i j}\right)-\min \left(\alpha_{i j}\right)\right\} \text { for each } i
$$

Equation 3: To obtain the importance score relative to the other attributes $W_{i}$ the values are normalised such that

$$
W_{i}=\frac{l_{i}}{\sum_{i=1}^{l_{j}} l_{i}}
$$

So that

\section{Equation 4:}

$$
\sum_{i=1}^{m} W=1
$$

Several different procedures are available to estimate the parameters of the basic model, the simplest of which is dummy variable regression. This model may be represented as:

Equation 5: $\quad U=b_{0}+b_{1} X_{1}+b_{2} X_{2}+b_{3} X_{3}+b_{4} X_{4}+b_{5} X_{5}+b_{6} X_{6}$

Where

$$
\begin{aligned}
& X_{1,}=\text { dummy variables representing cell phones } \\
& X_{2}=\text { dummy variables representing bathroom } \\
& X_{3} X_{4}=\text { dummy variables representing location } \\
& X_{5}=\text { dummy variables representing kitchen } \\
& X_{5}=\text { dummy variables representing recreation }
\end{aligned}
$$

For location the attribute options were coded as follows:

$\begin{array}{lll} & \mathrm{X}_{3} & \mathrm{X}_{4} \\ \text { Level 1 } & 1 & 0 \\ \text { Level 2 } & 0 & 1 \\ \text { Level 3 } & 0 & 0\end{array}$


The options of the other attributes were coded in a similar manner where each attribute has one less dummy variable than the total number of options within the attribute, for example with location there are 3 levels and 2 dummy variables. The parameters can now be estimated using multiple linear regressions with dummy variables. (Example of this is show in the results section in Table 6)

\subsubsection{Assessing reliability and validity}

In order to assess reliability and validity of the results it was first important to see if the conjoint results made sense. If any of them had differed wildly from the expected it could have indicated that his method of data collection could not be relied on. Despite my small sample size I would also have been suspicious if the attributes on the cards that had been ranked in first and last place by the majority of the adolescents had not been reflected in the utility results.

For the collection of the data the adolescents were all free to make their own decisions about their ordering of the cards, even though they were in a group. It was stressed at the beginning of the session that there were no right or wrong answers, so there was no pressure to place the cards in any particular order, or put them in the same order as a neighbour if they happened to see their cards. The one young person who was helped by a peer was only helped by the repeating of the explanation, not by helping with the ordering of the cards. All of the sets of cards used were exactly the same, in size, content and design so that there would be the same stimuli available for all of the participants. All data were double checked, first the data entry was double checked and any errors immediately rectified, and then there was an independent check by a colleague.

Ryan and Hughes (1977) assessed women's preferences for miscarriage management by conjoint analysis. In the conclusion to their paper they say that while it is potentially a very useful tool it has still not been used widely enough in the health care area to establish its total reliability and validity, and although this has been established in health economics further methodological and empirical work is need before the technique becomes an established instrument in health care. This research adds to the reliability and validity of the method. 


\subsection{Ethical Issues}

Ethical clearance was obtained for the research from the Regional Ethics Committee (Appendix 6). Participation in the research was voluntary, and no incentives were offered. The young people were all free to choose whether to participate or not. I thought that if I collected the information during a meeting there could be a question of choice, would the young people feel obliged to participate and feel uncomfortable about saying no. For this reason I asked the CanTeen coordinator if I could come along at the end of the meeting so that if any of the young people did not want to take part in the research they could comfortably leave after their committee meeting, before I started.

No formal consent was obtained, these young people were all of an age which they were considered to be competent (Gillick competent) and so able to make decisions for themselves. Rather attending the meeting and staying to complete the exercise was seen as consent. As discussed in the section regarding adolescent development, inclusion in decision making and discussion with adolescents does not always happen when dealing with this age group and that adolescents need to be involved and to be given enough responsibility to make decisions. By allowing these adolescents to make some decisions regarding the proposed environment that could be available to them it was hoped that they could see that their feelings and values were respected. However, this did raise one ethical issue for me. I did not want to raise the expectations of any of the adolescents taking part in the research that because I was undertaking this study and asking their opinions that there would in fact be any change in the facilities that were available to them. I reiterated this point in my introduction to the research.

The young people had all been advised previous to the meeting that the research would be conducted, and a short description of the research had appeared in the July issue of the Child Cancer Foundation publication to alert the adolescents and their parents/ caregivers to the research and to hopefully encourage as many adolescents to the August and September meetings as possible (Appendix 12). There was no 
possibility of any of the young people being identified by the research. The demographic sheets were anonymous and no diagnosis was asked for. Following two minor adjustments to the demographic collection sheet, an adjustment to the title and the wording of a question, ethical approval was granted.

\subsection{Cultural Issues}

The Treaty of Waitangi underpins health care practices in New Zealand as 'a framework within which Maori and other New Zealanders agree to work together in partnership’ (Maori Health Unit, 2003, p. 1). The relationship honours partnership, protection and participation, particularly in research, safeguards the rights and promotes the wellbeing of Maori'. The Health Research Council of New Zealand (2000) indicates that research involving Maori participants must demonstrate consultation with Maori. The Manager of the Maori Health Unit at Wellington Hospital was consulted, who asked that demographic information on ethnicity was collected as per the New Zealand Census figures (Appendix 7). All of the ethnic groups for the adolescents completing the conjoint analysis are outlined in Figure 6, together with the comparable percentage of the New Zealand population as a whole (Figure 7). In a larger study differences might be found in the type of environment that would be desirable for young people from different ethnic background, which could have implications for Maori and adolescents from other ethnic groups. However, it is acknowledged that this study was derived from a very small sample of adolescents so it does not reflect the true diversity or ethnic mix of our population in New Zealand. 


\section{Results}

The boredom in hospital is the worst thing, not having anything to do. The video games are always being used - there's just nothing to do. Sometimes I need to do something to take my mind off everything around me. In a way it feels a bit like you're locked up or something not like a prison, but sort of like you've got to stay in one area or it feels like something might happen to you. It's frustrating.

Natasha, 1998

This chapter contains the results from the conjoint analysis and describes the information that was collected. Demographic information describes the age, gender and ethnicity of the participants along with information relating to their exposure to the inpatient hospital environment. A number of the participants had not been inpatients themselves, but were siblings of young people who were or had been inpatients. The participants were all now adolescents, but some had been inpatients as younger children. The card ranking data obtained from the conjoint analysis exercise describes how the adolescents ranked their cards. The results of the rankings are compared to the demographic data. Finally the data that has been analysed by the SPSS Conjoint programme are outlined.

\subsection{Demographics}

The demographic information was collected from each of the participants by way of an information sheet which each adolescent was asked to complete at the time of the card sorting exercise. The demographic information describes the adolescents who participated in the study and was collected from all respondents. These comprised 29 in total, 19 males and 10 females. 
The young people were asked how they obtained their knowledge of the inpatient setting (Figure 2). Nineteen of the adolescents, 11 males and eight females, were inpatients as adolescents, which was described as over 12 years of age. Three males and one female were now adolescent and had been inpatients as young children. The remaining nine adolescents had not been in hospital themselves but were siblings of inpatients, who were either inpatient now or had been in the past. I did not ascertain at what exact age the inpatient experience had occurred. The age and gender of the siblings who were inpatients was also not asked. This research gender mix of the adolescents was $65.5 \%$ males and $34.5 \%$ females. The gender mix and age of adolescent was compared with their ranking of the card scenarios, no significant differences were found.

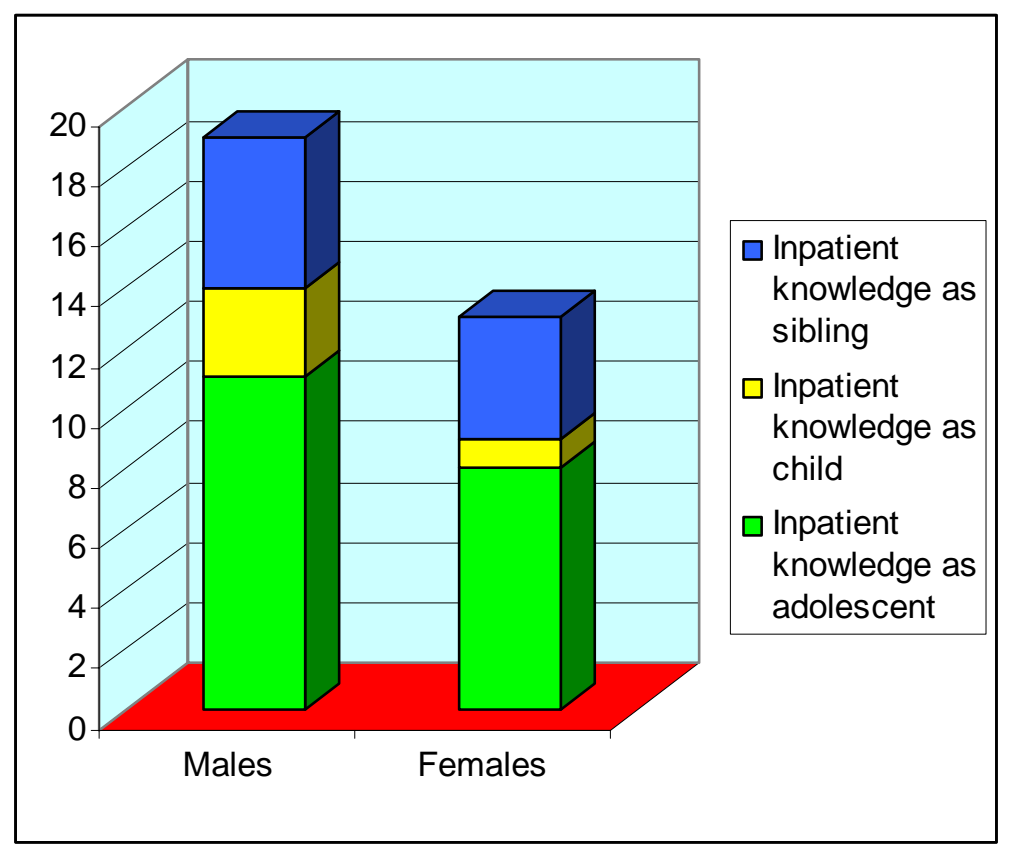

Figure 2: Gender mix of adolescents in study and exposure to inpatient setting

The age range of the adolescents was examined when divided into the three developmental stage of adolescence and these are shown in Figure 3. Early adolescence encompasses the 12 to14 year age range, mid adolescence the 15 to17 year group and late the 17 to 20 year group. The 22 year old young woman was 
included in the results as she was a member of CanTeen and had been hospitalised as an adolescent. The mean age for the adolescents was $151 / 2$ years of age, while the median was 15. Length of stay and age of inpatient experience was compared with card ranking information as described Table 3 and no significant differences were found.

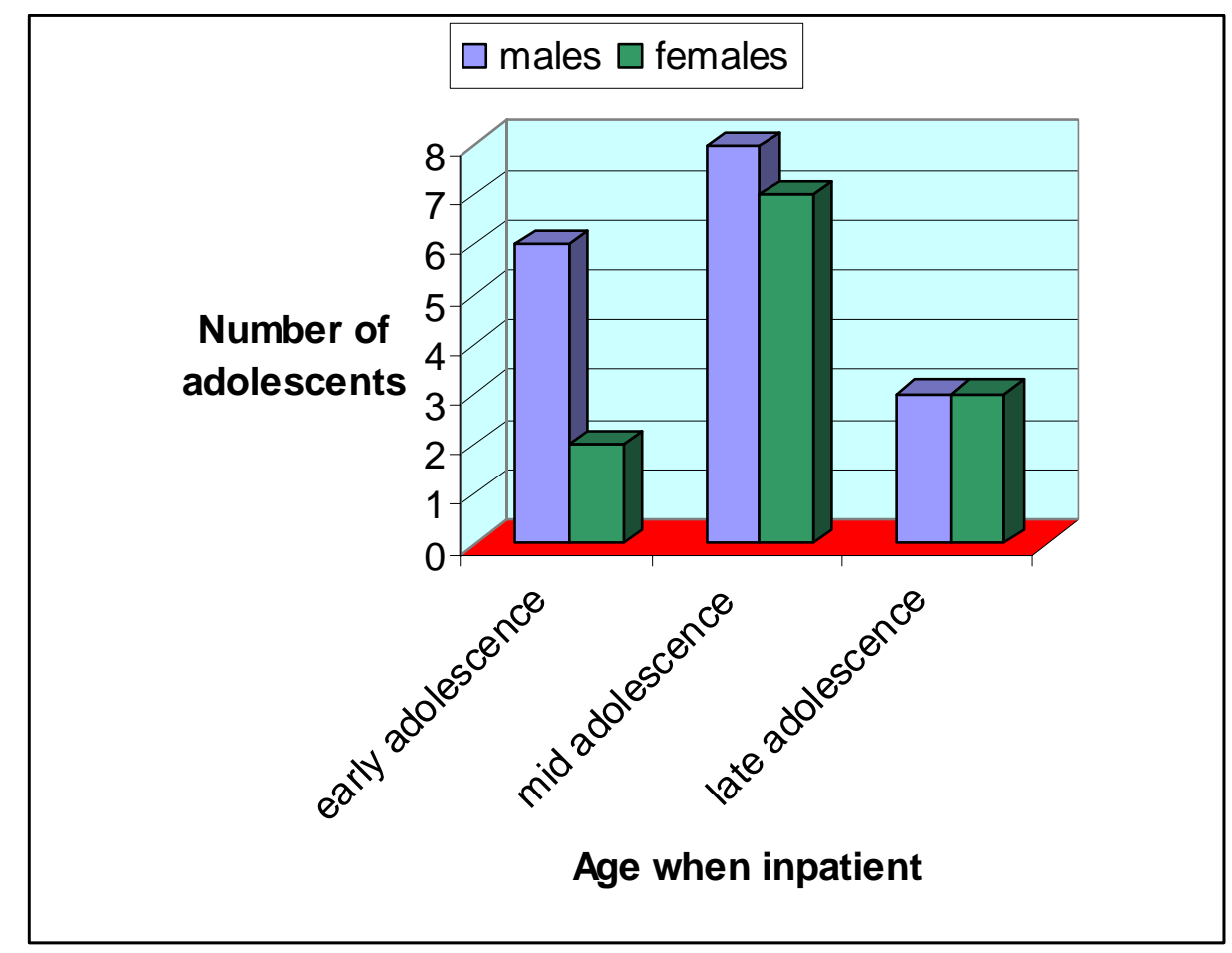

Figure 3: Developmental age of adolescent when inpatient stay occurred

All of the adolescents would have been nursed at tertiary centres because they were all, or were siblings of, children or young people with cancer. The 19 participants who had been inpatients themselves, had been admitted to hospitals throughout the country, in Auckland, Wellington, Dunedin and Christchurch (Figure 4). I did not ask which hospital the siblings of inpatients had had experience in, nor whether this was in an adult or paediatric setting, so they are not represented in this graph. Only two of the 19 adolescents had been nursed in an adult ward, one in Wellington and one in Dunedin. The inpatient stay was compared with their ranking of the card scenarios, and no significant differences were found. 


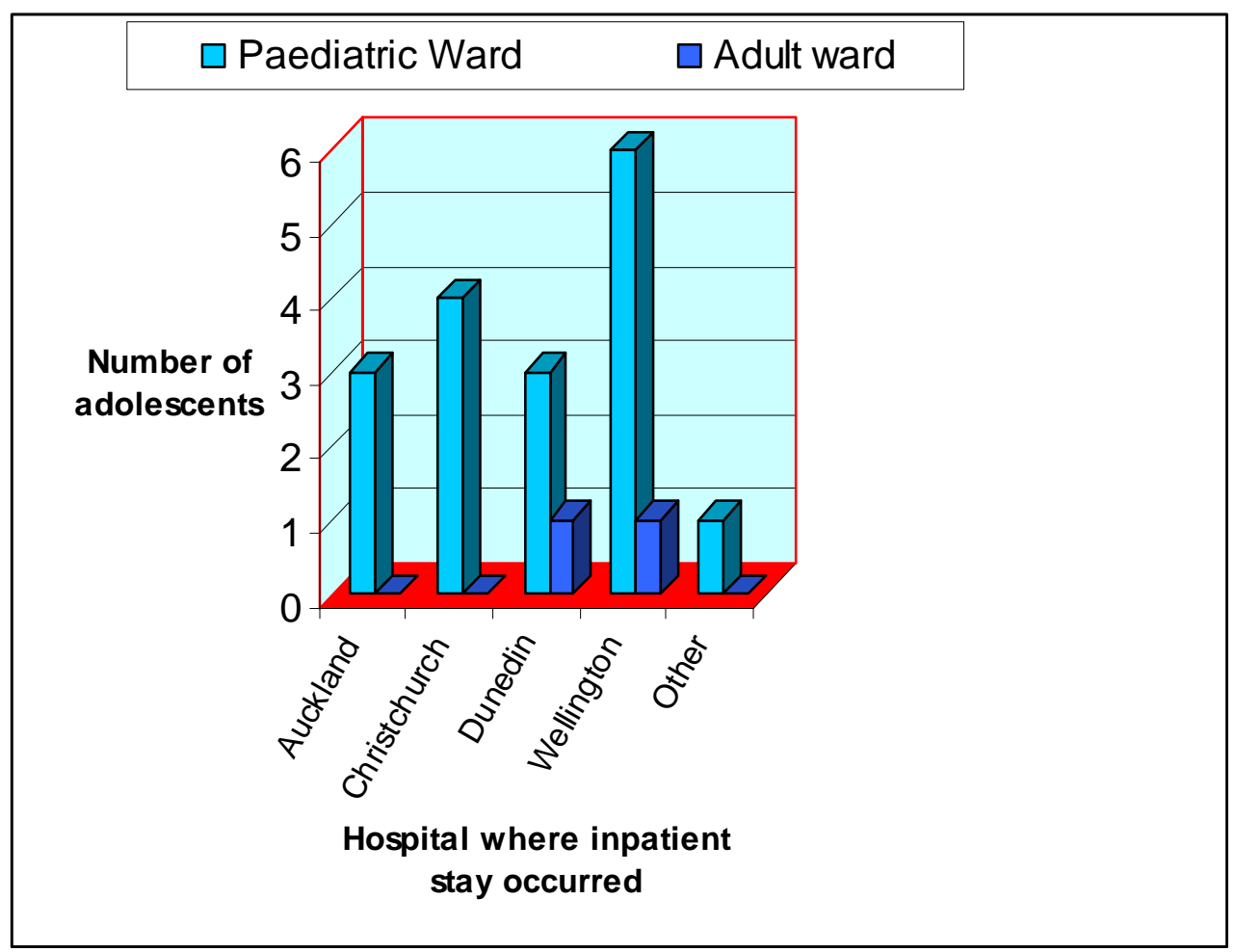

Figure 4: Location of inpatient stay

The number of times the adolescents had been to hospital since the age of 12 was asked, but the total length of stay was not. The young people were asked to answer in the affirmative if the stays had been over three days (Figure 5). Five adolescents said that they had only been in hospital once, five that they had been in hospital twice, and seven that they had been in hospital more than twice. The length of time spent with siblings in hospital was not established, nor was the length of time spent in hospital as a child. The number of times admitted was asked to ascertain if there was any difference in card ranking preference, related to the amount of time spent in hospital. This is reproduced in Table 5 and shows that there was no difference in the most preferred and the least preferred scenario but the intervening ones varied. 


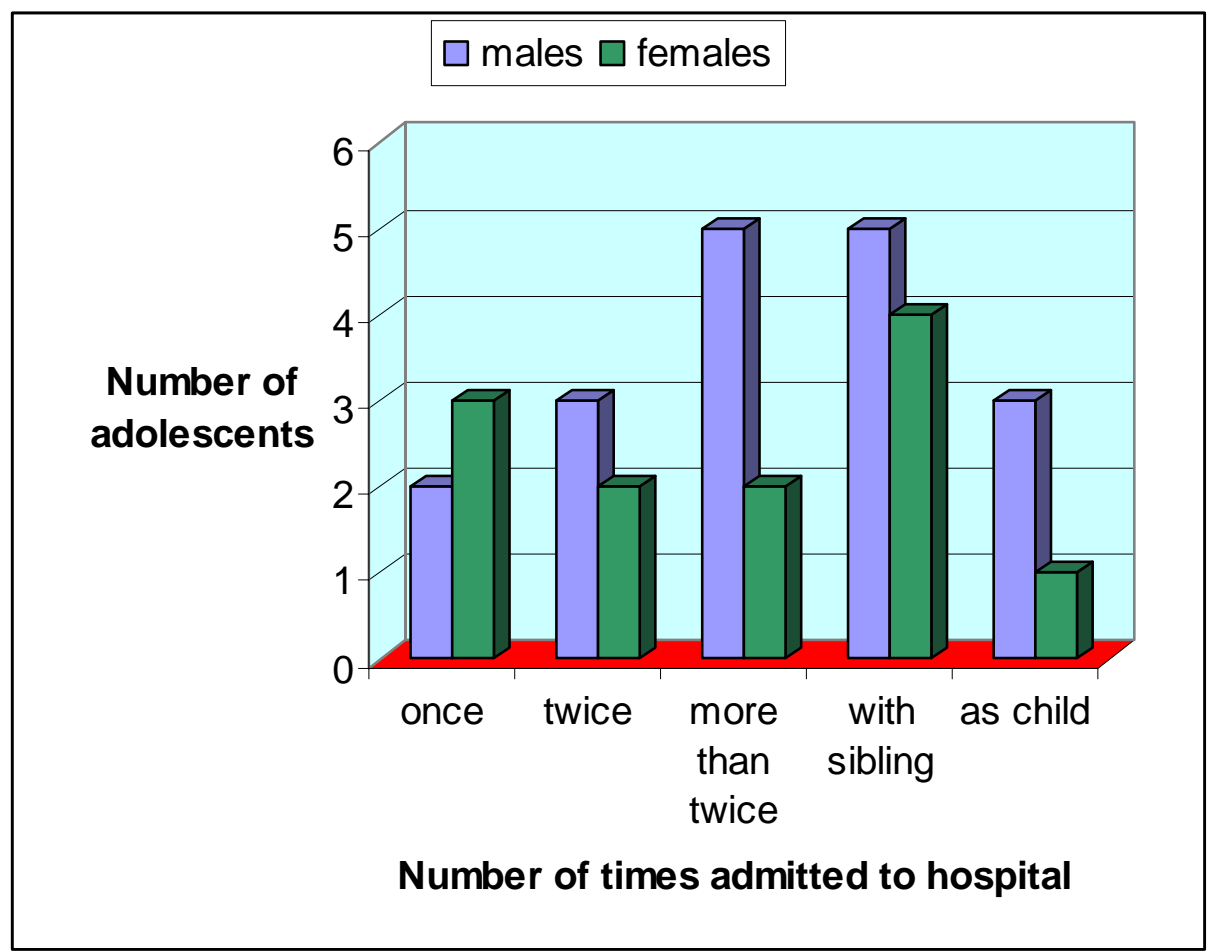

Figure 5: Number of inpatient admissions (longer than three days)

Of the adolescents who participated (Figure 6) New Zealand Europeans made up $83 \%$, the remaining 17\% comprised two Chinese, one Indian, one Maori, one Samoan and one British participant. The ethnic mix described in Figure 7 is taken from the profile of New Zealand Youth which is a national secondary school youth health survey conducted by the Adolescent Health Research Group in Auckland in 2003. This data shows that New Zealand Europeans make up 67\% of New Zealand students, Maori 17\%, Pacific 7\%, Asians 7\% and others 2\%. This ethnic breakdown represents the ethnicity distribution of students in the national population. 


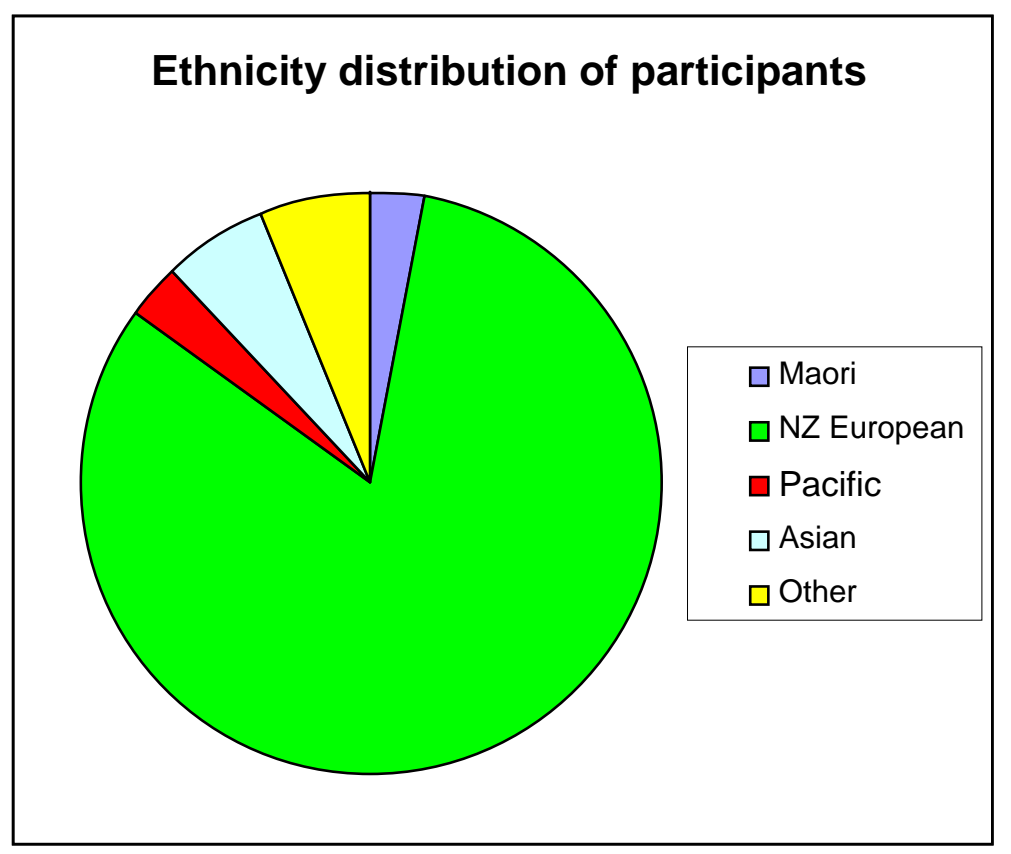

Figure 6: Ethnic mix of study participants

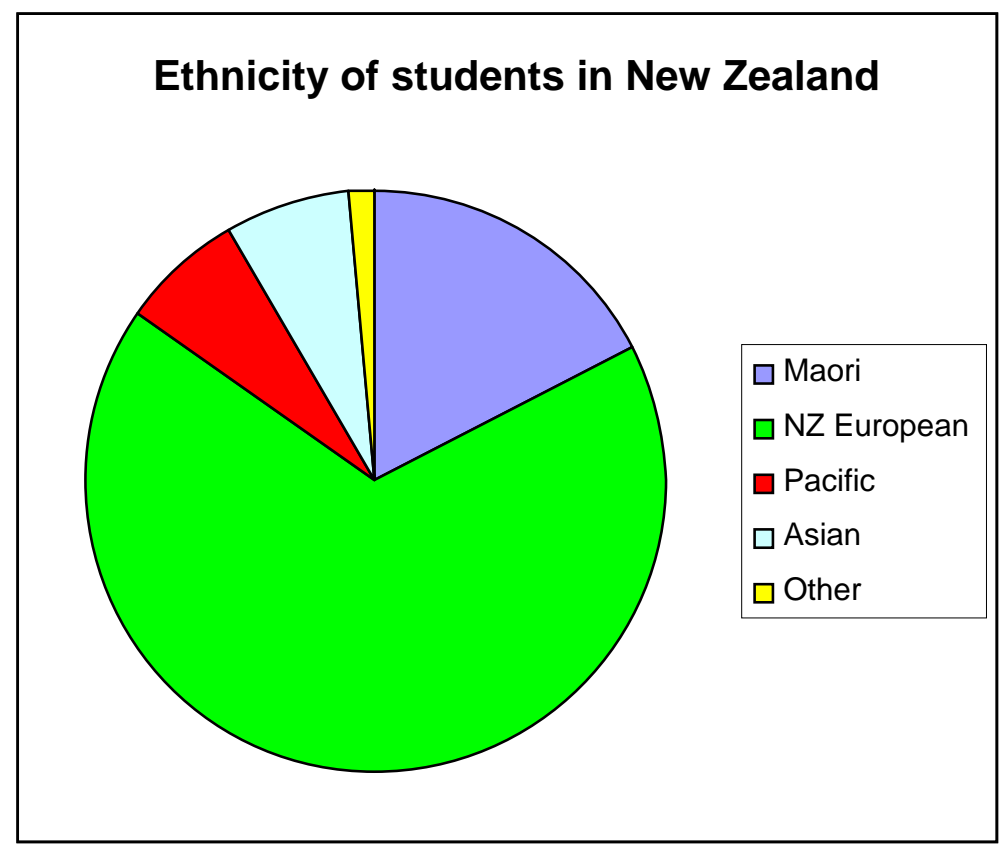

Figure 7: Ethnic mix of students in New Zealand (Adolescent Health Research Group, 2003) 


\subsection{Card Ranking Data}

Following the ranking of the cards the data was entered onto a spread sheet (Table 3). It can be seen on the spreadsheet that after the card sequence data had been entered each of the columns was summed (summary score). This was done to ascertain the overall preference ranking for each of the cards so that this information could be compared with the results following the running of the analysis. Table 3 shows that card number 8 was ranked $1^{\text {st }}$ on 26 occasions, $2^{\text {nd }}$ on two occasions and $3^{\text {rd }}$ on one occasion. Therefore the total for card 8 was $31(26 \times 1+2 \times 2+1=31)$. The total for card number 6 summed to the highest score which was 218 which is derived because it was ranked $5^{\text {th }}$ on one occasion, $6^{\text {th }}$ on two occasion, and 7 th on seven occasions and $8^{\text {th }}$ on 19 occasions $(5 \times 1+6 \times 2+7 \times 7+8 \times 19=218)$.

The range of ranking for each of the cards was also ascertained (Table 4). From this is can be seen, for example, that card number 1 was most frequently ranked in position 3, but was never ranked in position 1, 7 or 8 and that card number 8 was ranked in position 1 by 26 respondents or 86\%, position 2 by 2 (10\%) of the respondents and position 3 by 1 (3\%) of the respondents. All of the percentages in Table 4 were rounded to the nearest percent. This table also shows the minimum and maximum rank for each of the cards and the number, which makes up the range. The expected value describes the preference rating, which corresponds with the preference rating summary score in Table 3.

The data from Table 3 was entered into the Conjoint programme and a data page was produced for each of the 29 participants, and an example of one of these is shown in Figure 11. 
Table 3 : Individual participant card ranking

\begin{tabular}{|c|c|c|c|c|c|c|c|c|c|}
\hline \multirow{2}{*}{\multicolumn{2}{|c|}{ Card Identification }} & 1 & 2 & 3 & 4 & 5 & 6 & 7 & 8 \\
\hline & 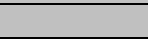 & & & & & & & & \\
\hline 1 & Ranking & 6 & 4 & 5 & 7 & 3 & 8 & 2 & 1 \\
\hline 2 & & 3 & 4 & 6 & 5 & 2 & 7 & 8 & 1 \\
\hline 3 & & 3 & 4 & 8 & 6 & 2 & 7 & 5 & 1 \\
\hline 4 & & 5 & 6 & 1 & 7 & 3 & 8 & 4 & 2 \\
\hline 5 & & 3 & 2 & 4 & 6 & 5 & 8 & 7 & 1 \\
\hline 6 & & 6 & 4 & 3 & 8 & 2 & 5 & 7 & 1 \\
\hline 7 & & 2 & 3 & 5 & 4 & 7 & 8 & 6 & 1 \\
\hline 8 & & 3 & 2 & 6 & 7 & 4 & 8 & 5 & 1 \\
\hline 9 & & 4 & 2 & 6 & 7 & 3 & 8 & 5 & 1 \\
\hline 10 & & 3 & 2 & 4 & 8 & 7 & 6 & 5 & 1 \\
\hline 11 & & 2 & 3 & 7 & 8 & 5 & 6 & 4 & 1 \\
\hline 12 & & 4 & 2 & 6 & 8 & 3 & 7 & 5 & 1 \\
\hline 13 & & 3 & 4 & 7 & 5 & 2 & 8 & 6 & 1 \\
\hline 14 & & 4 & 5 & 6 & 8 & 3 & 7 & 2 & 1 \\
\hline 15 & & 3 & 4 & 6 & 7 & 2 & 8 & 5 & 1 \\
\hline 16 & & 4 & 3 & 6 & 7 & 2 & 8 & 5 & 1 \\
\hline 17 & & 4 & 1 & 6 & 7 & 3 & 8 & 5 & 2 \\
\hline 18 & & 4 & 2 & 5 & 7 & 3 & 8 & 6 & 1 \\
\hline 19 & & 3 & 2 & 6 & 7 & 4 & 8 & 5 & 1 \\
\hline 20 & & 3 & 1 & 5 & 7 & 4 & 8 & 6 & 2 \\
\hline 21 & & 4 & 2 & 5 & 7 & 3 & 8 & 6 & 1 \\
\hline 22 & & 2 & 3 & 6 & 8 & 4 & 7 & 5 & 1 \\
\hline 23 & & 4 & 2 & 6 & 7 & 5 & 8 & 3 & 1 \\
\hline 24 & & 3 & 2 & 5 & 7 & 4 & 8 & 6 & 1 \\
\hline 25 & & 3 & 2 & 6 & 8 & 5 & 7 & 4 & 1 \\
\hline 26 & & 4 & 3 & 5 & 7 & 2 & 8 & 6 & 1 \\
\hline 27 & & 3 & 2 & 6 & 7 & 4 & 8 & 5 & 1 \\
\hline 28 & & 2 & 4 & 6 & 8 & 3 & 7 & 5 & 1 \\
\hline 29 & & 2 & 1 & 6 & 7 & 4 & 8 & 5 & 3 \\
\hline & $\begin{array}{c}\text { Summary } \\
\text { score }\end{array}$ & 99 & 81 & 159 & 202 & 103 & 218 & 148 & 34 \\
\hline
\end{tabular}


Table 4 : Percentage ranking for each card

\begin{tabular}{|c|c|c|c|c|c|c|c|c|}
\hline & \multicolumn{8}{|c|}{ Card Number } \\
\hline & 1 & 2 & 3 & 4 & 5 & 6 & 7 & 8 \\
\hline 1 & $0(0 \%)$ & $3(10 \%)$ & $1(3 \%)$ & $0(0 \%)$ & $0(0 \%)$ & $0(0 \%)$ & $0(0 \%)$ & $26(90 \%)$ \\
\hline 2 & $5(17 \%)$ & 12 (41\%) & $0(0 \%)$ & $0(0 \%)$ & $7(24 \%)$ & $0(0 \%)$ & $2(7 \%)$ & $2(7 \%)$ \\
\hline 3 & 12 (41\%) & $5(17 \%)$ & $1(3 \%)$ & $0(0 \%)$ & $9(31 \%)$ & $0(0 \%)$ & $1(3 \%)$ & $1(3 \%)$ \\
\hline 4 & $9(31 \%)$ & $7(24 \%)$ & $2(7 \%)$ & $1(3 \%)$ & $7(24 \%)$ & $0(0 \%)$ & $3(10 \%)$ & $0(0 \%)$ \\
\hline 5 & $1(3 \%)$ & $1(3 \%)$ & $8(28 \%)$ & $2(7 \%)$ & $4(14 \%)$ & $1(3 \%)$ & $13(45 \%)$ & $0(0 \%)$ \\
\hline 6 & $2(7 \%)$ & $1(1 \%)$ & $14(48 \%)$ & $2(7 \%)$ & $0(0 \%)$ & $2(7 \%)$ & 7 (24\%) & $0(0 \%)$ \\
\hline 7 & $0(0 \%)$ & $0(0 \%)$ & $2(7 \%)$ & $16(55 \%)$ & $2(7 \%)$ & 7 (24\%) & $2(7 \%)$ & $0(0 \%)$ \\
\hline 8 & $0(0 \%)$ & $0(0 \%)$ & $1(3 \%)$ & $8(28 \%)$ & $0(0 \%)$ & $19(66 \%)$ & $1(3 \%)$ & $0(0 \%)$ \\
\hline Total & 29 & 29 & 29 & 29 & 29 & 29 & 29 & 29 \\
\hline Minimum & 2 & 1 & 1 & 4 & 2 & 5 & 2 & 1 \\
\hline Maximum & 5 & 6 & 8 & 8 & 7 & 8 & 8 & 3 \\
\hline Range & 4 & 6 & 8 & 5 & 6 & 4 & 7 & 3 \\
\hline $\begin{array}{l}\text { Expected } \\
\text { ranking }\end{array}$ & $\begin{array}{l}3.41 \\
3^{\text {rd }}\end{array}$ & $\begin{array}{l}2.79 \\
2^{\text {nd }}\end{array}$ & $\begin{array}{l}5.44 \\
6^{\text {th }}\end{array}$ & $\begin{array}{l}6.96 \\
7^{\text {th }}\end{array}$ & $\begin{array}{l}3.55 \\
4^{\text {th }}\end{array}$ & $\begin{array}{l}7.51 \\
8^{\text {th }}\end{array}$ & $\begin{array}{l}4.68 \\
5^{\text {th }}\end{array}$ & $\begin{array}{l}1.13 \\
1^{\text {st }}\end{array}$ \\
\hline
\end{tabular}

Table 3 showed how each of the respondents ranked their cards. A complete set of the cards is profiled in Appendix 13. From this table it can be seen that Card No. 8, was the most popular choice for $1^{\text {st }}$ position. It provided the scenario outlined in Figure 8

Adolescent unit adjacent to paediatric ward
Adolescent only recreation room,
Kitchen facilities to make snacks
Cell phones could be used in designated area
Locks on the bathroom doors

\section{Figure 8 : Most popular card scenario}

Following the running of the conjoint data analysis the most preferred scenario was compared with the most popular scenario found from the card ranking. The most preferred scenario from the conjoint analysis, with the highest utility score of 7.9754 
was also found to be card number 8 . Utility scores represent the desirability of a scenario and the higher the number, the higher the desirability.

The least preferred scenarios were also compared, the one offered by the ranking of the cards and the one from the Conjoint programme. The least preferred card scenario, placed mostly in $8^{\text {th }}$ place by the adolescents was card number 6 outlined in Figure 9.

\begin{tabular}{l} 
Adolescent unit adjacent to paediatric ward \\
Shared ward sitting room \\
No kitchen facilities \\
No cell phones allowed \\
No locks on bathroom doors \\
\hline
\end{tabular}

Figure 9 : Least popular card scenario

This also was the same scenario which, when computed by the Conjoint programme, was given a low utility value of 3.6494 .

When the utility values were calculated for the remainder of the cards the order did not match exactly with that found in the card sorting exercise. For example Conjoint gave the scenario for card number 2, which is shown in Figure 10 the second highest utility value total whereas this card was ranked $6^{\text {th }}$ out of the 8 by the adolescents, the order for $2^{\text {nd }}, 3^{\text {rd }}, 4^{\text {th }}, 5^{\text {th }}$ and $6^{\text {th }}$ place were all different.

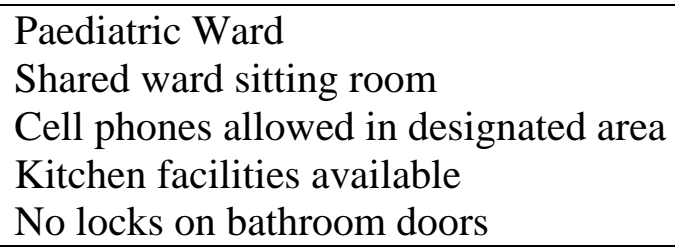

Figure 10 : Card no. 2

Demographic data regarding age, length of stay, number of inpatient stays and place of inpatient stay was compared with the card ranking data. One example of these comparisons is shown in Table 5. The scenario which was most preferred and least preferred does not vary between the lengths of stay as an inpatient. 
Table 5 : Preference in card ranking by one, two and more than two inpatient admissions

\begin{tabular}{|c|c|c|c|c|c|c|c|c|}
\hline $\begin{array}{c}\text { Card } \\
\text { No }\end{array}$ & $\mathbf{1}$ & $\mathbf{2}$ & $\mathbf{3}$ & $\mathbf{4}$ & $\mathbf{5}$ & $\mathbf{6}$ & $\mathbf{7}$ & $\mathbf{8}$ \\
\hline & 3 & 2 & 4 & 6 & 5 & 8 & 7 & 1 \\
\hline & 2 & 3 & 5 & 4 & 7 & 8 & 6 & 1 \\
\hline & 2 & 3 & 7 & 8 & 5 & 6 & 4 & 1 \\
\hline & 3 & 4 & 7 & 5 & 2 & 8 & 6 & 1 \\
\hline & 2 & 3 & 6 & 8 & 4 & 7 & 5 & 1 \\
\hline Total & $\mathbf{1 2}$ & $\mathbf{1 5}$ & $\mathbf{2 7}$ & $\mathbf{3 1}$ & $\mathbf{2 3}$ & $\mathbf{3 7}$ & $\mathbf{2 8}$ & $\mathbf{5}$ \\
\hline Rank & 2nd & 3rd & 5th & 7th & 4th & 8th & 6th & 1st \\
\hline
\end{tabular}

These are the preference ranking for the scenarios that were completed by adolescent who had only had one inpatient admission

\begin{tabular}{|c|c|c|c|c|c|c|c|c|}
\hline $\begin{array}{c}\text { Card } \\
\text { No }\end{array}$ & $\mathbf{1}$ & $\mathbf{2}$ & $\mathbf{3}$ & $\mathbf{4}$ & $\mathbf{5}$ & $\mathbf{6}$ & $\mathbf{7}$ & $\mathbf{8}$ \\
\hline & 3 & 4 & 6 & 5 & 2 & 7 & 8 & 1 \\
\hline & 3 & 2 & 4 & 8 & 7 & 6 & 5 & 1 \\
\hline & 3 & 4 & 6 & 7 & 2 & 8 & 5 & 1 \\
\hline & 3 & 1 & 5 & 7 & 4 & 8 & 6 & 2 \\
\hline Total & $\mathbf{1 2}$ & $\mathbf{1 1}$ & $\mathbf{2 1}$ & $\mathbf{2 7}$ & $\mathbf{1 5}$ & $\mathbf{2 9}$ & $\mathbf{2 5}$ & $\mathbf{5}$ \\
\hline Rank & 3rd & 2nd & 5th & 7th & 4th & 8th & 6th & 1st \\
\hline
\end{tabular}

These were the preference rankings for the scenarios that were completed by adolescents who had had two inpatient admissions

\begin{tabular}{|c|c|c|c|c|c|c|c|c|}
\hline $\begin{array}{c}\text { Card } \\
\text { no }\end{array}$ & $\mathbf{1}$ & $\mathbf{2}$ & $\mathbf{3}$ & $\mathbf{4}$ & $\mathbf{5}$ & $\mathbf{6}$ & $\mathbf{7}$ & $\mathbf{8}$ \\
\hline & 3 & 4 & 8 & 6 & 2 & 7 & 5 & 1 \\
\hline & 4 & 5 & 6 & 8 & 3 & 7 & 2 & 1 \\
\hline & 4 & 3 & 6 & 7 & 2 & 8 & 5 & 1 \\
\hline & 4 & 2 & 6 & 7 & 5 & 8 & 3 & 1 \\
\hline & 3 & 2 & 5 & 7 & 4 & 8 & 6 & 1 \\
\hline & 4 & 3 & 5 & 7 & 2 & 8 & 6 & 1 \\
\hline & 3 & 2 & 6 & 7 & 4 & 8 & 5 & 1 \\
\hline Total & $\mathbf{2 5}$ & $\mathbf{2 1}$ & $\mathbf{4 2}$ & $\mathbf{4 9}$ & $\mathbf{2 2}$ & $\mathbf{5 4}$ & $\mathbf{3 2}$ & $\mathbf{7}$ \\
\hline Rank & 4th & 2nd & $\mathbf{6 t h}$ & $\mathbf{7 t h}$ & 3rd & $\mathbf{8 t h}$ & $\mathbf{5 t h}$ & 1st \\
\hline
\end{tabular}

These were the preference rankings for the scenarios that were completed by adolescents who had had more than two inpatient admissions. 
Figure 11: Example of data page produced for each respondent 
A page of data was produced by Conjoint for each respondent, an example of one of these pages is shown in Figure 11. The data produced are listed in three columns which show the importance, utility (desirability) and factor for each respondent for each of the facilities. The importance of each of these factors can be compared by looking at the ranges (highest-lowest) of the utility scores. Conjoint uses these ranges to compute importance scores for each factor. The importance scores (Equation 3 in section 5.1.6) are derived by taking the utility range for the particular factor and dividing it by the sum of all the utility ranges. The middle column shows the utility (partworth) scores and their standard errors for each factor option. The partworth scores are described in the left column and the standard error in parenthesis. The standard error for each utility is one indication of how well the model fits that particular subject's data. The lower the standard error, the better the fit. The total utility of a specific combination can be computed for each of the participants, or as a summary for all of the participants, when these values are added together (Equations 1 and 5).

A summary sheet showing the total percentage importance for each of the facilities was generated by Conjoint, this is shown in Appendix 9. The graph reproduced from this sheet (Figure 12) shows the percentage importance of each of the facilities on the decisions made by the adolescents. This graph shows that the location where the adolescents were nursed had the most influence on the ranking of the cards with a percentage score of $29.35 \%$. When the cell phone total of $28.1 \%$ is added, this shows that location and the use of a cell phone in a designated area had the biggest influence on the choice that was made. 


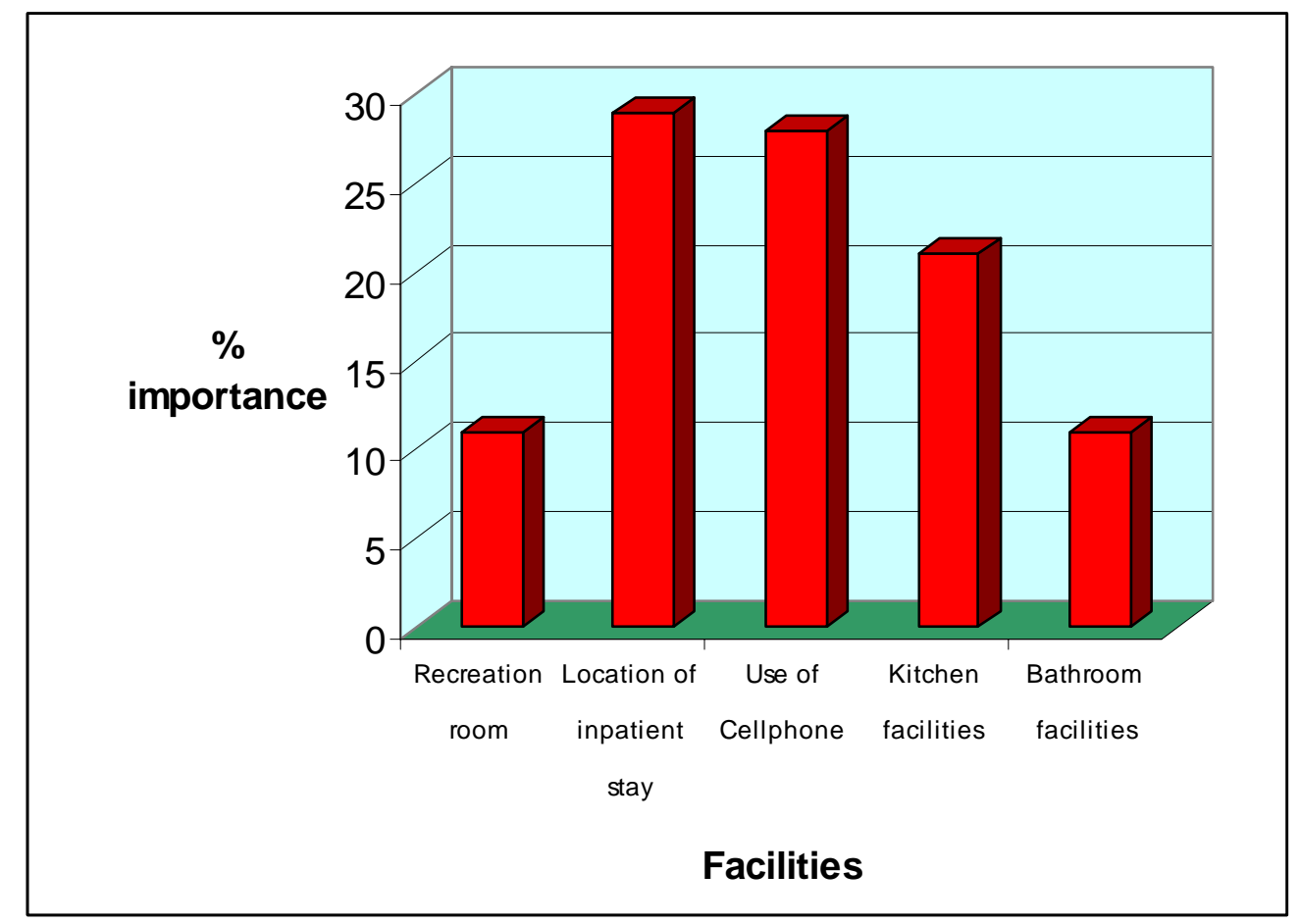

Figure 12: Summary of percentage importance of facilities for all participants

An attribute utility spreadsheet was created (Table 6) from the summary sheet partworth scores so that different scenarios could be tested. The spreadsheet enabled different combinations of partworth scores to be entered and the partworth scores added for the variety of different combinations. In this way combination giving the highest and the lowest utility scores could be examined, along with any others of interest. Four of these are listed in Table 7. By undertaking this exercise it can be seen that by changing one option of an attribute, the total utility or desirability of a scenario can be significantly changed. 
Table 6 : Attribute utility spreadsheet

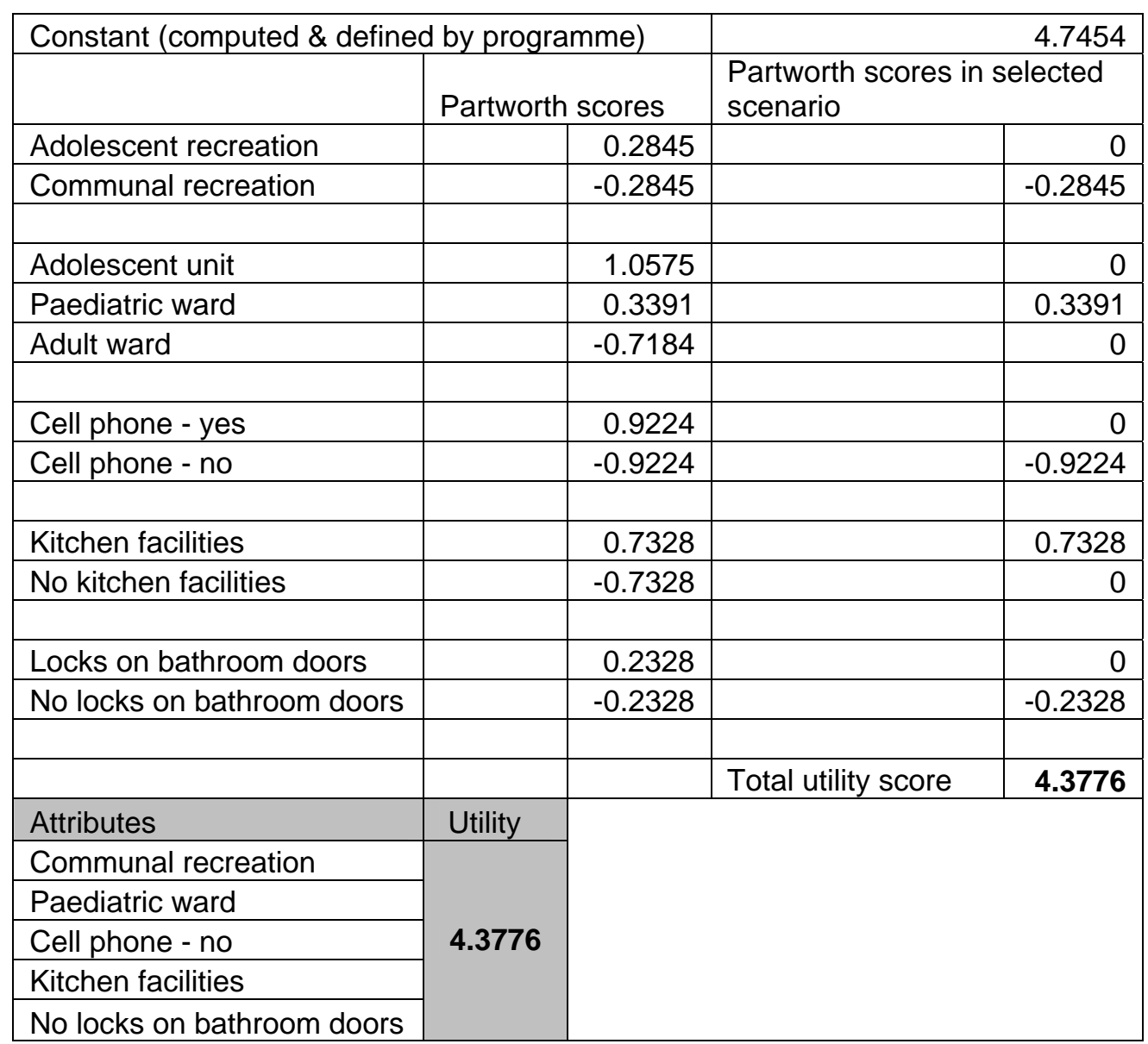


Table 7: Attribute utility summary

\begin{tabular}{|l|c|}
\hline Most preferred scenario & Utility \\
\hline Attributes & 7.9954 \\
\hline adolescent recreation & \\
\hline adolescent unit & \\
\hline cell phone - yes & \multicolumn{2}{|l|}{} \\
\hline kitchen facilities & Utility \\
\hline locks on bathroom doors & 2.2338 \\
\hline Least preferred scenario & \\
\hline Attributes & \\
\hline communal recreation & \\
\hline adult ward & \\
\hline cell phone - no & \\
\hline no kitchen facilities & Utility \\
\hline no locks on bathroom doors & 3.1562 \\
\hline Least preferred scenario with one changed attribute \\
\hline Attributes & \\
\hline communal recreation & \\
\hline adult ward & \\
\hline cell phone - yes & \\
\hline no kitchen facilities & Utility \\
\hline no locks on bathroom doors & \\
\hline Ward 18 scenario at present & \\
\hline Attributes & \\
\hline communal recreation & \\
\hline paediatric ward & \\
\hline cell phone - no & \\
\hline no kitchen facilities & \\
\hline no locks on bathroom doors & \\
\hline
\end{tabular}

Table 7 shows the total utility values for most and least preferred scenarios following the conjoint data analysis. This illustrates how the total utility value changes with the changing of one aspect of the scenario. The low utility value (attractiveness) of the least preferred scenario can be increased by changing one attribute, in this case from no cell phone usage, to being able to use a cell phone. The scenario which is available in Ward 18 at present is also shown. This exercise was undertaken to show how, in the event of this research being used when the new facilities at Wellington Hospital are finally decided on, if a combination of facilities that have not been discussed are contemplated, their attractiveness can be examined. 


\subsection{Utility Scores}

The range of utility scores is outlined in the summary produced by the Conjoint programme (Appendix 9). Utility scores describe the preference that is shown by the participants for the attributes. The utilities with the largest ranges are the utility influences the adolescents’ preference the most.

\section{Location - this score ranged from -0.7184 to 1.0575 \\ Recreation room - this score ranged from -0.2845 to 0.2845 \\ Cell phone - this score ranged from -0.9224 to 0.9224 \\ Kitchen facilities - this score ranged from -0.7328 to 0.7328 \\ Bathroom facilities - this score ranged from -0.2328 to 0.2328}

As can be seen from the above summary the location of the stay (range 2.4759) and the use of a cell phone (1.8448) covered the greatest range so were the two aspects which influenced the choice of scenarios the most. The range of utility scores for bathroom facilities was the least (0.4656) therefore this attribute had least impact on choice of scenarios. This can be seen by the bar graph summary sheet shown in Figure 12.

\subsection{Post card sorting discussion}

Following the ranking of the cards, the data collection was completed by asking adolescents three questions and then inviting them to discuss any other points they wished to raise. They were asked whether they found any difficulty in ranking the cards, if the information given to them before the ranking was easily understood or if there was anything that was difficult to understand. They all indicated that they found the exercise easy to understand and undertake.

The young people were then asked if there were any aspects of an inpatient service that they thought important that were not mentioned on the cards, or if there were any aspects of an inpatient stay that they would like to discuss. Several themes emerged. 
In relation to physical surroundings two attributes were identified that could be included that I had not described. One was the availability of parent accommodation and the other was the ability for siblings or friends to stay overnight. The young people said that they found the adult ward to be 'gloomy' and 'dull' and conversely, the paediatric wards, with their 'bright, busy decorations' were also not well liked often making them feel worse, particularly when feeling really ill. One adolescent described the fairy and toadstool wallpaper in the children's ward as being particularly 'difficult to look at' when she was feeling sick. One young woman described how 'frightened' she had felt on an adult ward and wished that she had had the opportunity to be nursed in an area with other adolescents. She said that if given the choice she would rather be admitted to a paediatric unit than an adult ward, as the adult ward was 'always scary', and she felt 'too young to be there'. A couple of the young people said that the ideal place to be admitted to would be a unit which catered for all the adolescents of the age group that are catered for in CanTeen. This would encompass the young, mid and late adolescent age group, with the 20 year olds being given the choice of remaining in the adolescent unit or going to the adult ward. The transition to the adult service was also viewed with trepidation. They commented that they had become familiar with the medical and nursing staff in the Paediatric Service along with the environment and that the adult service was seen as an unknown and rather frightening place.

Two of the adolescents mentioned that they would have liked to have one of their school friends to stay in for the occasional night when they were an inpatient, and one mentioned that she would have liked her sister to stay. The desire for friends to be included was also mentioned in respect of a sitting or recreation room. Three of the adolescents said that they did not like their friends visiting them because there was nowhere for them to sit and talk by themselves, they would have liked to have a sitting room where there were no small children or adults. It was also discussed that if there was an adolescent's sitting or recreation room then adolescents who were elsewhere in the hospital might be able to use it. A young woman who was an inpatient on the renal ward highlighted this.

Bathing facilities were mentioned. One of the young people said that she didn't like the bathrooms on the children's ward because she couldn't lock the door and she was 
sure that one of the younger children would come in when she was having a bath. One of the young boys commented that he didn't like the bathrooms on the adult ward where he visited his brother because they were gloomy. One of the older girls said that she disliked having to use the small toilets on the children's ward and also that the toilets were a cubicle style with fairly low walls which she found embarrassing.

One adolescent said she that if there wasn't an adolescent unit built she suggested that the role of adolescent liaison nurse would be useful. She said that if there was a nurse who went and visited the adolescents wherever they were in the hospital they would feel less isolated. She also mentioned that if there were a nurse in this role the transition from the paediatric to the adult service would be easier as there would be a link with both of the services.

Following the discussion the young people were thanked for their time and their invaluable input. The points raised are discussed, with reference to the literature and the information from the conjoint analysis, in the following chapter. 


\section{Discussion of results}

I am fifteen, but legally I am still a child. There is nothing I can do today that I couldn't do yesterday. Worse luck!

‘Adrian Mole’, 1982

This chapter discusses the finding that came out of the conjoint analysis, the demographic information and the subsequent discussion. These findings are presented in relation to the literature. Given the multicultural nature of New Zealand society, it is acknowledged that the young people who took part in this research are not a representative sample of New Zealand adolescents, and do not offer a reflection of the ethnic mix, social diversity or age breakdown of adolescents in this country. I recognise that it is important to include the perspective of people from as many cultures as possible in health related research, thus a limitation of this research lies with the fact those included were from a very narrow field. However, as a single small snapshot of a group of adolescents who had prior knowledge of an inpatient hospital setting I was able to gain an understanding of whether this method of data collection could be understood by adolescents and so would be of use in the future for this age group. I also received very clear ideas about what this age group wanted in respect of inpatient facilities.

\subsection{Methodology}

The young people appeared to have no difficulty in understanding what was expected of them and in deciding what to do with the conjoint analysis cards presented to them. One of the younger participants required the explanation about ordering the cards a second time, but after this sorted the cards without hesitation. All of the adolescents appeared to be able to make the decision as to which of the scenarios was the most appealing to them and which the least and the whole exercise took less than 20 minutes. 
A number of authors commented on the fact that a relatively small number of cards should be produced because it was too much of an onerous task to expect participants to compare a great number of cards (Aaker et al., 1998; Ryan \& Farrah, 2000; Ryan \& Hughes, 1997). However, the method I adopted mitigated this effect. I instructed the participants to take only two cards, consider them in relation to one another and place them in order of preference. They were then asked to take one more card compare it with the more desirable of the two cards if they thought the new card to be more desirable to place the new card in first place and then pick up another card and repeat the process. If the card was less appealing, look at the next card down and repeat the process. They were instructed to repeat this procedure until all of the eight cards were ranked in order. In this way only two cards were being considered at any one time. Because they were being asked to consider only two cards at a time it would be easy for them to consider many more cards at any one time. By adopting this method more attributes and more levels could have been considered and SPSS Conjoint would have produced a larger subset than eight. This would have allowed a much more comprehensive picture of a facility design, with more attributes and options to be examined. I consider this approach in no way undermines conjoint analysis as each card contains all the attributes but with different options. The main question which this research set out to answer as to whether conjoint analysis was a research method that could be used for this age group was answered in the affirmative.

The potential difficulties in choosing the possible scenarios were described in the literature (Ryan \& Farrah, 2000; Ryan \& Hughes, 1997). These authors state that too many scenarios can lead to an overwhelming number of choices which make responding difficult and unrealistic. However, as discussed, if the respondent is asked to just consider two cards at a time many more scenarios can be compared each card can be placed in order of preference. In this way the respondent shouldn't be overwhelmed by choice. One of the assumptions of conjoint models is that there will be "perfect knowledge" and awareness in the participant group. However, it has been reported by Markham et al., (1999) that it is sometimes difficult to make tradeoff judgements about two attributes while holding all the others constant. I disagree with these authors as I found that by asking the respondents to only consider two 
cards at a time it was not difficult to make the trade off judgements. I believe I have demonstrated that when the method of ordering the cards by the participants is restricted to just comparing two cards at a time, then the total number of cards and scenarios can be increased.

Conjoint analysis is also reported to be prescriptive, in that it does not give respondents any latitude in their responses. There is no 'no choice' choice (Aaker et al., 1998). It was because of this observation that I utilised a discussion following the ranking of the cards. The discussion provided the adolescents with an opportunity to air their views on other aspects of an inpatient service that had not been mentioned. It also provided material to enhance the data extrapolated from the card sorting exercise.

\subsection{Card sorting exercise}

One observation I made on giving out the cards for ranking was the inability of some of the participants to understand the term paediatric without a brief explanation. Working in child health, where the word paediatric is common parlance, I had not appreciated that this was not a word that came easily to young people's minds. Since the word was not easily understood to young people who had knowledge of hospitals, I suspect it would have been even more unknown to adolescents who did not have

previous experience or knowledge of hospitals. Therefore, if any further study is undertaken in the future the paediatric location would be described as a children's ward.

The final ranking of the cards selected by the participants did not offer any surprises. The scenario that was predominantly placed in first place was the one I expected. The scenario that was the most pleasing to the adolescents gave them all of the attributes that I thought they would wish to find within an inpatient admission, that is an adolescent unit, recreation room, cell phone usage and adolescent friendly kitchen and bathroom facilities. Three respondents did not place this scenario first. When reviewing the demographic data I discovered that one of the adolescents has been hospitalised as a child, and had placed a paediatric ward as first choice of scenario. 
The other two who had not placed this card in first place, had placed adolescent units as their first choice but not the scenarios that contained kitchen facilities. All of the remaining adolescents, young, middle and older adolescents placed the same card in first place. This result reflects the information gathered from the literature when adolescents surveyed opted for care in a dedicated adolescent unit (Blunden, 1993), or expressed the preference that if an adolescent unit were not available that the environment was suitable for adolescents (Resnick et al., 1990; Whelan, 2003). This preference was also supported by the research carried out by Sharma and Finlay (2003). On reviewing the summary data from the conjoint data run, the importance of location (Figure 6) was highlighted. From the placing of the remainder of the cards, the ones that contained either a dedicated adolescent area with a shared sitting room, or a dedicated adolescent recreation area available in a paediatric or adult ward were valued highly and placed mostly in $2^{\text {nd }}, 3^{\text {rd }}$ and $4^{\text {th }}$ position.

I found it interesting to note that although it was not apparent to me from just looking at the ranking of the cards, the ability to use the cell phone was also important. When the data was examined in more details and some of the workings behind the statistics completed, the utility for cell phone was found to be particularly high. Because the conjoint programme examines all of the cards and scenarios relative to one another, cell phone use is shown to have a big influence on the choice of scenario. However, Card number 5 was ranked relatively highly (mostly in $2^{\text {nd }}, 3^{\text {rd }}$ and $4^{\text {th }}$ place) and this scenario did not allow for cell phone. This anomaly could be due to the small number of participants, which is described by Schneider et al. (2003). Only opinions, as detailed regarding Wellington's adolescent schoolgirls (Aikman, 2005) appear to be available to back up the importance of cell phones. I could find no research available on cell phone use in this age group. There is plenty of information available as to the number of cell phones in use in the general population but none that I could find relating specifically to adolescents. Knowing the importance of age specific factors, it would be important to include attributes such as cell phone ownership or usage in this type of work in the future.

Following the running of SPSS Conjoint and the determining of the utilities for each of the scenarios, a number of different scenarios that had and had not been presented to the participants were examined. This exercise was undertaken in Excel. The 
summary data that was produced by the Conjoint programme was entered and different scenarios examined. By entering the data into a spreadsheet the total utility value for any scenario which I wanted to look at could be established and the effect of altering one or more of the options could be ascertained. The scenario that gave the highest and the lowest utility scores were determined. I found, as expected that when the partworth scores for the scenario that the majority of the adolescents had placed in first place were added together, the highest utility score resulted. Aaker et al. (1998) describe that when the partworths of each of the attributes are summed for each of the scenarios being considered, the rank order of these total value scores should match the respondents' rank ordering of preference as closely as possible. However the results from the Conjoint programme failed to completely support the observed results from the participants' card sorting exercise. There are two reasons why some of the ranking may be different. The first is that the Conjoint programme examines all of the cards and scenarios entered (Table 3) and determines the effect of the positioning of each of the cards relative to one another, and the second is that the number of participants is small. This explanation is offered by Hair, Anderson and Tatham (1990) and Schneider et al. (2003) who, although they do not state an optimum number for a conjoint analysis, do comment that the more participants than can be surveyed the more definitive the trends are.

As described, the utility of attributes was compared for a variety of scenarios. Examples of four of these are shown in Table 7. From this table it can be seen that by changing one aspect of the scenario, for example in the least preferred scenario, giving the young people the option to be able to use their cell phone increases the total utility value of the scenario. The utility for the present ward set up at Wellington Hospital was also calculated, this is shown at the end of Table 7. The utility for this scenario is 3.2913. Again, if one aspect of this scenario is changed, allowing cell phones to be used in a designated area, the utility value changes to 4.2137 . One of the main benefits of a conjoint analysis is that different scenarios can be compared, even those which have not been presented to the participants, and the utility of them can be examined. In this way economic considerations could be factored in and compared. Appendix 8 provides an explanation of how the different utility scores are calculated and Appendix 11 how the different costs can be examined. The simple extension of conjoint analysis to relate utilities and partworths to cost of providing those facilities 
could prove to be an invaluable tool in the decision making process when trying to optimise the perception of value against the cost of providing that value.

The summary graph presented in Figure 12 shows which of the attributes were most important in the decision making process for the adolescents. This summary shows that the location of the inpatient experience and the ability for the young people to use their cell phones carried the most weight, and that the type of bathroom facilities had the least impact on choice. The importance of location was not unexpected as the literature indicated that the adolescents prefer to be nursed with others of their own age (Burr, 1993; Gillies, 1992; Russell-Johnston, 2000). The discussion with the adolescents also highlighted this and is discussed in 7.4.

\subsection{Demographics}

Given the high levels of agreement of the preferred choice it is not unexpected that the demographic information did not appear to give me any particularly discriminative data. It was useful however in that it enabled me to compare the ages of the adolescents and their exposure to hospitals with the data obtained from the card sorting exercise. I was also able to examine the age range of the participants to see how representative the participants were of the general adolescent population. The age breakdown graph Figure 3 shows that 15 of the respondents were in the mid adolescent age group and the median and mean age was 15 . Seven were in the early adolescent age group and six in the late adolescent group. This range provides twice as many 'mid adolescent' adolescents as the two other groups, the same number of each of the groups would be more representative sample. A detailed look at the difference in preference rating of the cards between the age groups did not show any differences between the three groups.

The demographic data also enabled me to look at the gender breakdown and ethnic mix of the participants. The gender mix of the adolescents was $65.5 \%$ males and 34.5\% females which is unrepresentative of the gender mix of New Zealand's students. Statistics from the Ministry of Health (2002) report that there are 50.3\% males and $49.7 \%$ female students in New Zealand. The ethnic mix was also different. 
Figures produced by the Adolescent Health Research Unit in 2003 reported 67\% European, 17\% Maori, 17\% Pacific and 2 \% other, whereas the ethnic mix of my participants was predominantly New Zealand European with only 17\% from other races. I decided not to examine the information gathered regarding the suburbs in which the young people lived. Originally I thought I might find a difference in environmental preferences from different areas, but on reflection this would require input from a much larger number of young people and would be very difficult to interpret in a meaningful way. This I felt was also true for the ethnicity question. Any differences that might become apparent would only emerge from a much larger study.

\subsection{Post card sorting discussion}

The ideas from the post sort discussion reflected the results from the card sorting exercise, the main one relating to the location of the inpatient experience. The young people talked of wanting a 'bright environment', not the 'gloom' of the adult ward or the over busy wall decorations of a paediatric ward. This echoed the information that I had read in the literature where natural light and appropriate wall decorations were mentioned (Harding Price, 2003; Sharma \& Finlay, 2003; Shelley, 1993). The paediatric wards in Wellington were built 17 years ago and are now beginning to look dated. One young woman commented that the paediatric wall decorations made her feel more ill, when she was already feeling ill. She said this was particularly bad one Christmas period when she had to 'endure' fairies and toadstools when she was feeling particularly sick. Another CanTeen member suggested that perhaps if a separate unit was not available then one room, in both the paediatric and the adult ward, could be decorated suitably for adolescents. She acknowledged that the room might not always be available, but that if it was, it could be utilised for her age group. This reflects the view offered by Resnick et al. (1990) and supported by Whelan (2003) that even if a specific unit was not available, then an adolescent area would be acceptable.

Another environmental aspect that was highlighted from the discussion was the 'frightening' aspect of being nursed in an adult environment which is also mentioned 
in the literature (Whelan, 2003: Gilles \& Parry Jones, 1992). The young woman who was admitted to an adult ward was frightened because of the nature of the illness of the other, much older woman, in her cubicle. If she had been admitted to a single cubicle or into a room with another adolescent this would possibly not have been her abiding memory. Burr (1993) comments on the isolation felt by adolescents, when there is an absence of anyone their own age, which often happens when they are admitted to an adult ward. Unfortunately hospital policy does not take the 'developmental' age of adolescents into account when allocating bed space. The young woman in CanTeen had just turned 16 years of age, and she acknowledged that she felt 'too young' to go to an adult ward. One of the suggestions offered by the adolescent group was that if an adolescent unit was established then perhaps it could accommodate older adolescents up to their $18^{\text {th }}$ rather than their $16^{\text {th }}$ birthday. A suggestion was that adolescents between the ages of 16 and 18 be given the choice as to where they wanted to be admitted. However, in reality the consultant teams under whom the adolescents are admitted and the progression from paediatric to adult services also govern the placing of these young people in either the paediatric or the adult environment. In my experience hospital policy is not always totally patient focused, and they are placed for the convenience of the 'system' rather than the needs of the adolescent. However, regardless of where these young people are nursed, the vividness of the memories relayed by the young woman about her fear highlights the need for nurses to always be vigilant when allocating bed spaces, whatever the environment. Adolescents need to be nursed somewhere where they can fit in, feel comfortable and have something in common with the other patients.

The post card sorting discussion backed up the findings from the card sorting exercise that shows that there was a preference for admission to either an adolescent unit or a paediatric ward. However, in the discussion importance was also placed on having somewhere to meet with their peers, where they could watch television and socialise. Several authors indicated that separate recreation facilities for adolescents were desirable. They pointed out that when there are limited recreation facilities available the young people can be told to make less noise and are unable to entertain their peers (Gillies, 1992; Russell-Johnston, 2000; Sharma \& Finlay, 2003). When discussing a recreation or sitting room the CanTeen adolescents also mentioned the desire for friends to be included. Three of the adolescents said that they did not like their 
friends visiting them in the children's ward because there was nowhere for them to sit and talk by themselves. They would have liked to have a sitting room where there were no small children or adults. It was also discussed that if there was a dedicated adolescent's sitting or recreation room available then adolescents who were elsewhere in the hospital might be able to use it. I did not ask any questions directly relating to the adolescents' needs in regards to having their parents live in. Parents are encouraged to stay overnight in paediatric environments, but not in adult wards. This would be an interesting attribute to explore in any future work. One of the adolescents also said that she would have liked to have her sister stay the night, and another commented that he would have liked to have one his school friends to stay. Neither of these seems an unreasonable request, and both would improve the quality of the adolescents inpatient stay if they could be accommodated. In these instances ward policy might need to be revised and also the adolescent be made aware of the fact on their admission, and this is a recommendation that I will take back to the workplace.

The mixed approach I used to collect the data, card sorting and discussion worked well, as the discussion expanded on some of the ideas represented in the cards and also presented new ones which could be used in further research. Authors whom described focus groups beforehand might have acquired the richness of the data earlier (Aaker et al., 1998; Longworth et al., 2001). However, I believe that in the context of this research the approach used did not detract from the value of the conjoint analysis.

\subsection{Conclusion}

In conclusion conjoint analysis is a useful quantitative tool that can be used to determine patient preference for a wide variety of different elements of a hospital visit. It is my opinion that conjoint analysis is a methodology that could be further used to test what is important to C\&CDHB population as a whole. C\&CDHB send out surveys to elicit comments about inpatient experiences. We know from summaries of the feedback that lack of parking spaces and the cost of parking are two aspects of the Wellington Hospital experience that generate negative comments (Gordon, D., personal communication, 19 ${ }^{\text {th }}$ November, 2005). Would a higher price 
for more spaces be an agreeable alternative to the cheaper option of less space? Conjoint analysis appears to be easily understood by consumers as young as the early adolescent age group; a younger age group may be able to participate but this research was not designed to ascertain the lower developmental age necessary to understand and comply with the tasks to be done. One of the main disadvantages of using conjoint analysis would appear to be that this method of analysis is relatively new. Few papers appeared to be available in the nursing arena, and most of the health related papers were from a medical perspective, and none had examined environmental aspects of a service. The market research fields in which the method has mainly been used are by definition economically driven so tend to approach questions from a different perspective to ones that are used in nursing. However, in today's health environment many management decisions have to be made within economic constraints and it would seem that a new method to direct decisions could be considered?

It is important that services and facilities for adolescents are reviewed regularly and changes implemented where appropriate. Although this is a group that is not in hospital a lot, meeting their needs will help to minimise the adverse stress associated with an inpatient stay. Adolescents have firm views and they should be consulted so that improvements can be made. I was, and continue to be, so impressed that the young people with whom I spoke did not just talk of problems, but also of solutions. This to me is an indication that they would be a group who could be consulted and who could give opinions and suggestions that could be considered by the hospital. This research has demonstrated how conjoint analysis could be used to explore the facilities that would be most acceptable to our adolescent population. However, no matter what facilities adolescents say they would like to see, there is always a defined budget available to provide these facilities. Conjoint analysis gives us the opportunity to establish what the customer (adolescents) want and in relation to what the producer (the DHB) can supply.

During the course of this research I have changed my job focus from education to an advisory role. I feel that I am now in a much stronger position to advocate for adolescents when the children's wards are upgraded. However, wherever adolescents are nursed in our upgraded facility, this study has provided me with two 
recommendations for immediate action that I will take back to the workplace. In the first instance I will look into instigating a policy change to allow responsible siblings and friends to stay overnight with adolescent patients, and for the adolescent to be informed of this when they are admitted. Secondly I consider that the allocation of bed space within the ward environment is something that needs to be reviewed. I intend to educate the nurses on both the adult and the paediatric wards of the necessity of appropriate allocation, and remind them that inappropriate 'neighbours' can cause a lasting negative impression.

With regards to the conjoint analysis, I believe that this method of research can help hospital planners to plan a service that better meets the needs of their target population. The adolescents in this research clearly showed that they had preferences for inpatient facilities. Although this was a small study I will work to ensure that C\&CDHB hear the adolescents' voice. Conjoint analysis can show the relative importance between different characteristics of the service and so can, if required, determine the individual impact of each characteristic on overall benefit. If the characteristics of the service which are important to the adolescent can be ascertained by conjoint analysis and if economic considerations were added, the result could show how an optimal service could be provided within a definable resource. 


\title{
Appendix 1 : Starship Teenage room information
}

\author{
www.starship.org.nz (accessed $17^{\text {th }}$ July, 2004)
}

Starship Hospital, Auckland

\section{Teen Room}

If you ask any teenager, they will usually say that being in hospital is really boring!!! At Starship we have a team of Play Specialists who are here to help children and young people cope with being in hospital. Sometimes this means explaining medical procedures in child or teenage language, and sometimes this means finding young people things to do to keep their minds off being in hospital.

The Teen Room is a place in the hospital where teenagers can go to hang out, listen to music, play computer games or do whatever they want to do. It has a stereo, Internet access, a Playstation, and cupboards full of games and activities to keep teenagers occupied. The Teen Room usually opens in the afternoon at 3.00ish and is run by the Adolescent Play Specialist. It's located on the 5th level of Starship next to the classroom.

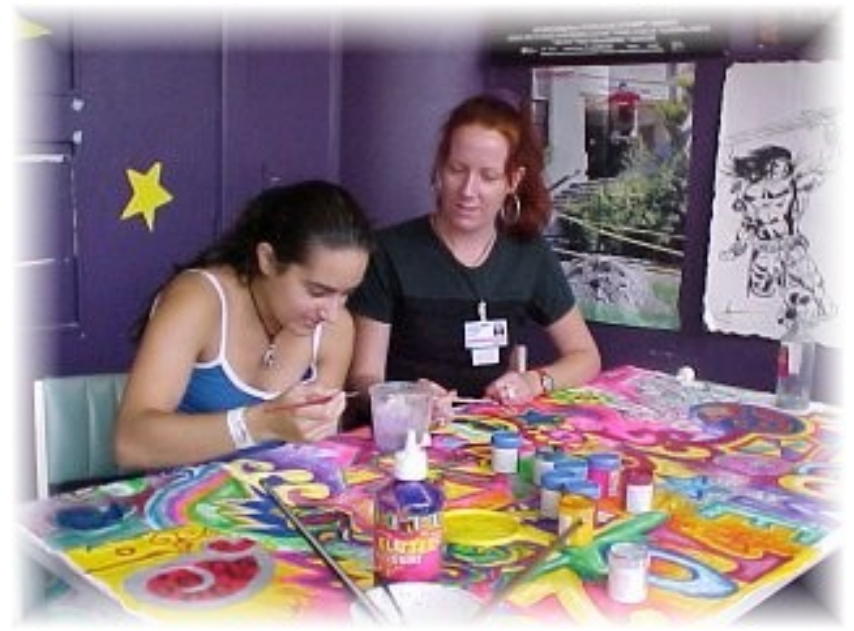

The Play Specialist is really into getting teenagers to produce art work to put up around the hospital and so she usually has some crazy project for teenagers to work on. If you look around the wards you might notice some large, colourful banners.

These are all painted by young people in hospital and are heaps of fun to create - you don't even have to be that artistic to have a go!!

So if you're bored, want to get way from the babies or oldies or just want something to do - check out the Teen Room when you come to hospital. It's even painted purple with yellow stars so you can almost forget you're in hospital at all. (Well. . . almost!). Just ask your nurse or you can contact the Adolescent Play Specialist . 


\section{Appendix 2 : Subset of conjoint cards}

Profile Number 1

Card Number 7

Recreation: Adolescent recreation room

Location: Paediatric Ward

Cellphone: Not permitted anywhere

Kitchen facilities: No cooking facilities

Bathroom facilities: Locks on bathroom door

Profile Number 2

Card Number 8

Recreation: Adolescent recreation room

Location: Dedicated adolescent area

Cellophone: Yes - in designated area

Kitchen facilities: Facilities to make snacks

Bathroom facilities: Locks on bathroom doors

Profile Number 3

Card Number 1

Recreation: Adolescent recreation room

Location: Adult Ward

Cellphone: Not permitted anywhere

Kitchen facilities: Facilities to make snacks

Bathroom facilities: No locks on bathroom doors

Profile Number 4

Card Number 2

Recreation: Adolescent recreation room

Location: Dedicated adolescent area

Cellphone: Yes - in designated area

Kitchen facilities: No cooking facilities

Bathroom facilities: No locks on bathroom doors

Profile Number 5

Card Number 3

Recreation: Communal recreation room

Location: Paediatric Ward

Cellphone: Yes, in designated area

Kitchen facilities: Facilities to make snacks

Bathroom facilities: No locks on bathroom doors

Profile Number 6

Card Number 6

Recreation: communal recreation room

Location: Dedicated adolescent area

Cellphone: Not permitted anywhere

Kitchen facilities: No cooking facilities

Bathroom facilities: No locks on bathroom door

Profile Number 7

Card Number 5

Recreation: Communal recreation room

Location: Dedicated adolescent area

Cellphone: Not permitted anywhere

Kitchen facilities: Facilities to make snacks

Bathroom facilities: Locks on bathroom door

Profile Number 8

Card Number 4

Recreation: Communal recreation room

Location: Adult Ward

Cellphone: Yes, in designated area

Kitchen facilities: No cooking facilities

Bathroom facilities Locks on bathroom doors: 
Appendix 3: Examples of cards used

This stay you are:

- In an adolescent unit adjacent to the paediatric ward

- There is a shared sitting room with the paediatric ward

- Kitchen facilities where you can make a snack

- No cell phones allowed

- Locks on the bathroom doors

This stay you are:

- In a paediatric ward

- There is a sitting room for adolescents only, your friends can visit you here and parents only by invitation

- No kitchen facilities

- Cell phones can be used in the sitting room

- No locks on bathroom doors 


\section{Appendix 4: Demographic information sheet}

\section{Adolescent survey - Inpatient hospital facilities}

You are not quite an adult and you are definitely not a big child, you are that special person called an adolescent - so can you tell me a bit about yourself?

Age: Male or Female (just circle one please)

Which suburb do you live in?

Which ethnic group do you identify with:

NZ European

Maori

Samoan

Cook Island Maori

Tongan

Niuean

Chinese

Indian

Other (such as Dutch, Japanese, Toklelaun

Please state:

Since becoming 12 years of age, have you been an inpatient in hospital for more than two days Yes/No

If yes, how many times? Once / twice / lots

Which hospital(s)?

Were you on an adult or a children's ward?

If you have not been an inpatient as an adolescent - were you in hospital as a child? Yes / No

If no, was your brother or sister an inpatient Yes / No

This form will be attached to your cards, thank you for your help. 
Appendix 5: Letter from CanTeen 
Appendix 6: Regional Ethics Committee approval 
Appendix 7: C\&CDHB Maori Health Unit 


\section{Appendix 8: Statistical examples}

Equation 1: The desirability of the utility equals the sum of the partworth contributions

$$
U(X)=\sum_{i=1}^{m} \sum_{j=1}^{k_{i}} \alpha_{i j} X_{i j}
$$

\section{Example 1}

The total utility which participant 3 sets for scenario 4 is:

$\begin{array}{lc}\text { Description of ward } & \underline{\text { Partworth }} \\ \text { Adult Ward } & -0.3333 \\ \text { Communal recreation room } & -1.0000 \\ \text { No kitchen facilities. } & 1.0000 \\ \text { Cell phones can be used in designated areas } & 1.0000 \\ \text { There are locks on the bathroom doors } & -0.5000\end{array}$

The total for participant 3 an be found by adding the utility partworth scores together

Utility (adult ward) + utility (shared sitting room) + utility (no kitchen facilities) + utility (cell phones can be used) + utility (locks on bathroom doors) + constant

$$
(-0.33)+(-1.00)+(1.00)+(1.00)+(-0.50)+(4.833)=5.003
$$

Therefore the utility score for Scenario 4 for participant 3 was 5.003

\section{Example 2}

For scenario 1 the utility score for participant 3 is:

Adult Ward

Adolescent only recreation room

Snack making facilities available

Cell phones can be used

No locks on the bathroom doors
$-0.3333$

1.0000

$-1.0000$

1.0000

0.5000

$(-0.33)+(1.000)+(-1.000)+(1.000)+(0.500)+(4,833)=5.91$

Therefore the utility score for Scenario 1 for participant 3 was 6.003 
Out of the two scenarios above for participant 3, the scenario given in example 2 has the highest utility score so was the most preferred out of the two scenarios by this particular respondent.

Conjoint analysis computes out how each of the participants ranks attributes in relation to one another. Because this is undertaken, scenarios can be entered that haven't been presented to the participants and the programme, when taking those participants previous choices into account, will simulate the utility of that scenario for the individual participant

A spreadsheet was created in Excel to allow these attribute utilities to be computed, this is shown in Table 7.

Factor: This describes the attributes that are being examined that were displayed on the plan-cards.

Constant: This is the scaling factor produced by the model and included in all of the calculations.

Pearson's $\mathbf{R}$ and Kendall's tau: The Pearson's R and Kendall's tau statistics are displayed at the bottom of each participant's output and is another indication of how well the model fits the data. They are correlations between the observed and estimated preferences. These coefficients should always be very high (ie 1.00 is high).

The importance of attribute $I_{i}$ is defined in terms of the range of the partworths $\alpha_{i j}$ across the options for that attribute: 
Equation 2

$$
I_{i}=\left\{\max \left(\alpha_{i j}\right)-\min \left(\alpha_{i j}\right)\right\} \text { for each } i
$$

This looks at the range of utility scores, and describes how the importance equals the maximum minus the minimum score.

Location - this score ranged from -0.7184 to 1.0575

Recreation room - this score ranged from -0.2845 to 0.2845

Cell phone - this score ranged from -0.9224 to 0.9224

Kitchen facilities - this score ranged from -0.7328 to 0.7328

Bathroom facilities - this score ranged from -0.2328 to 0.2328

Therefore, the importance of the attributes can be seen to be:

Location $=1.0575--0.7184=2.4759$

Recreation room $=0.2845--0.2845=0.569$

Cell phone $=0.9224--0.9224=1.8448$

Kitchen facilities $=0.7328--0.7328=1.4656$

Bathroom facilities $=0.2328--0.2328=0.4656$

From these calculations it can be seen that the range across the attribute for cell phone is greater than the range across the attribute for bathroom facilities, therefore the importance of the attribute of cell phone is greater than the importance of the attribute of bathroom facilities. The range across the attribute location is the greatest, therefore the attribute location had a greater influence on choice than any other.

\section{Appendix 9: Conjoint summary}


Appendix 10: Conjoint summary graph 


\section{Appendix 11: Decision making and cost}

Conjoint analysis gives us the opportunity to examine what the customer (the adolescent) wants and in relation to what the producer (the hospital) can supply.To do this the cost of the individual options of the facilities need to be ascertained. The total cost can then be examined for the scenarios which are most desired by the participants. This can be illustrated in the following manner by giving fictitious cost weighting to each of the attributes.

Cost Weighting

Adolescent recreation room 100

Communal recreation room

10

Adolescent Bay 1000

Paediatric Unit

50

Adult ward

50

Cell phone 100

No cell phone 0

Kitchen facilities 100

No separate kitchen facilities 10

Adult bathroom facilities 100

No adult facilities 10

$\begin{array}{lrll}\text { Communal recreation } & 10 & \text { Adolescent recreation } & 100 \\ \text { Paediatric Ward } & 50 & \text { Adolescent unit } & 1000 \\ \text { No cell phone } & 0 & \text { Cell phone } & 100 \\ \text { Kitchen facilities } & 100 & \text { Kitchen facilities } & 100 \\ \text { No adult facilities } & 10 & \text { Adult facilities } & 100 \\ & & & 1400\end{array}$

This demonstrates that if a cost or cost weighting is allotted to each of the factors, a total cost can be established. If there is, for example, a cost weighting ceiling of 300 , which most desirable scenario can be can be achieved? We can offer a paediatric 
ward with adult bathroom facilities and kitchen facilities, but no recreation room, is this more desirable than a recreation room and no bathroom facilities? Different scenarios can be tested so that the most desirable combination for our consumer group can be established. 


\section{Appendix 12: Insert in CanTeen Newsletter}

$H i-c n \cup$ hlp me plz?*

My name is Catherine Gibson and I am a final year Masters' student at Victoria University of Wellington's Graduate school of Nursing and Midwifery. To complete my Masters study I am doing a research project to find out your views on the type of environment that would make a stay in hospital more comfortable for you.

I am doing research called conjoint analysis. It's market research. I would like to try it out on a group of adolescents and Penny has agreed that I can come along to one of your meetings, probably August. If you agree to help. I need you to look at some cards describing what you might find in a hospital ward - such as having to share a room, having or not having somewhere to make a snack to eat, or being able to use your cellphone. After looking at eight different cards I just want you to sort them in order of importance. The idea is that a service can't always provide everything that you want, so you have to choose what is important. You will not necessarily have to have been in hospital to participate, just be an adolescent.

Along with the card sorting I would like to know your gender, if you have been in hospital and if yes, how many times. I would also like to know what ethnic group you identify with, but I do not need to know your name. I would also like to have a general chat to see whether you think there are other things that could be mentioned on the cards.

When I have completed the research I will share the results with you all. If you have any questions I would be very happy to answer them - Penny has my phone number.

* for ethics purpose, please note this is telephone 'text talk' for "can you help me please?” 


\section{Appendix 13: Complete set of Cards}

\begin{tabular}{|c|c|c|c|c|c|}
\hline $\begin{array}{l}\text { Card } \\
\text { Number }\end{array}$ & Location & $\begin{array}{l}\text { Adolescent } \\
\text { only } \\
\text { recreation } \\
\text { room }\end{array}$ & $\begin{array}{l}\text { Facilities to } \\
\text { make } \\
\text { snacks }\end{array}$ & $\begin{array}{l}\text { Able to use } \\
\text { cellphone }\end{array}$ & $\begin{array}{l}\text { Adolescent } \\
\text { friendly } \\
\text { bathroom } \\
\text { facilities }\end{array}$ \\
\hline 1 & Adult ward & Yes & Yes & Yes & No \\
\hline 2 & $\begin{array}{l}\text { Adolescent } \\
\text { area }\end{array}$ & Yes & No & Yes & No \\
\hline 3 & $\begin{array}{l}\text { Paediatric } \\
\text { ward }\end{array}$ & No & Yes & Yes & No \\
\hline 4 & Adult ward & No & No & Yes & No \\
\hline 5 & $\begin{array}{l}\text { Adolescent } \\
\text { area }\end{array}$ & No & Yes & No & Yes \\
\hline 6 & $\begin{array}{l}\text { Adolescent } \\
\text { area }\end{array}$ & No & No & No & No \\
\hline 7 & $\begin{array}{l}\text { Paediatric } \\
\text { ward }\end{array}$ & Yes & No & No & Yes \\
\hline 8 & $\begin{array}{l}\text { Adolescent } \\
\text { area }\end{array}$ & Yes & Yes & Yes & Yes \\
\hline
\end{tabular}




\section{References}

Aaker, D. A., Kumar, V., \& Day, G. S. (1998). Marketing research. New York: John Wiley \& Son, Inc.

Adolescent Health Research Group. (2003a). New Zealand youth: A profile of their health and wellbeing. Auckland: The University of Auckland.

Adolescent Health Research Group. (2003b). Wellington regional report. A profile of student health and wellbeing. Auckland: The University of Auckland.

Aikman, T. (2005). Cellphones plague schools. The Wellingtonian, February $24^{\text {th }}$, p.3.

Atherton, J. S. (2003). Learning and teaching Piaget's developmental psychology. Retrieved 3 May, 2004, From the World Wide Web: http:/www.dmu.ac.uk/ jamesa/learning/piaget.htm.

Aynsley-Green, A., Barker, M., Burr, S., Macfarlane, A., Morgan, J., Silbert, J., Turner, T., Viner, R., \& Waterson, T. (2000). Who is speaking for children and adolescents and for their health at policy level? British Medical Journal(321), 229-232.

Battrick, C., \& Glasper, A. (2004). The views of children and their families on being in hospital. British Journal of Nursing, 13(6), 328-336.

Beauchamp, T., \& Childress, J. (2001). Principles of biomedical ethics (5th ed.). Oxford: Oxford University Press.

Bennett, D. L. (1998). Essentials of adolescent health care. In M. J. Robinson, Robertson, D.M. (Ed.). Practical Paediatrics (4 ${ }^{\text {th }}$ ed., pp. 177-186). Edinburgh: Churchill Livingstone.

Bering, L., \& Gephardt, J. (1997). Priorities for adolescent health; recommendations of a national conference. Maternal and Child Nursing, 12(3), 161-164.

Berk, L. A. (2003). Cognitive development, Piagetian core knowledge and Vygoitskian perspectives. In Pauken (Ed.), Child development (6th ed., pp. 217-267). New York: Pearson Education, Inc.

Blunden, R. A. (1993). An artificial state. Paediatric Nursing, 5(4), 12-13.

Boyd, J. R., \& Hunsberger, L. H. (1998). Chronically ill children coping with repeated hospitalizations: their perception and suggested interventions. Journal of Paediatric Nursing, 13(6), 330-341.

British Paediatric Association. (1996). The needs and cares of adolescents (Report). London: British Paediatric Association.

Brook, C. (1986). All about adolescence. ( $2^{\text {nd }}$ ed.) Chichester, John Wiley \& Son. 
Burr, S. (1993). Adolescents and the ward environment. Paediatric Nursing, 5(1), 10 13.

Carr-Gregg, M., \& Shale, E. (2002). Adolescence: a guide for parents. Sydney: Finch Publishing.

Clarke, G. M., \& Cook, D. (1986). Spotlight on children: an awkward age? Nursing Times, 82(30), 59.

Cole, M., \& Cole, S. (2001). Adolescence. In Seymour (Ed.), Child development (4 ${ }^{\text {th }}$ ed., pp. 342-408). New York: Worth.

Collins. (1979). Collins dictionary of the English language. London: Collins.

Committee on Child Health Services. (1976). Fit for the future (The Court report). London: Her Majesties Stationery Office.

Denholm, C. (1990). Memories of adolescent hospitalisation: results from a 4 year follow up study. British Medical Journal, 291, 227-229.

Department of Health. (1959). The welfare of children in hospital (The Platt report). London: Her Majesties Stationery Office.

Department of Health. (1991). Welfare of children and young people in hospital. London: Her Majesties Stationery Office.

Department of Health. (2003). Getting the right start: National service framework for children. Standard for hospital services. Department of Health. Retrieved 13th March, 2004, from the World Wide Web: http://www.dh.gov.uk/ PolicyAndGuidance/HealthAndSocialCareTopics/ChildrenServices Information

Edgar, E. (1998). You are not alone. Journal of Paediatric Nursing, 3(4), 276-279.

Erickson, E.H. (1968). Identity, youth and crisis. New York: Norton.

Evans, M. (1998). Interacting with teenagers with cancer. In P. B. Selby, C. (Ed.), Cancer in the adolescent (pp. 251-263). London: BMJ Group.

Fallon, D. (2003). Gillick v West Norfolk and Wisbeck Area Health Authority and the DHSS. Journal of Clinical Nursing, 12, 12.

Farrelly, R. (1994). The special care needs of adolescents in hospital. Nursing Times, 90(38), 31-33.

Fisher, M. (1994). Adolescent inpatient units. Archives of Disease in Childhood, 70, 461-463. 
Flatman, D. (2002). Consulting children: are we listening? Paediatric Nursing, 14(7), 28-31.

Fotheringham, M., \& Sawyer, M. G. (1995). Adherence to recommended medical regimes in childhood and adolescence. Journal of Paediatrics and Child Health, 31(2), 72-78.

Frank, A. (1975). The diary of a young girl. New York. Pocket Books.

Freud, S. (1961). Some psychological consequences of the anatomical distinction between the sexes. In J. Strachey (Ed.), Standard edition of the complete psychological works of Sigmund Freud (Vol. 19, pp. 248-258). London: Hogarth Press. (Original work published 1923)

Friedman, E.R. (1989). Tackling the anguish of youth. Health Visitor, 66(3), 76-77.

Geehan, S. (2003). The benefits and drawbacks of treatment in a specialist teenage unit - a patient's perspective. European Journal of Cancer, 39(18), 2681-2683.

Gillies, M. (1992). Teenage traumas. Nursing Times, 88(27), 26-29.

Gillies, M. L., \& Parry Jones, W. L. (1992). Suitability of the paediatric setting for hospitalised adolescents. Archives of Disease in Childhood, 67, 1506-1509.

Glasper, A., \& Cooper, M. (1999). Hospitals need specialist inpatient adolescent units. British Journal of Nursing, 8, 548-549.

Godfrey, K. (1998). The young ones: teenagers in hospital. Nursing Times, 11(94), 26-28.

Gordon, R. (1981). The adolescent in hospital. Nursing, 29(8), 1048-1050.

Gray, A. (1988). Teenangles: Being a New Zealand teenager. Sydney: Allen \& Unwin.

Gregorowski, J. (1998). The adolescent with cancer. In: Child with cancer - nursing care. (Ed. J. Thompson). Scutari Press, London.

Hair, J. F., Anderson, R. E., \& Tatham, R. L. (1990). Conjoint analysis in Multivariate data analysis, with readings (pp. 407-447). New York: Macmillan Publishing Company.

Hallstrom, I., \& Elander, G. (2004). Decision-making during hospitalization: parents' and children's involvement. Journal of Clinical Nursing, 13, 367-375.

Harding-Price, D. (2003). Adolescent facilities: a parent's view. Paediatric Nursing, 15(7), 24-25.

Hart, R. (1992). Children's participation in health care facility design. Child Health Design(5), 1. 
Havinghurst, R. J. (1971). Developmental tasks and education. New York: David McKay.

Health Research Council of New Zealand. (2000). Guidelines for researchers on health research involving Maori. Wellington: Health Research Council of New Zealand.

Henderson, J., Goldacre, M., \& Yates, D. (1993). Use of hospital inpatient care in adolescence. Archives of Disease in Childhood, 69, 559-563.

Hentinen, M. (1996). Diabetic adolescents' compliance with health regimes and associated factors. International Journal of Nursing Studies, 33(3), 325-327.

House of Commons Select Committee on Health. (1997). The specific needs of children and young people. House of Commons Select Committee on Health, $5^{\text {th }}$ report of session 1996-96. London: Stationery Office.

Hutton, A. (2000). Ward design - where is the adolescent voice? Neonatal, Paediatric and Child Health Nursing, 3(4), 12 - 16.

Kari, J. A., Donovan, C., Li, J., \& Taylor, B. (1999). Teenagers in hospital: what do they want? Nursing Standard, 13(23), 49-51.

Kiell, N. (1964). The universal experience of adolescence. New York: International University Press.

Krueger, R. A., \& Casey, M., A. (2000). Focus groups, a practical guide for applied research. ( $3^{\text {rd }}$ ed.). California: Sage Publications, Inc.

Kmietowicz, Z. (2003). Teenagers need special health services they can get outside school hours. British Medical Journal(326), 7402.

Kuykendall, J. (1989). Teenage trauma. Nursing Times, 85(27), 26-27.

Kyngas, H. (2000). Compliance of adolescents with chronic diseases. Journal of Clinical Nursing, 9, 549-556.

Kyngas, H. (2003). Patient education: perspective of adolescents with a chronic disease. Journal of Clinical Nursing, 12, 744-751.

Lansdown, R. (1996). Adolescents, children in hospital: a guide for family and carers. Oxford: Oxford University Press.

Longworth, L., Ratcliffe, J., \& Boulton, M. (2001). Investigating women's preferences for intrapartum care: home versus hospital births. Health and Social Care in the Community, 9(6), 404-413.

Lore, A. (1993). Adolescents: People not problems. American Journal of Nursing, 64(24), 1232-1234. 
Macdonald, P. (2004). Understanding smoking behaviour in children and adolescents. Paediatric Nursing, 16(3), 26-27.

Macfarlane, A., \& McPherson, A. (1995). Primary health care and adolescence. British Medical Journal, 311, 825-826.

Mackenzie, H. (1988). Teenagers in hospital. Nursing Times, 84(32), 58-61.

Maguire, D. (1996). Adolescent potential for participation in health care. Issues in Comprehensive Paediatric Nursing, 6, 147-156.

Maori Health Unit. (2003). Te Tiriti Waitangi/Treaty of Waitangi. Wellington: Capital and Coast District Health Board.

Markham, Diamond, \& Herjmeansen. (1999). Studying patient satisfaction. British Medical Journal, 422, 742-745.

McKinney, M. (1977). Children with ongoing health needs. Nursing Series, 23(7). 871-875.

Meyers, K. E., Thompson, P. D., \& Weiland, H. (1996). Non-compliance in children and adolescents after renal transplantation. Transplantation, 62(2), 186-189.

Miller, S. (2001). Facilitating decision-making in young people. Paediatric Nursing, 13(5), 31-35.

Ministry of Education. (2001). New Zealand in Profile. Wellington: Ministry of Education

Ministry of Health. (1998). Child Health Strategy. Wellington: Ministry of Health

Ministry of Health. (2002). Youth Health Status. Wellington.: Ministry of Health

Ministry of Health Information Service (2004) Retrieved 27 $7^{\text {th }}$ June, 2004 from the World Wide Web: moh.govt.nz/moh.nsf.wpg_index/News+and+Health topics.

Ministry of Youth Development. (2003). Young people in New Zealand. Wellington: Ministry of Youth Development.

Muscari, M. E. (1998). Rebels with a cause: when adolescents won't follow medical advice. American Journal of Nursing, 98(12), 26-30.

Muscari, M. E. (1999). Prevention: are we really reaching today's teens? Maternal and Child Nursing, 24(2), 87-91.

National Association for the Welfare of Children in Hospital. (1990). Setting standards for children in hospital. NAWCH, London. 
New Zealand Health Information Service (2004) Retrieved $18^{\text {th }}$ July, 2004 from the World Wide Web: http:/www.nzhis.govt.nz/stats/hospstats-p.html.

Norwich Union Healthcare. (2003). The views of adolescents and nurses on the provision of healthcare in hospitals. Eastleigh: Norwich Union Healthcare.

Office of Ethnic Affairs.(2001). Retrieved $21^{\text {st }}$ August, 2004 from the World Wide Web. http:/www.ethnicaffairs.givt.nz.oeawebsite.nst.wpg.

Oppong-Odiseng, A. C. K., \& Heycock, E. G. (1997). Adolescent health services through their eyes. Archives of Diseases in Childhood, 77, 115-119.

Oxford Dictionary of Quotations. (1979). Oxford: University Press.

Pattison, H. M., \& Robertson, C. E. (1996). The effect of ward design on the wellbeing of post-operative patients. Journal of Advanced Nursing, 23, 820-826.

Patton, G. C., Sanci, L. A., \& Sawyer, S. M. (2002). Adolescent medicine. Medical Journal of Australia, 176, 3.

Piaget, J. (1969). The Formal Operational Stage, The theory of stages of cognitive development. New York: McGraw-Hill.

Platt, H. (1959). The welfare of children in hospital: report of the committee on child health services. HMSO, London.

Reddihough, D. S., \& Court, J. M. (1979). Adolescents in hospital. Australian Paediatric Journal, 15, 170-172.

Resnick, M., Blum, R., \& Hedin, D. (1990). The appropriateness of health services through their eyes. Archives of Disease in Childhood, 1(22), 137.

Ross, M. A., Avery, A. J., \& Foss, A. J. E. (2003). Views of older people on cataract surgery options: an assessment of preferences by conjoint analysis. British Medical Journal, 12, 13-17.

Royal College of Paediatrics and Child Health. (2003). Bridging the Gaps: Health care for adolescents (CRii4). London: Royal College of Paediatrics and Child Health.

Runeson, I., Enskar, K., Gunnel, E., \& Goran, H. (2001). Professionals' perception of children's participation in decision making in healthcare. Journal of Clinical Nursing, 10, 70-78.

Russell-Johnston, H. (2000). Adolescent survey. Paediatric Nursing, 12(6), 15-19.

Ryan, M., \& Farrah, S. (2000). Developing outcome measures and establishing patient's preferences in the doctor-patient relationship. Health Economics, 10, 310-316. 
Ryan, M., \& Hughes, J. (1997). Using conjoint analysis to assess women's preferences for miscarriage management. Health Economics, 6, 261-273.

Santrock, R. (2004). Adolescence. New York: Macmillan Publishing Company.

Schneider, Z., Elliott, D., LoBiondo-Wood, G., \& Haber, J. (2003). Quantative data collection. In M. O'Hanlon (Ed.), Nursing research ( $2^{\text {nd }}$ ed.). Marrickville: Moseby.

Schultz, A. W., \& Liptak, G. S. (1998). Helping adolescents who have disabilities negotiate transitions to adulthood. Issues in Comprehensive Paediatric Nursing(21), 187-201.

Sharma, S., \& Finlay, F. (2003). Adolescent facilities: the potential. Paediatric Nursing, 15(7), 25-27.

Shelley, H. (1993). Adolescent needs in hospital. Paediatric Nursing, 5(9), 16-18.

Smith, S. (2004). Adolescent units - an evidence-based approach to quality nursing in adolescent care. European Journal of Oncology Nursing, 8(1), 20-29.

Society for Adolescent Medicine. (1992). Access to health care for adolescents: A position paper of the Society for Adolescent Medicine. Washington.

Sproth, R. (1989). Applying conjoint analysis of consumer preferences to the development of utility-responsive health promotion programmes. Health Education Research, 4(4), 439-449.

SPSS Inc. (1990). SPSS categories. Chicago.

Statistics New Zealand. (1996). National census summary. Wellington.

Statistics New Zealand (2001). Retrieved 28 ${ }^{\text {th }}$ July, 2004 from the World Wide Web. www.myd.govt.nz/media/pdf/yp-at-large-pdf.

Steven, D. (1992). Lump it or like it. Nursing Times, 88(27), 30.

Stevens, M. S. (1998). Benefits of hospitalisation: the adolescent's perspective. Issues in Comprehensive Paediatric Nursing, 11(4), 19-212.

Suresh., Doull, I.J.M., \& Thomas, P. (2000). Adolescent inpatient units. Archives of Diseases in Childhood. 82, 226-233.

Taylor, J., \& Muller, D. (1995). Nursing adolescents. Oxford: Blackwell Science.

Tesler, H., \& Zweifel, P. (2002). Measuring willingness to pay for risk reduction: an application of conjoint analysis. Health Economics, 11(2), 129-139.

Thomas, C. (2004). Pulling together: a book for young people living with cancer. Auckland: Reed Publishing. 
Thomas, L. H., \& Bond, S. (1996). Measuring patients' satisfaction with nursing: 1990-1994. Journal of Advanced Nursing, 23, 747-756.

Townsend, S. (1982). The secret diary of Adrian Mole, aged 131/2. Bungay, Suffolk. Chaucer Press.

Turner, J.S., \& Helms, D.B. (1987). Lifespan development. New York. Holt, Rinehart and Winston.

Underhill, P. (1999). Why we buy, the science of shopping. London: Orion Business Books.

United Nations Children's Fund (UNICEF) (1999). Child rights: United Nations Convention on the rights of the child. Retrieved $29^{\text {th }}$ September, 2004 from the World Wide Web: http://www.unicef.org/crc/prt 1.htm.

United States Department of Health. (1994). Adolescence. In M. Green (Ed.), Bright Futures: Guidelines for health supervision of infants, children, and adolescents (pp. 197 - 256). Arlington: National centre for education in maternal and child health.

Viner, R.M. (2001). National survey of use of hospital beds by adolescents aged 12 to 19 in the United Kingdom. British Medical Journal, 322, 957-958.

Viner, R., \& Keane, M. (1998). Youth matters: Evidence based best practice for the care of young people in hospital. London: Action for Sick Children.

Whaley, J., \& Wong, R. (1996). The nursing of sick children. New York: McGraw Hill.

Whelan, J. (2003). Where should teenagers with cancer be treated? European Journal of Cancer, 39(18), 2573-2578.

World Health Organisation. (1977). Health needs of adolescents (Expert committee technical report 609). Geneva: World Health Organisation. 